\title{
The Heat Shock Protein Story-From Taking mTORC1,2 and Heat Shock Protein Inhibitors as Therapeutic Measures for Treating Cancers to Development of Cancer Vaccines
}

\author{
Peter Chin Wan Fung ${ }^{*}$, Regina Kit Chee Kong² \\ ${ }^{1}$ Division of Medical Physics, Department of Medicine, University of Hong Kong, Hong Kong, China \\ ${ }^{2}$ School of Traditional Chinese Medicine, Southern Medical University, Guangzhou, China \\ Email: *peterallegro333@gmail.com
}

How to cite this paper: Fung, P.C.W. and Kong, R.K.C. (2017) The Heat Shock Protein Story-From Taking mTORC1,2 and Heat Shock Protein Inhibitors as Therapeutic Measures for Treating Cancers to Development of Cancer Vaccines. Journal of Cancer Therapy, 8, 962-1029.

https://doi.org/10.4236/jct.2017.811086

Received: October 7, 2017

Accepted: November 25, 2017

Published: November 28, 2017

Copyright $\odot 2017$ by authors and Scientific Research Publishing Inc. This work is licensed under the Creative Commons Attribution-NonCommercial International License (CC BY-NC 4.0). http://creativecommons.org/licenses/by-nc/4.0/ (c) (i) \&) Open Access

\begin{abstract}
Heat shock proteins (HSPs) serve to correct proteins' conformation, send the damaged proteins for degradation (quality control function). Heat shock factors (HSFs) are their transcription factors. The protein complexes mTOR1 and 2 (with the same core mTOR), the phosphoinositide-dependent protein kinase-1 (PDK1), the seine/threonine-specific protein kinase (Akt), HSF1, plus their associated proteins form a network participating in protein synthesis, bio-energy generation, signaling for apoptosis with the help of HSPs. A cancer cell synthesizes proteins at fast rate and needs more HSPs to work on quality control. Shutting down this network would lead to cell death. Thus inhibitors of mTOR (mTORI) and inhibitors of HSPs (HSPI) could drive cancer cell to apoptosis-a "passive approach". On the other hand, HSPs form complexes with polypeptides characteristic of the cancer cells; on excretion from the cell, they becomes antigens for the immunity cells, eventually leading to maturation of the cytotoxic $\mathrm{T}$ cells, forming the basic principle of preparing cancer-specific, person-specific vaccine. Recent finding shows that HSP70 can penetrate cancer cell and expel its analog to extracellular region, giving the hope to prepare a non-person-specific vaccine covering a variety of cancers. Activation of anti-cancer immunity is the "active approach". On the other hand, mild hyperthermia, with increase of intracellular HSPs, has been found to activate the immunity response, and demonstrate anti-cancer effects. There are certain "mysteries" behind the mechanisms of the active and passive approaches. We analyze the mechanisms involved and provide explanations to some mysteries. We also suggest future research to improve our understanding of these two approaches, in which HSPs play many roles.
\end{abstract}




\section{Keywords}

Heat Shock Proteins and Heat Shock Factors, mTORC1,2 Complexes, Mild Hyperthermia, Anti-Cancer Drugs and HSP-Based Anti-Cancer Vaccine, Immunity Cells Trafficking through High Endothelial Venules of Cancer Site, Intrinsic, Extrinsic, FOXO Translocation, and the PERK-CHOP Apoptotic Pathways, Tyrosine Kinase Receptors

\section{Introduction to the Basic Function of Heat Shock Proteins}

Numerous proteins are synthesized in the cells to function as enzymes for various physiological functions. Through evolution, a very sophisticated "quality control and repair system" has been developed for survival of the organisms, from primitive to advanced species alike. A cell-system must maintain proteins in their functional states by facilitating their proper folding, or their degradation; this process is called protein homeostasis or proteostasis. A very delicate equilibrium between synthesizing proteins and quality control, with degradation involved, is of prime importance for survival. The key families of proteins participating in the quality control functions are the heat shock protein (HSP)/chaperone families. A certain number of HSPs of various families are constitutively synthesized and are translocated to the proper sites for action; some can also be found in extra-cellular space. This is the situation when there is no disturbance from the external environment. To show some basic functions of this quality control machinery schematically, we present Figure 1. The left part of Figure 1(a) indicates a properly folded protein. A newly synthesized protein (called a naïve one) may be in an unfolded form; aging or disease may also cause it to unfold (middle part of the figure). Some constitutive heat shock protein(s) will fold the unfolded structure to its proper form. Part (b) represents the situation where naïve synthesis, aging/disease may also disturb the protein's structure so that it become misfolded. The body needs special HSP(s) to refold it to its functional form. Part (c) indicates that during aging or under certain pathological condition, some proteins may be damaged. The host cell needs $\operatorname{HSP}(\mathrm{s})$ to send it for degradation in the lysosome. In fact, a ubiquitin-dependent proteasome system is at work in the lysosome to identify and degrades unwanted proteins, called defective ribosomal products (DRiPs), in the cytoplasm of all cells. During de novo protein synthesis by the ribosome, around $3 \%$ of the proteins belongs to types (b) and (c) of Figure 1, resulting from gene mutation, transcriptional and translational mistakes. Signals are sent from the lysosome to the cell nucleus, initiating mRNA translation of proteins so needed for such physiological processes [1]. HSP 90, HSP70 plus HSP40 participate in processes (b) and (c). These two processes are competitive, but process (c) proceeds if a protein is in a state beyond repair. The green structure with a small and large unit in Figure 1 (d) represents the ribosome where the protein translation takes place. Apart from 

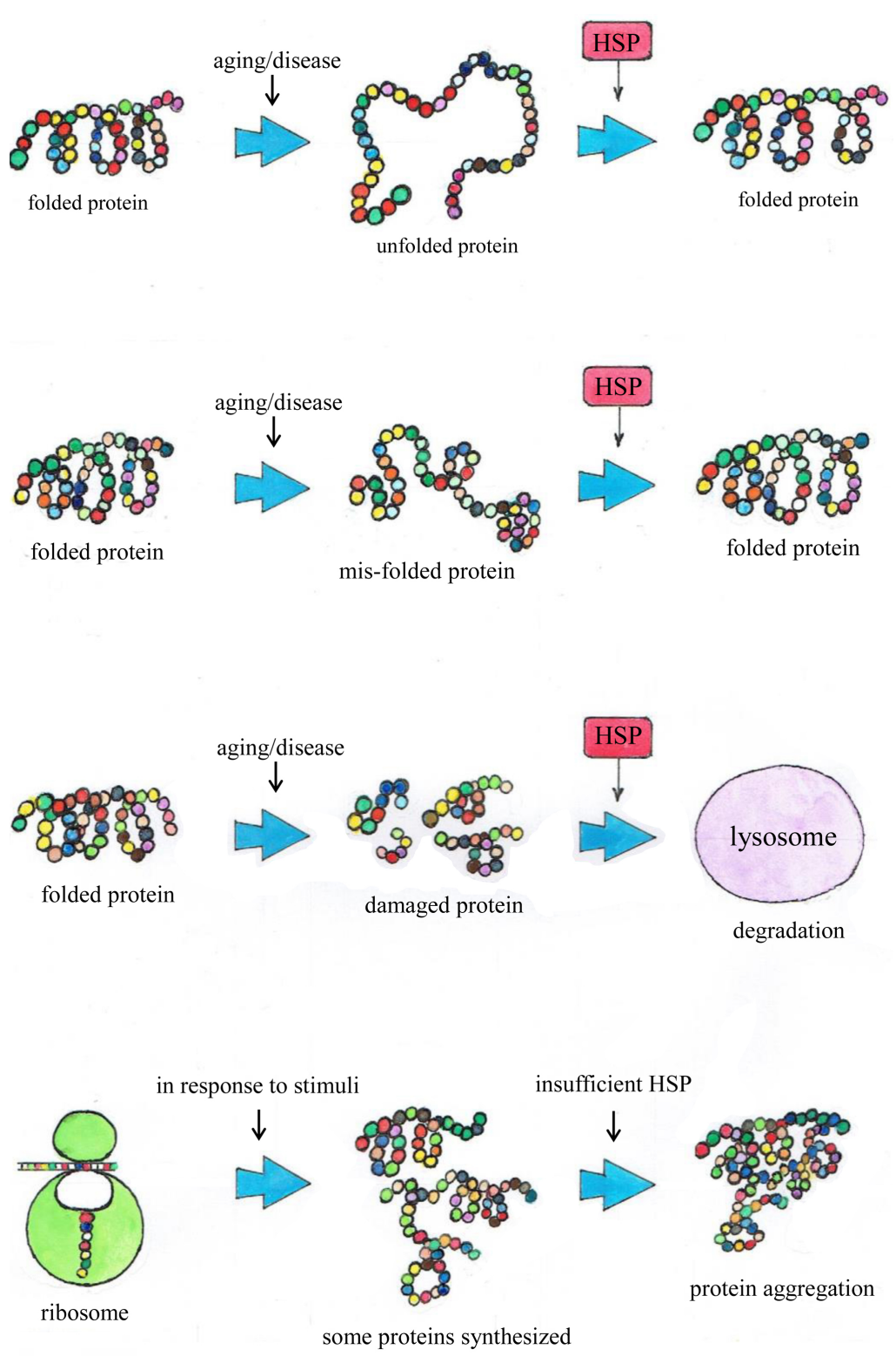

Figure 1. General basic functions of Heat Shock Proteins as chaperones. (a) When a protein is synthesized and "shaped" properly in the endoplasmic reticulum, it is in a particular folded conformation. Aging or disease may cause it to unfold. A naïve protein may be unfolded too. Some constitutive heat shock protein(s) will fold the unfolded structure to its proper form. (b) A naïve protein, due to age/disease, may be misfolded. The body needs HSP(s) to refold it to its functional form. (c) Also, during aging or under certain pathological condition, some proteins may be damaged. The body needs HSP(s) to send it for degradation. Processes (b) and (c) are competitive. Process (c) will happen if the protein is beyond repair. (d) Proteins are synthesized via a complicated series of procedures which are well established. The green structure represents the ribosome where the protein is translated from mRNA. If there are not enough HSPs to handle processes (a)-(c), these proteins are prone to aggregate into a lump. Protein aggregation inside the cells are associated with diseases [2]. Figure 1 was hand-painted by author PCWF.

the general bio-synthesis, during stress stimuli, more proteins are synthesized naturally. If there are not enough HSPs to handle processes (a)-(c), these pro- 
teins, may they be of the same type, or of difference ones, together with DRiPs, are prone to aggregate. Protein aggregation inside the cells are associated with diseases (such as AD in the brain), and may even cause cell death. Hence, HSPs are indispensable in cell survival. More details may be found in Figure 2 (see also [2]). Detail description is presented in Section 5.

In living, a number of signals (or stresses) often come from outside the cell rather frequently, and a series of sensors/receptors at the cell membrane exist there to pass on these signals to a machinery/network within the cell and parts of this machinery must be closely interacting with the membrane sensors/receptors. These stresses include heat shock, sudden change in $\mathrm{pH}$ value, change in osmotic stress, presence of heavy metals, occurrence of hypoxia, ischemic injury and others. Such stresses are in general transient, depending on the nature of the disturbances. Therefore, during stressful conditions, more HSPs are synthesized, and they are called inducible HSPs (iHSPs).

Based on the simple schematic representation in Figure 1, since HSPs are essential ones to make other proper proteins which take parts in numerous physiological reactions for survival, it is not at all surprising to find that HSPs to be evolutionarily conserved in basically all types of species, being around 2.6 billion years old. Plant HSP70 is found to be about 70\% homologous with human

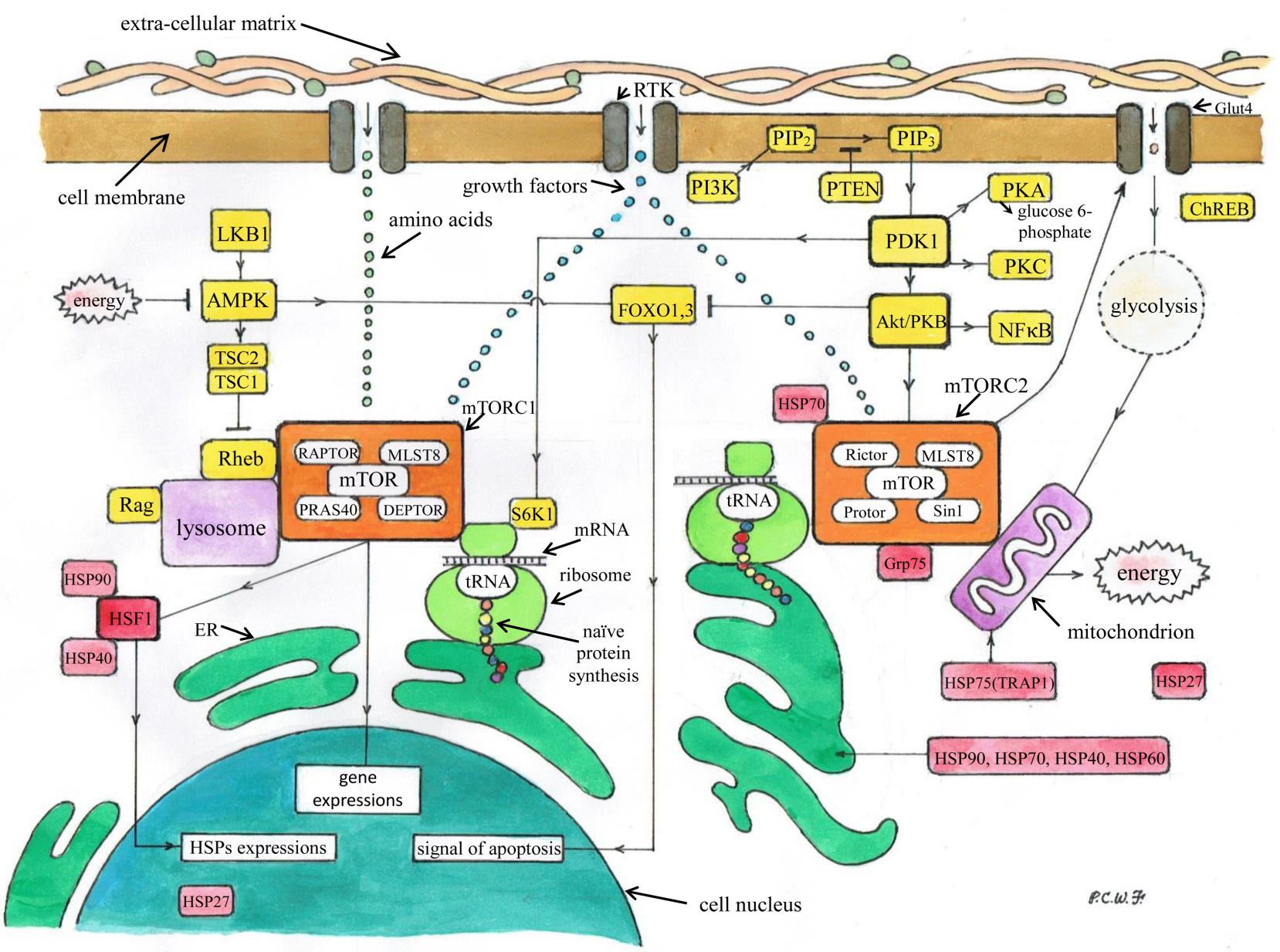


Figure 2. mTOR Complex 1 (mTORC1) is composed of the "core" protein mTOR, plus four other subunits Raptor, MLST8, PRAS40, and DEPTOR. In order to synthesize proteins, the mTORC1 complex must also be attached to a ribosome. The complex mTORC1 received signals from growth factors, amino acids, mechanical stimulus, oxidative stress, and cytosolic energy availability to activate gene expressions of proteins. The mRNA passes between the small unit and large unit (which contains the tRNA) of the ribosome. The sequence of amino acids building up the newly synthesized protein enters the Endoplasmic Reticulum for "quality control" as explained in Sections 1 and 2. Since some of those proteins synthesized are beyond repair, they must be degradated. The protein Ragulator, interacting with the Rag GTPases, recruits the mTORC1 complex and amino acids to the surface of lysosomes, where Rheb is localized and can act on mTORC1, because lysosomes are locations where degradations of proteins take place. Remark that the heat shock factor 1 (HSF1) is also attached to mTORC1; on being released, HSF1 is translocated to the nucleus and cause activation of a group of HSPs' expressions. The synthesized HSPs work as chaperones in the ER and near mitochondria as explained. Activation of the PDK1-Akt-mTORC2 pathway is also shown in the same diagram. Receptor tyrosine kinases (RTKs) are cell surface receptors for many polypeptide growth factors, cytokines, and hormones, including insulin. Phosphatidylinositol-3 kinase (PI3K), which is a signaling molecule, is recruited to the cell membrane by the activated growth factor receptors. Phosphatidylinositol 4,5-bisphosphate or $\mathrm{PIP}_{2}$ or $\mathrm{PI}(4,5) \mathrm{P}_{2}$, is a minor phospholipid component of cell membranes. Then lipid $\mathrm{PIP}_{2}$ generates the activation of lipid $\mathrm{PIP}_{3}$, another phospholipid that resides inside the cell membrane, leading to the activation of the "master kinase" PDK1. PDK1 activates 4 kinases: (1)-(3) Protein Kinase A, B, C and (4) Ribosomal protein kinase $\beta$-1 P70-S6K (or S6K1). Protein Kinase B is also called Akt protein. In the mTORC2 pathway, the isoform Akt2 is involved, which activates the mTORC2. The ribosomal protein kinase S6K1 is attached to a small unit of the ribosome, which in general is free inside the cytosole. Thus, PDK1 regulates both mTORC1 \& 2 complexes. mTORC2 also controls the Glut4 receptor, which is activated by the ChREBP $\alpha$ and $\beta$ complex in adipose and muscle, thus involving in metabolism. Glucose/carbohydrate enters the cell undergoes glycolysis and the product becomes the fuel of the mitochondria for bio-energy production. Note that mTORC2 is located in the MAM, a layer between a mitochondrion and the surface of an ER. Grp75 is a chaperone of the HSP90 family, participating in Calcium ion transfer from store to the mitochondria to work on the electron transport chain. Recent studies indicate that HSP70 activates mTORC2, which also participates in the translation of mRNA to protein after the initial stage (by the mTORC1). Therefore, a ribosome is drawn in the neighborhood of mTORC2 complex. On the other hand, the tumor suppressor LKB1 activates the AMPK pathway, leading to activation of the TSC 1 and 2 complex, which inhibits protein Rheb and hence mTORC1, as a negative regulation to protein biosynthesis. Sufficient bio-energy inside the cell inhibits the AMPK pathway, and thus effectively activating the synthesis proteins. AMPK also regulates the activity of the forkhead box transcription factors (FOXO), which gives signal to the nucleus of apoptosis in case there is insufficiency in bio-energy. Hence, sufficient intracellular energy also rescues the cell from apoptosis. PTEN is the negative feed-back protein for the activation of PDK1, and thus controlling the amount of energy generated by the mitochondrion. In this figure, some typical locations of the dominant HSPs are shown. In particular, we note that recent findings show that HSP40 works closely with HSP70, and they are therefore expected to be colocalized in their active forms [30]. We note also that recent discovery indicates that the small HSPs are regulators of cell death, and their locations could then be translocated from the cytosole to the nucleus when they function as such [33]. Active mTORC2 protein is also found to be close to the cell membrane [79]. Finally, p53, as an anti-cancer protein, activates AMPK, effectively leading to apoptosis. The network in this diagram is well-known by researchers in this field by now, with different settings, depending on the proteins involved in the text. The authors compiled results from many sources without major adaptation, to the best of recollection of the authors. Figure 2 was hand-painted by author PCWF.

HSP70 [3]. These proteins are generally anti-inflammatory intracellularly but become pro-inflammatory extracellularly as a warning signal to foreign intrusion.

Through rather extensive studies in the past several decades, we now know that each HSP is consists of two basic types of protein structures, the molecular chaperones and co-chaperones, which together handle protein conformation briefly sketched above. There are several families of heat shock proteins to be classified in more details in the next section. In general, the number attached after the symbol HSP represents the (approximate) molecular mass in units of $\mathrm{kDa}$; several of these numbers are not all accurate due to their discoveries at different times, under different conditions. 
For simplicity, the "intermediate steps" are omitted in Figure 1. We add in a few words here. First the unfolded protein transits to the intermediate state with the help of HSP90, 70, 40 and others. If the unfolded proteins form aggregates, they may be rescued by the members of the HSP100 family and go to the intermediate state. Proteins at the intermediate state can also form aggregates and they are degraded by the appropriate enzymes. The "proper intermediate proteins" interact with ATP-dependent chaperones in the families of HSP90, 70; these chaperones work with the assistance of co-chaperons (e.g., Bag1, Hip, and Hdj1, as the non-client binding molecules that assist in protein folding mediated by HSP70 and HSP90) proceed to make sure that the intermediate proteins have the proper conformations to become the natural native proteins [4].

It was learned long ago that heat or other shocks induce HSP genes to express only in the presence of heat shock elements (HSE) in the genes' non-transcribed regulatory sequences [5]. Heat shock factors (HSFs) are proteins that bind specifically to these HSE sequences. Therefore, it is commonly accepted now that the expressions of the HSPs are regulated mainly by heat shock factors, in particular heat shock factor 1 (HSF1) [6].

When certain dysplasia and carcinogenesis is in progress, many proteins generated are abnormal in structure. For a cancer cell to exist as such, we consider that it needs many more HSPs because the growth and cell cycle progression is abnormally fast, leaving a large number of peptides/proteins inside the cell to go through the steps sketched in Figure 1. When the HSPs are bound to these clients (proteins being handled), they form complexes and have certain signatures of the special carcinogenesis process involved. Many HSP complexes are found to be in close proximity of the cancer cells, and have been invoked to be participating in the carcinogenesis process in many studies. In fact, they appear, together with some other proteins, as small lumps of molecules, outside, around a cancer, now to be called the "exosomes". During the past decade, a number of anti-cancer drugs have been designed/developed employing certain HSP inhibitors. In in vivo studies, these drugs do show anti-cancer effects (see e.g. [7]).

On the other hand, whole body or local mild hyperthermia has been applied along or in adjunct with radiotherapy/chemotherapy as anti-cancer therapy for $2 / 3$ decades (see e.g. [8]). We know that hyperthermia will induce more HSPs to be synthesis in response to the heat shock. So there seems to be a big contradiction between finding many HSPs in the exosomes and many HSPs intracellularly to protect the host organism.

Moreover, the PDK1-Akt-mTOR network is involved in the growth, survival, apoptosis of a cell, and a string of enzymes are regulating a large number of reactions in a holistic way. So far we know, the mTORC1 complex is regulating the synthesis of proteins (plus other functions) and the mTORC2 complex is involved more in metabolism and protein "shaping" in the neighborhoods of the quality control factory-endoplasmic reticulum, as well as the mitochondrion, with the help of many HSPs. The mTORC1 \& 2 are not working alone, but re- 
gulating each other via down-stream pathways (Section 5, Figure 2). To inhibit excessive protein synthesis, a series of inhibitors of mTOR1,2 (mainly mTORC1, such as the well-known rapamycin; see also [9]) have been found, studied rather extensively up to clinical trials to treat cancer, with certain efficacies plus side effects.

While developing a number of inhibitors of HSPs and mTORC1 to treat cancer, the cancer vaccines have also been developed around the past decade. The basic principle is based on the existence of HSP-complexes with cancer signatures as antigens on the cell surface; these antigens activate antigen-presenting cells (APC) to internalize such HSP-complexes via endocytosis and re-present these antigens with major histocompatibility complexes (MHCI, MHCII) molecules on the cell surface, to the CD4+ T \& CD8+ T cells respectively. The lymphocytes can register the antigen signals, leading eventually to cytotoxic action on the cancer cells, after maturation. There is also new evidence that even the helper $\mathrm{T}$ cells $(\mathrm{CD} 4+\mathrm{T})$ can also become cytotoxic lymphocytes directly if the cancer cells are MHCII positive. The role played by efficient trafficking, via adhesion molecules, of the antigen-presenting cells and $\mathrm{T}$ cells through the postcapillary venous swellings called high endothelial venules (HEV) across the cancer, is also important and is discussed in this paper, because heat shock and overexpression of nitric oxide endothelial synthase [10] would lead to vessel dilation, counteracting the hypoxia condition, which is well-known to be impeding the arrival of medicine during chemotherapy treatment.

Numerous regulatory pathways are involved in a single cell in physio-pathological processes. Though some interactions are more prominently or more easily detected/observed scientifically, we need to consider the contributions from as many interactions as possible. All analyses are thus limited by practical reasons; all we can do is to identify certain key regulators or check-points so that therapeutic measures can be developed and applied, leading to beneficial effects. As communication is very fast nowadays, detail reviews, based on discoveries of different groups and on different aspects published from time to time serve to help understanding the progress of curing this particular disease which is better specified by hallmarks rather than a small number of well-defined pathways. Suitable treatments can then be developed accordingly with fine adjustments from time to time. Therefore, review for this disease is inevitably long.

In Section 2, we introduce the classes of HSPs and their basic functions. The typical evidence on the benefits of mild hyperthermia alone or adjunct to other therapies is presented in Section 3. Since heat shock would lead to synthesis of HSPs, we might, at first sight, expect that cancers are short of HSP. On the contrary, abundant HSPs and HSFs proteins are found among cancers of various types. Typical examples of these findings are reviewed in Section 4, including the report on the maintenance of cancer stem-like cells by HSF1. The detailed review of the key regulatory functions of the PDK1-Akt-mTOR-HSF network is presented in Section 5. Some examples of various drugs targeting mTORC1 
and/or mTORC2, HSPs, or their combinations relevant to the discussion of this paper are reviewed in Section 6. The basic principles of the HSP70-based cancer vaccines are reviewed in Section 7, including analyzing the roles played by HSP70 in the cross-presentation process, which is the key process that a cancer vaccine works. There are quite a number of "mysteries" or unexpected results behind in the development reviewed in the materials up to Section 7. In Section 8 , we attempt to provide some answers/explanations to some of these issues. In particular, we discuss the discovery that mild hyperthermia improves trafficking of APC and T cells through the narrow vessels around the cancer site with the help of adhesion molecules, and a detail account of the mechanism of the cross-presentation process. We also introduce the finding that HSP70 complex can induce NK cells to eradicate cancer. The plausibility of preparing a cancer vaccine to cover a wide range of cancers is also analyzed. The evidence of mild hyperthermia being able to protect the integrity of the telomeres is briefly discussed. Several examples of FDA approved HSP-based and mTOR-based (also closely related to HSP function) anti-cancer drugs, plus a HSP-based cancer vaccine are discussed also. In Section 9, we put forth some suggestions on developing therapeutic measures/vaccines to treat cancers (as a matter of principles) and further research. We find that HSPs are involved in many interactions discussed in this paper. Our suggestions include works that are related to finding clues to unanswered questions of the stated inhibitors and vaccines, inclusion of analysis in lipidomics, analysis of gene mutations using whole-exome sequencing (WES) of multiple regions of individual cancer biopsies, a technology already being used in some clinical organizations. Despite still facing some hurdles ahead, our analysis seems to suggest that biomedical scientists and medical experts would see dawn to the state where cancer might mostly disappear, and if they emerge, most of them can be cured with proper fine tuning therapeutic treatments, as a matter of principle.

Cancer is the second leading cause of death globally, and was responsible for 8.8 million deaths in 2015; about 1 in 6 deaths are caused by cancer [11].

\section{Classes and General Functions of Heat Shock Proteins}

\subsection{The Large HSP110 Family and Grp170 Family}

There are several classes of HSPs according to their molecular masses: One of the largest family of HSP so far found, tentatively called the HSP110 family, has three members-HSP110, APG-1 \& APG-2, being found in humans, rodents and some primitive organisms such as Drosophila, Arabidopsis and a few others. Another member of "large HSP family" is Grp-170, having members found in humans, rodents, Saccharomyces cerevisiae, Drosophila, Caenorhabditis plus a few others [12]. Different members of the HSPs are found in the cytoplasm, nucleus, mitochondria, and endoplasmic reticulum (ER). We only specify the sites for those members related to their functions discussed in this paper.

HSPs, in the initial step of their action, can recognize exposed hydrophobic 
surfaces short of nonnative proteins and these surfaces should be buried in the native states to avoid protein-aggregation. HSPs then work in a series of steps to help producing proper native proteins. Historically, glucose starvation, oxygen deprivation, or calcium ionophores (capable of transporting ions across lipid membrane) could lead to disruption of the function of the ER, resulting in accumulation of the yet unfolded proteins in the lumen of ER. A number of stress proteins respond to this disruption and help to fold/refold the defective proteins. Such stress proteins were named glucose-regulated proteins (Grps) then. In mammals, the three main Grps are Grp78, Grp94, and Grp170. Hence in literature, two different names refer to the same protein if they are homologous in structure. Grp78, Grp94 are homologous to cytoplasmic HSP70 and HSP90 respectively and they are therefore referred to as the same proteins. Grp94 will be discussed with the group of HSP90 [12].

\subsection{The HSP100 Family}

The member HSP104 in this family was found in the budding yeast Saccharomyces cerevisiae. In general, members of this HSP family are involved in the function of thermotolerance [13]. Organisms with mutation of this gene cannot survive in both ends of extreme temperatures. The other members ClpA, B, C were found in bacteria such as the cytosol of E. coli. Recently, HSP105 $\alpha$ is found to be a new member of this family, working as mammalian disaggregation/refolding machine, and is anticipated to protect neuronal diseases [14].

\subsection{The HSP90 Family}

The most abundant chaperone family is the HSP90 family with 21 clients and 23 co-chaperones [15]. A HSP90 does not participate in de novo folding of most proteins but facilitates stabilization, refolding of denatured proteins after stress, and working on the final maturation of a selected client protein to the proper native form [16]. A HSP90 protein has a flexible dimeric structure composed of three different domains [17]. In carrying out physiological function, a number of co-chaperones and several hundred client proteins have been found so far to be attached to HSP90 to form a complex; recent discovery reveals that one cochaperone is the Heat Shock Factor 1 (HSF1), the key protein which can induce transcription of other HSPs [18]. There are four isoforms in this family: 1) inducible cytosolic HSP90 a, 2) constitutive cytosolic HSP90 $\beta$, 3) the Endoplasmic Reticulum localized glucose regulated protein 94 (Grp94, or Hsp90b1), 4) the mitochondrial tumor necrosis factor receptor type 1-associated protein (HSP75, which is encoded by the gene TRAP1 in human, having a mass $<90 \mathrm{kDa}$ ). A recent discovery reports that Hsp $90 \beta$ binds to the cytoplasmic tail of the LDL receptor-related protein-1 (LRP-1), anchoring the receptor at the dermal fibroblast's membrane. On the other hand, the cell secrets HSP90 $\alpha$ into the extra cellular matrix and HSP90 $\alpha$ binds and signals (via the LRP-1 receptor) to promote fibroblast motility during the wound closure process [19]. It is proposed in the same paper that a similar wound healing process might be at work in other parts 
of the body. The chaperone Grp94, or HSP90b1 contributes to the "working factory" ER on protein conformal quality control briefly mentioned in Section 1, including storing calcium for such process [20]. Since HSP75 (TRAP1) is located in the mitochondrion, we have to introduce the mitochondrial Permeability Transition Pore (PTP), which is a protein formed in the inner membrane of the mitochondrion during certain pathological conditions. Opening of the pore increases the permeability transition of the inner membrane, allowing small cytosolic molecules to enter into the mitochondrial matrix, leading to swelling and malfunction of the mitochondrion. The result is cell death through apoptosis or necrosis. HSP75 (TRAP1) interacts with preotein Cyclophillin D1 which controls the function of the PTP. Note also that the Complex II (of the respiratory chain) consists of four units: 1) succinate dehydrogenase, (SDHA); 2) succinate dehydrogenase [ubiquinone] iron-sulfur subunit; 3) succinate dehydrogenase complex subunit C; 4) succinate dehydrogenase complex, subunit D. TRAP1 also keeps the Complex 2 of the respiratory chain active, in order to avoid reduction of glycolysis and oxidative phosphorylation of the respiratory chain. Moreover, recent studies show that TRAP1 is also found in the intracellular domain of the type 1 receptor for the tumor necrosis factor (TNFR-1IC) on the ER [21]. This protein can activate the transcription factor NF- $\kappa \mathrm{B}$, mediate apoptosis, and function as a regulator of inflammation. Moreover, HSP75 is suspected to participate in largescale folding of chromatin fibers in the interphase nucleus also [22]. Note that the member Grp94 is attached to the ER, but other members can be found in the cytosol.

\subsection{The HSP 70 Family}

The HSP members of this family [23] [24] are mainly monomeric proteins that reside in any adenosine-5'-triphosphate (ATP)-containing eukaryotic intracellular compartment and more are found in cell membranes [25]. Human HSP70 proteins can be classified into seven evolutionary groups, with different Cterminal domains and $\mathrm{N}$-terminal domains, which are likely to define their distinctive functions [23]. HSP70s are also brought into organelles. One can say that members of the HSP70 family control various processes of cellular proteostasis. Nine typical HSP70s are within the molecular range of $(65-80 \mathrm{kDa})$ and six have molecular mass $>80 \mathrm{kDa}$. Extracellular HSP70s carry out immunomodulatory functions as cross-presenters of immunogenic peptides via the major histocompatibility complex (MHC) found on the surfaces of cells (in all higher vertebrates), helping the immune system to recognize foreign substances. In humans a MHC complex is also called the human leukocyte antigen (HLA) and functions as a chaperokine which stimulates innate and adaptive immunity as well as stimulating the innate immune responses mediated by natural killer (NK) cells (see review of [24]). Note also that the "immunoglobulin heavy-binding protein" or Grp78 or $\mathrm{BiP}$ is located in the lumen of the ER. The $67 \mathrm{kDa}$ member of this family, called calnexin, is responsible for folding the MHC class $1 \alpha$-chain in the membrane of the ER. The major chaperone of Escherichia coli is called 
DnaK, which is a member of this family. Therefore, HSPs (in particular HSP70) are involved in many physiological functions and are relevant to development of anti-cancer vaccine and drugs, as will be clear later. A HSP70 also has a few hundred clients.

\subsection{The HSP 60 Family}

The members of this family have molecular masses around $60 \mathrm{kDa}$ [26] [27]. It is considered as a mitochondrial chaperonin responsible for refolding and transportation of proteins from the cytoplasm into the mitochondrial matrix. Heat Shock Protein 60 is found to be a putative endogenous ligand of the Toll-Like Receptor-4 (TLR4) Complex. The activation of TLR4 triggers the intracellular signaling pathway NF- $\kappa \mathrm{B}$ and production of inflammatory cytokines, leading to the activation of the innate immune system.

\subsection{The HSP 40 Family}

In an attempt to identify and to characterize additional components of the HS response that may be aberrantly expressed in obese subjects, using the human $\mathrm{RT}^{2}$-Profiler PCR Array to target the HSR, the authors in [28] carried out a simultaneous screening of the expression profile of 84 heat shock-related genes and compared the resulting expression pattern with that of the control normal-weight subjects. They reported the existence of the HSP 40 family. A member called DNAJB3 in this family was found to be down-regulated in obese subjects both at the RNA and protein levels. HSP-40 members can be expressed both by constitutive process and also induced by stress. Members of this family are closely related to diabetes. Recent findings show that HSP40 works closely with HSP70, and they are therefore expected to be colocalized in active forms [29] [30].

\subsection{The Small HSP Family}

Members of this family have small molecular masses within the range (12 to 43 $\mathrm{kDa}$ ). They prevent stress induced aggregation of partially denatured proteins and promote their return to native conformations under certain physiological conditions [31]. Ten sHSPs, (called HSPB1-10), many of which are present at high concentrations in muscle and implicated in disease, are present in humans [32]. The ones commonly discussed are HSP 22, 25, 27 and 28. These proteins are found in the cytosol and have the ability to suppress protein aggregation. Recent discovery indicates that the small HSPs are regulators of cell death, and their locations could then be translocated to the nucleus [33] [34].

\subsection{Deletion of HSF1 Gene in Mammalian Cells Completely Abrogates HSPs Induced by Heat Shock and Other Types of Stresses}

HSFs are the primary regulators of stress-inducible expressions of HSPs in eukaryotic cells. HSF1, which is the dominant heat shock factor of the heat shock 
factor family, normally exists as a non DNA-binding monomer which undergoes trimerization in response to cellular stress. HSP90 is considered to be the sensor to trigger such a trimerization process of HSF1 [35].

In general, the HSFs bind heat shock elements (HSEs) within the promoter regions of HSP genes [36]. Of interest is the finding that deletion of HSF1 in mammalian cells allows normal basal expression of HSPs but completely abrogates HSPs induced by heat shock and other types of stresses [37]. In another study, using 1) HSF1 wild-type (+/+), 2) HSF1 heterozygous (+/-), and 3) HSF1 null (-/-) mice HSP $1^{-1-}$, and Embryonic Fibroblasts (Cells from recombinant clones), it was reported that constitutive expression of multiple HSPs (with HSPs $27,60,70$ as examples) in these cultured embryonic cells was not affected by using any of the three stated genetic models. On the other hand, thermotolerance (being able to survive high temperatures $-43^{\circ} \mathrm{C}$ for $60 \mathrm{~min}$ in the experiment) was not attained in $\mathrm{HSF}^{(-/-)}$cells. Their main conclusion is therefore: constitutive and inducible HSPs participate in distinct physiological functions [38]. Though only a limit of animal and cell types have been invested in studies such as that mentioned above, since the HSFs and HSPs are highly conserved throughout evolution, we consider such a conclusion remains true in our discussion.

\section{Mild Hyperthermia as a Therapeutic Measure to Treat Cancers}

\subsection{Typical Examples of Anti-Cancer Effects of Mild Hyperthermia, with Cases in Adjunct to Radio/Chemo Therapy}

Compelling evidence in the past two decades shows that local heating tumors within the temperature range of $39^{\circ} \mathrm{C}-45^{\circ} \mathrm{C}$ would induce anti-tumor immunity action. In practice, there are general three ways to treat cancer patients via heating: 1) Whole body mild hyperthermia within the temperature $39^{\circ} \mathrm{C}-41^{\circ} \mathrm{C}$. 2) Regional mild hyperthermia applied to a relatively large area of the body, such as a leg, also within $39^{\circ}-41^{\circ}$ (the surface temperature can be one or two degrees higher as the temperature reaching the tumor site is lower due to heat absorption). 3) Local hyperthermia to the tumor itself with a range of i) $41^{\circ} \mathrm{C}-45^{\circ} \mathrm{C}$ (without causing serious injury to normal tissues), or application of ii) high temperature (even up to $80^{\circ} \mathrm{C}$ ) for a very short time interval intending to ablate the tumor, with focusing technique such as radio frequency radiation. Methods 1) and 2) mimic fever reaction. Method 3) is intended to trigger immunity response usually not encountered in fever, a point to be echoed in point (e) below [8] [39] [40]. Mild hyperthermia technique can be applied as an adjunct measure of other treatments such as chemotherapy. When cells are exposed to hyperthermia, there are many changes in morphology and functions of proteins-to name a few: a) Temperatures in the range of $39^{\circ} \mathrm{C}-45^{\circ} \mathrm{C}$ can arrest cell proliferation and kill cells. b) Change in membrane characteristics would modify cell 
morphology (an aspect to be followed up in Section 9.10 on lipidomics). c) Members of the transient receptor potential (TRP) superfamily of the cation channels are found to be temperature sensitive, and we expect a change i.e. in intra- and extra-cellular level of calcium ion, which is the most important second messenger [41]. d) The secondary structures of proteins are extremely sensitive to heat, and hyperthermia could lead to protein denaturation [42]. e) Change in immunity activities, some of which could result from d) [43]. We consider all these changes are related directly or indirectly with carcinogenesis, to be amplified in later Sections.

Now innate immunity is the first line of defense and is mediated by granulocytes, monocytes, immature dendritic cells (DCs), natural killer (NK) cells, and cytokines. After heating cancer cells in vitro at $39.5^{\circ} \mathrm{C}$ for 6 hours, it was observed that the expression of ligand (MICA) (which is a Natural Killer Group 2D (NKG2D) receptor) induced on infected cells or cancer cells was increased (but not the MHC class I molecules), leading to increase in the chances of recognition and killing by the NK cells [44]. However, another research group reported that heating cancer cells at $43^{\circ} \mathrm{C}$ for only $30 \mathrm{~min}$, the surface MHC class I molecules increased, more CD8+ T cells were activated and there was a better anti-cancer immunity response [45]. The above two results mean that different hyperthermia dosage would lead to activation of different receptors on the cancer cell membrane as schematically shown in reference [46]. Already discussed in Section 2.8, HSF1 responds only to stress. Hyperthermia would increase the number of the inducible HSPs which contain potential cancer antigens HSPs, some of which are secreted outside the cells. These antigens are mixed with some other secreted peptides/proteins to be called exosomes on and around the cancer cell membrane, which contain the potential cancer antigens to be picked up by the antigen-presenting cells (APC) leading to killing of the cancer cells via crosspresentation mechanism to be explained in more details in Section 8. Moreover, immune cells such as NK cells, CD8+ T cells and DCs around the tumor structure are also activated at a temperature $\sim 40^{\circ} \mathrm{C}$ (after a relatively long duration $\sim 6$ hours), leading to enhanced immunity response against cancer cells [46]. It was also showed in another study that heating antigen-specific CD8+ T cells in vitro at $39.5^{\circ} \mathrm{C}$ (for 6 hours) increases antigen specific, soluble cytokine interferon gamma (IFN $\gamma$ ) production, which then participates in anti-cancer activity [47].

One interesting property in an in vivo study using mice models and magnetic nanoparticles is that the DCs in the heated cancer region migrate to the lymph node with better efficiency than the ones in the unheated tumor [48]. We have already noted that poor diffusion though blood vessel hinders the therapeutic chemical and immunity cells to reach the cancer site. It has been shown that in situ local hyperthermia increases the diameter of arterioles entering the cancer region by $35 \%$ [46], allowing better trafficking of $\mathrm{CE}+8 \mathrm{~T}$ cells to undergo extravasation from the vessel via adhesion molecule receptors, whose expressions are 
also enhanced by mild hyperthermia, an aspect to be amplified in Section 8 .

In another investigation, twenty-eight patients suffering from the following cancers participated in a test on the T cells activity after hyperthermia at $41.8^{\circ} \mathrm{C}$ for 60 hours, in adjunct to radio/chemo-therapy: metastatic colorectal cancer, cholangiocellular cancer, pleural mesothelioma, soft tissue sarcoma, ovarian cancer, non-small-cell lung cancer. In these clinical trials, the activities of both CD4+ and CD8+ T cells were significantly enhanced after the fever-like hyperthermia (priming at 48-hr post-treatment) [49]. There are many other cases reporting the anti-cancer effects of mild hyperthermia [50] [51].

\subsection{The Evidence of Strong Anti-Cancer Effects of a Combined Hyper- and Hypo-Thermic Modality on Mammary Metastatic Cancer to the Lungs Based on in Vivo Animal Model Study-HSP70 Appeared to Play Key Roles in Restoring Immunity Power Which Has Been Suppressed by Myeloid Derived Suppressor Cells (MDSCs)}

Under quite a number of clinical settings, hyperthermia is used in combination with other therapy, in order to achieve a better therapeutic result. On the other hand, myeloid derived suppressor cells (MDSCs) are a heterogenous group of immune cells originated from bone marrow stem cells. Under pathological conditions such as chronic infections, neoplastic disorders, increase in reactive oxygen species, nitric oxide generated via inducible nitric oxide synthase, cytokines and many factors would effectively alter the haematopoiesis process (see Figure 1 of [52]), with the result that these cells proliferate and possess strong immunosuppressive activities by interacting with other immune cells-including $\mathrm{T}$ cells, dendritic cells, macrophages and NK cells. The consequence is that carcinogenesis is promoted. In addition to their suppression on innate (via modulation of cytokine production of macrophages) as well as suppression on adaptive immune responses, MDSCs have also been reported to promote tumor angiogenesis. MDSCs, which could well be a high potential cause of metastatic cancer, were already found in blood circulation, spleen, lung and liver [52]. Therefore, it is important to find out if hyperthermia could change this immunosuppressive property of the MDSCs, for the benefits of the patients.

Using a transplantable mammary cancer cell line, the mammary metastatic lung cancer murine model was created [53]. A special combined hyper- and hypo-thermia program was tried on these animal models: 1) Radio frequency (RF) hyperthermia at $50^{\circ} \mathrm{C}$ for $15 \mathrm{~min} ; 2$ ) hypothermia at $-20^{\circ} \mathrm{C}$ for 5 minutes; 3) then followed by RF heating again at $50^{\circ} \mathrm{C}$ for 10 minutes. The result of this treatment was compared with that of surgical resection or RF hyperthermia treatment 1) alone. Based on analysis of the survival rate, serum HSP70, characteristics of lungs \& splenocytes, the main findings were: a) HSP70 induced MDSC differentiation into mature macrophages in splenocytes on day 10 after the stated three-step heat treatment. b) HSP70 induced MDSC differentiate into matured macrophages in serum in vitro. c) Reduced expression of inducible ni- 
tric synthase (iNOS) in MDSCs. Note that iNOS could help to produce a large amount of nitric oxide, which combining with the free radicals super oxide (produced automatically in mitochondria during energy production) would form the detrimental free radical peroxynitrite ONOO-. Peroxynitrite could affect the structure of the molecules on the surface of any cell. In this case, $\mathrm{T}$ cells (as example) became inactive (see Figure 1 of ref [54]). d) HSP70 induced MDSC differentiate into matured DC in vitro. e) There is a significantly larger amount of HSP70 released from necrotic cancer cells in tumor stroma, implying more cancer cells have been killed. f) Reduction in number of immunosuppressive MDSCs and increase of splenic immune effector cells. g) There was a higher survival rate as compared to pure RF hyperthermia and surgical resection models. In short, this very recent study indicates that using this combined hyper- and hypo-thermia method, HSP70 seemed to be able to inactivate the harmful MDSCs and restore the immune cells to participate in their normal immunity duty, thus inhibiting the metastasis process of mammary metastatic lung cancer model [53]. That immunity cells being sensitive to temperature change is well-known, learned through the benefits of fever during infectious attack, but the restoration of immunity power after such hyper- and hypo-thermia treatment is new. The power of HSP70 in promoting maturity of immunity cells is well demonstrated.

\section{On the Other Hand, There Are Numerous Examples Showing the Association of HSFs and HSPs with the Progress of Carcinogenesis}

\subsection{HSPs Are Found in Cancer Cites}

There are many reports depicting the correlation of overexpression of HSPs and carcinogenesis. For example, HSP27 expressions from specimens of 77 patients suffering from the late stage of ovarian carcinoma were determined in ref [55]. All these patients received cisplatin- and doxorubicin-based chemotherapy. In 30 patients, HSP27 immunostaining was positive in $86 \%$ of patients before and in $72 \%$ of patients after the stated chemotherapy. HSP27 expression was not related to any clinic-pathologic factor, including p53 expression. In particular, the authors concluded "... however, the prognostic impact of HSP27 appears to be somewhat weak and not independent. Which mechanism is responsible for the possible impact of HSP27 on the biological behavior of ovarian carcinoma remains to be elucidated". In another clinical study [56], 10 specimens of dysplastic nodules and 38 specimens of hepatocellular carcinoma were obtained from 52 hepatitis B surface antigen-positive patients. Immunohistochemical analyses of the following HSPs were carried out in the stated specimens at different stages of carcinogenesis: HSP27, HSP60, HSP70, HSP90, glucose regulated protein Grp78, and Grp94. The expressions of HSPs are generally up-regulated during the development of the disease. In particular, expressions of Grp78, Grp94, or HSP90 were reported to be correlated significantly with vascular invasion and intrahe- 
patic metastasis. In the investigation of [57], it was reported that up-regulated expressions of Grp78 and Grp94 were possibly involved in pathogenesis, growth, invasion, and metastasis of gastric carcinomas. They were considered objective markers for the aggressive behavior and poor prognosis of the disease [57].

Many take the view that constant stressful conditions exist in the cancer environment, with HSPs helping cancer cells to survive, and to obtain invasive phenotypes under these stresses. For some time, upregulation of HSPs have been taken as diagnostic and prognostic markers in a number of cancers, eventually leading to the development of inhibitors of certain HSPs and HSF1 as therapeutic medicines for a number of cancers (see more details in the review of [58]).

We note also that there appears to be a tumor-selective effect of hyperthermia in a critical range of temperature $\left(40^{\circ} \mathrm{C}-43^{\circ} \mathrm{C}\right)$ in vivo when applied adjunct to chemotherapy [59].

\subsection{HSF1 Has a Role in the Maintenance of Cancer Stem-Like Cells (CSCs)/Cancer-Initiating Cells (CICs) Independent of Stress}

A stress-responsive system is essential in primitive organisms as well as humans for survival because various kinds of stress occur frequently. For obvious reasons, (normal) stem cells and repair/regenerate cells of the organ are equipped with such stress resistance ability [60]. However, another type of stem cells, called cancer stem-like cells (CSCs)/cancer-initiating cells (CICs) were also isolated from several tumors of breast, lung, colon and prostate. Cancer stem cells (CSCs) are defined as a small population of cancer cells having the ability of high self-renewal, differentiation, and having cancer-initiating functions. The stressresponsive mechanisms are related to malignant phenotypes. Recent studies have demonstrated that aldehyde dehydrogenase 1 (ALDH1) is a marker for CSCs in adult cancers (see e.g. [61]). Injection of $10^{4} \mathrm{ALDH}^{\text {high }}$ cells isolated from endometrioid adenocarcinoma (HEC1) cell line, cancer initiation was observed in 10 out of 11 mice models in [62]. Note that siRNA is a synthetic RNA duplex designed to specifically target a particular mRNA for degradation. The upstream transcription factor of HSP27 is heat shock factor-1 (HSF1) which could be activated by phosphorylation at the serine 326 residue (pSer326) in CSCs/CICs, and the evidence of phosphorylation at pSer326 is considered to be necessary for induction of HSP27. In this very recent paper [62], using human ovarian cancer samples, the authors showed that higher expressions of HSF1 pSer326 and hence transcription of HSP27 is associated with the survival of the CSCs/CICs in these samples. The authors also noted that in the in vitro experiment, both down-regulation and overexpression of HSF1 affect cancersphere-formation under non-stress conditions. These results indicate that HSF1 has a role in the maintenance of CSCs/CICs independent of stress, when these cells are matured. Based on the discussed in Section 2.8, HSF1 is only responsible for the transcription of the inducible HSPs, such result in [62] is surprising, and deserves re-confirmation and further study of similar experiments, to find 
out whether HSF1 would significantly induce transcription of HSPs constitutively.

\section{The PDK1-Akt-mTOR-HSF1 Network}

\subsection{The mTORC1 Pathway}

Growth represents the synthesis of new cellular components, which include nucleic acids, proteins, and lipids. Growth is obviously related to the availability of nutrients and energy. When the levels of these two sources are low, the organism must have developed a set of machinery 1) to suppress biosynthesis, 2) to recycle the already old proteins in order to maintain an internal source of metabolites for survival. Under the steady state condition, this machinery must ensure the synthesis and degradation rates are balanced, and must maintain that the components are synthesized in the proper conformations (Section 1). This machinery must be very robust to adjust for the emergence of external stimuli, which could occur in unpredictable ways. Malfunction of this complex machinery is certainly related to aging, various diseases, or even death. Two crucial protein complexes mTORC1 \& mTORC2, are working in concert with other proteins and lipids in this machinery for such purposes. They share the same core protein mTOR (Figure 2). The multicomponent kinase mTORC1 is a nutrient/energy/redox sensor and controls protein synthesis for cells to grow, via the normal mRNA translation. In addition to the "core" protein mTOR, the mTORC1 Complex 1 is composed of the regulatory-associated protein Raptor, mammalian lethal with SEC13 protein 8 (or subunit MLST8), PRAS40, and DEPTOR. These five-member complex regulates cell growth by coordinating signals from growth factors, cytosolic energy levels, mechanical stimuli, oxidative stress and amino acids (and their derivatives) availability, and is deregulated in diseases such as cancer and diabetes.

Under physiological conditions, if the signals favors the generation of proteins, mTORC1 sends signals to the nucleus to activate gene expressions of the relevant proteins. The mRNA of the gene passes between the small unit and large unit of the ribosome (which contains the tRNA), resulting in de novo protein synthesis. The sequence of amino acids then enters the ER for "quality control" of the naïve protein.

On the other hand, the tumor-suppressor LKB1, which encodes a serinethreonine kinase, directly phosphorylates and activates the 5 ' adenosine monophosphate-activated protein kinase (AMPK), which is a central metabolic sensor. AMPK regulates lipid, cholesterol and glucose metabolism in liver, muscle and adipose tissue [63]. Biochemically, AMPK phosphorylates the tumor-suppressor complex TSC1-TSC2 (hamartin-tuberin) which also helps to inhibit mTORC1.

Recently, it has been found that the Rag GTPases (there are 4 isoforms A, B, $\mathrm{C}, \mathrm{D}$ found in mammals and $\mathrm{B}$ is the one involved in the interaction here), which are members of the Ras family, transmit signals on the levels of glucose 
and amino acid to mTORC1, playing a role to initiate the mTORC1 pathway [64]. Moreover, it has been demonstrated that the protein Rheb is required for amino acids to activate the mTORC1 pathway [65] [66]. The protein Ragulator, interacting with the Rag GTPases, recruits the mTORC1 complex and amino acids to the surface of lysosomes, where Rheb is localized. We can say that the Ragulator-Rag-GTPases complex serves as an amino acid-regulated docking site for mTORC1 on the lysosomal membrane [67]. This part of the mTOR pathway is necessary, because some of the newly synthesized proteins may be beyond repair in their structure (Section 1). Degradation of them is carried out in the lysosome. The analysis in [68] revealed that Rheb has a significant positive effect on the binding of the $4 \mathrm{E}$-binding protein 1 (4E-BP1) to mTORC1, thus activating the mTORC1 complex, but not the mTORC2 complex [69]. In short, when amino acids enter a cell, the mTORC1 pathway is activated [70] and the mTORC1 complex is translocated to lysosomal membrane structures and also to the neighborhood of a ribosome [67].

Note that the heat shock factor 1 (HSF1) is also attached to mTORC1. On being released, HSF1 is translocated to the nucleus and causes activation of a group of HSPs' expressions. The synthesized HSPs work as chaperones in the ER and near mitochondria.

The p53 protein is obviously involved in the mTORC1 pathway. It has been demonstrated that activation of p53 would inhibit the action of AMPK and hence the action of the TSC1/TSC2 complex, leading to natural cell death, a result similar to energy deprivation [71]. In 2000, plasmids expressing chicken HSF3, mouse c-Myb (a gene taking part in cell growth and neoplastic transformation), and human p53 were constructed in ref [72]. The result of this in vitro study indicates that $\mathrm{p} 53$ suppresses the $\mathrm{c}-\mathrm{Myb}$-induced activation of HSF, in line with the well-known property of the anti-cancer effect of the p53 protein via promoting cell apoptosis or cell cycle arrest. The simple schematic diagram representing the crucial pathways related to mTORC1 is shown on the left side of Figure 2.

\subsection{The mTORC2 Pathway and Its Connection with the mTORC1 Pathway, Forming the PDK1-Akt-mTOR-HSF1 Network}

Activation of the Akt-mTORC2 pathway is also shown in the same diagram. The complex mTOR2 is composed of five sub-units: mTOR, mLST8, Rictor (large protein with molecular weight of $200 \mathrm{kDa}$ ), SIN1 (has several isoforms with molecular weights ranging from 52 to $80 \mathrm{kDa}$ ), and PROTOR, which is insensitive to the drug rapamycin [73]. Receptor tyrosine kinases (RTKs) are cell surface receptors for many polypeptide growth factors, cytokines, and hormones, including insulin. Phosphatidylinositol-3 kinase (PI3K), which is a signaling molecule, is recruited to the cell membrane by the activated growth factor receptors. Phosphatidylinositol 4,5-bisphosphate or $\mathrm{PIP}_{2}$ or $\mathrm{PI}(4,5) \mathrm{P}_{2}$, is a minor phospholipid component of cell membranes. Then lipid $\mathrm{PIP}_{2}$ generates the activation of 
lipid $\mathrm{PIP}_{3}$, another phospholipid that resides inside the cell membrane, leading to the activation of the "master kinase" PDK1 (phosphoinositide-dependent protein kinase-1).

Now PDPK1 activates the following enzymes. 1) Protein kinase A, (PKA) whose activity is dependent on cellular levels of cyclic AMP and is a regulator of glycogen, sugar, and lipid metabolism. 2) Protein kinase C, (PKC), which is a member of the family of protein kinase enzymes which are involved in controlling the function of other proteins through the phosphorylation of hydroxyl groups of serine and threonine amino acid residues. 3) Ribosomal protein kinase $\beta$-1 P70-S6K (or S6K1), the phosphorylation of which induces protein synthesis at the ribosome. 4) Protein Kinase B or Akt. The ribosomal protein kinase $\beta-1$ P70-S6K (or S6K1) is attached to the small unit of the ribosome which in general is free inside the cytosole. For the generation of protein, a ribosome is attached to mTORC1 (Section 5.1). Thus, PDK1 regulates both mTORC1 and 2 complexes.

mTORC2 also controls the Glut4 receptor, which is activated by the ChREBP $\alpha \& \beta$ complex, mainly found in muscle and adipose [74]. Glucose/carbohydrates enters the cell undergoes glycolysis and the product becomes the "fuel" of the mitochondrion for bio-energy production. Note that mTORC2 is located in the MAM, a layer between a mitochondrion and the surface of an ER. In fact, there is direct evidence that the ER, mitochondria, and MAM (mitochondria associated ER membrane) are physically joined together by the IP3 receptor (IP3R)-Grp75VDAC1 (voltage-dependent anion-selective channel 1) trimeric complex [75].

The inositol 1,4,5-trisphosphate receptor (IP3R) is on the endoplasmic reticulum (ER) and the voltage-dependent anion channel (VDAC) is located on the outer mitochondrial membrane. Remember that Grp75 (TRAP1) is classified as a member of the HSP90 family. The mitochondria must be working within a very narrow range of $\mathrm{Ca}^{2+}$ concentration for proper metabolic rate for survival, and the $\mathrm{Ca}^{2+}$ ion is supplied by the calcium store in the ER. Isolating ER from mouse liver extract, the proteins Rictor and Sin1 (and hence mTORC2) were identified at the MAM. Therefore, we can say that Grp75 participates in regulating the electron transport chain process.

On the other aspect of the whole regulatory network, the tumor suppressor LKB1 activates the AMPK pathway, leading to activation of the TSC 1 and 2 complex, which inhibits Rheb and hence mTORC1, as a negative regulation (left side of Figure 2). Sufficient bio-energy inside the cell inhibits the AMPK pathway [63], and thus effectively activating the synthesis proteins. AMPK also regulates the activity of the fork head box transcription factors (FOXO), which gives signal to the nucleus for apoptosis. Sufficient intracellular energy also rescues the cell from apoptosis.

PTEN is the negative feed-back protein for the activation of PDK1, and thus controlling the amount of energy generated by the mitochondria in the cell. Note also that HSP70 is required for mTORC2 formation and its activity via interaction with Rictor [76]. Whereas mTORC1 is responsible in the initial process 
of RNA translation, there is evidence that coordinated control of mRNA translation and processing of nascent polypeptides (as generated in the large unit of the ribosome) requires the participation of mTORC2 by interacting with the ribosomal protein S6 [77] [78]; in other words, mTORC2 is also physically associated with a ribosome. There are many ribosomes inside a cell. Whether mTORC1 and 2 are physically associated with the same ribosome is not yet fully understood. The active mTORC2 protein is also found to be closed to the cell membrane [79]. Thus, the two complexes are working in an intermingled way, and the locations are yet to be identified under different situations.

The mTORC2 pathway is also shown schematically on the right-hand side of Figure 2. Many HSPs have to be involved in shaping the newly synthesized proteins in the proper forms. We do not specify all the types of HSPs involved, but refer the reader back to Section 2 for details. Summarizing, the PDK1-AktmTOR-HSF1 network, a name assigned to the complex regulation mechanism of all the pathways schematically represented in Figure 2, plays very important role in metabolism, growth, survival of a cell in general.

Recent findings show that HSP40 works closely with HSP70, and they are expected to be colocalized in active forms [29] [30]. Recent discovery also indicates that the small HSPs are regulators of cell death, and their locations could then be translocated to the nucleus when they function as such [33].

A well balance mechanism of the PDK1-Akt-mTOR-HSF1 network is of prime importance in health. Upsetting this balance, such as over synthesis of proteins either constitutively, or responding to continuous external stress (such as ROS), could fall into hallmarks of carcinogenesis, quick aging, or diabetes.

\subsection{Influence of Mechanical Stimuli on the Protein Complex mTORC1}

Half a century ago, an antifungal-antibiotic compound produced by microbes (Streptomyces hygroscopicus) was isolated and subsequently named rapamycin. Rapamycin was found later to inhibit the phosphorylation of the mitogen-activated $70 \mathrm{kDa}$ ribosomal protein S6 kinase (p7056K) leading to cell cycle arrest from the G1 to $S$ phase, implying rapamycin would suppress growth [80]. The mechanistic target of rapamycin (mTOR) is found in the multiprotein complex, mTORC1, and has been inferred to regulate protein synthesis and skeletal muscle mass. As skeletal muscle makes up around $45 \%$ (by weight) of the whole human body, such muscle also plays crucial role in the regulation of the metabolism process in normal life [81]. Hence, the maintenance of skeletal muscle mass is important for mobility, (indirectly) disease prevention and quality of life. Obviously, a balance of the rates of protein synthesis and protein degradation is the determining factor of muscle mass homeostasis. Muscle mass homeostasis can be shifted either way quickly due to variations in nutrients, neural activity, cytokines, growth factors, hormones and mechanical loading, among which mechanical loading plays the key role (see e.g. [82]). 
Activity of S6K1 has been linked to activation of mTORC1. In general, exercise is anticipated to be related to mTORC1 activity. However, the correlation of mTORC1 activation and the specific type of exercise (such as endurance exercise, which is characterized by the repetition of low to moderate force contractions over a prolonged period of time) is still under investigation (see review of [83]). Since there is no evidence, and one does not see the logic that exercise would lead to carcinogenesis, we consider that proper activation of the mTORC1 pathway is part of healthy living.

\subsection{Activation of Helper T Cells by the Two mTOR Complexes}

Apart from participating in metabolism and growth, there is increasing evidence that the mTOR complexes also integrate signals from the immune microenvironment to promote dendritic cell activation and maturation, to regulate (killer) $\mathrm{T}$ cell activation against energy.

The first step (called signal 1) of adaptive $\mathrm{T}$ cell response is the ability of $\mathrm{T}$ cell receptors (TCR) to specifically recognize a large number of different antigens. For a $\mathrm{T}$ cell to take action, it has to receive another signal (Signal 2), which is a specie-specific accessory signal delivered by the antigen-presenting cell (APC). When the peripheral membrane protein B7 (or during virus infection, this protein could be a virus peptide) is located on the surface of an APC, and a surface receptor protein called CD28 is found on the membrane of a T cell, the interaction/binding between $\mathrm{B} 7$ and $\mathrm{CD} 28$ causes the activation of $\mathrm{T}$ cell, recognizing the APC. Now the activation of the APC is considered to be the result of stimulation by virus-associated, pathogen-associated molecular patterns (PAMPs). This is a typical (positive) signal 2. If another protein CTLA-4 (a cytotoxic T-lymphocyte-associated protein 4 (a "check-point" for immunity regulation)) appears on the surface of the T cell, there is no interaction between the APC and $\mathrm{T}$ cell, leading to $\mathrm{T}$ cell tolerance (we may call it a negative signal 2 ). If the $\mathrm{T}$ cell receives a net positive signal, immunity action takes place. For non-infectious response such as cancer and organ transplant, the "Danger theory" states that in this model, immune activation (of the APC) occurs when antigen is presented together with the "danger signals", which could be fragments of DNA, RNA, HSPs, serum amyloid A protein, uric acid and also cytokines. These are naturally released to the extra-cellular matrix during cell necrosis. Thus, the antigen-presenting process is not simple, and the mechanism must be through the function of some intracellular components after integrating a series of intracellular and extracellular signals from the microenvironment [84].

It is also interesting to learn that CD4+ T cells in the absence of mTOR would not differentiate into effector cells which are relatively short-lived activated cells, but would become Foxp3+ regulatory $(\mathrm{T})$ cells. Regulatory $\mathrm{T}$ (Treg) cells play crucial role in regulation of immune responses to self-antigens \& allergens, demonstrating immune responses to infectious agents and tumors, whereas the transcriptional factor Foxp3 is a lineage specification factor of Treg cells [85]. 
Using gene-knockout mice model T-Rheb-/- mice, it was demonstrated that $\mathrm{m}$-TORC1 signaling leads to the differentiation of helper T cells of the types Th1 and Th17, but m-TORC2 signaling leads to the differentiation of helper Th2 cells. Of interest also is that cytokines IL-12 and IFN- $\gamma$ promote the sustained activation of mTORC1 activity in CD8+ T cells [86]. Note that Type 1 helper cells produce interleukin (IL)-2, gamma-interferon (IFN- $\gamma$ ) and tumor necrosis factor- $\beta$ (TNF $\beta)$, and they induce delayed-type hypersensitivity reactions. Related to carcinogenesis, there is evidence that Th1 renders macrophages to kill cancer cells [87]. Th17 cells secret cytokines IL-17A, IL-17F, IL-21, and IL-22. Th17 cells with their effector cytokines mediate host defense against extracellular bacterial infections, and are involved in the pathogenesis of many autoimmune diseases [88]. The effects of Th17 on the cancer microenvironment are still unclear [89]. On the other hand, Th2 cells express cytokines IL-4, IL-5, IL-6 and IL-10, which very effectively lead to the secretion of, particularly Immunoglobulins $\mathrm{E}$ ( $\mathrm{IgE}$ ), being antibodies participating in allergic responses, by B lymphocytes [90]. In another group, transferring ovalbumin (OVA)-specific Th1 or Th2 into mice bearing MHC class II OVA-expressing cancer cells (A20-OVA, or lymphoma cells expressing ovalbumin), it was demonstrated in [91] that both types of helper $\mathrm{T}$ cells have strong anti-cancer immunity activities. Very recent study under clinical setting shows that the combination of Th1 and Th2 cells have anti-cancer effects of lymph node metastasis [92].

As the inhibition of the mTORC1 signaling has been shown to be related to anti-cancer effects, but the evidence of this Section 5.4 just reviewed suggests the opposite result. Such a result indicates that the involvement of the PDK1-AktmTOR-HSF1 network must have very subtle, regulatory properties, as expected. The pro- or anti-carcinogenesis process has to be considered in a holistic manner. This issue will be followed up in Section 8 .

\subsection{The FOXO, Intrinsic, \& Extrinsic Pathways of Apoptosis}

A naturally occurring cell death process is critical for the development of multicellular organisms and survival factors which suppress the intrinsic cell death machinery so that a balance is reached, while protein synthesis is going on and is regulated [93]. It is well known that cell cycle progression is activated by cyclin-dependent kinases (CDKs) which are a family of multifunctional enzymes that can regulate/modify different protein substrates involved in cell cycle progression. Cyclins are the activators of these enzymes. Cyclins D, E, A, B of this family are involved in the progression of the G1, S, G2, phases, eventually to mitosis. Hence, inhibitors of these cyclins (CDKIs), such as the CDKI p27KIP1, will cause cycle arrest. Now Akt can phosphorylate FOXO3 (Figure 2) on the three residue sites: T32, S253 and S315 both in vitro and in vivo. It has been shown that down regulation of PI3K-AKT pathway (e.g. through inhibition by PTEN) leads to translocation of the dephosphorylated FOXO3A into the nucleus. Nuclear FOXOs (in particular FOXO3A) activates several pro-apoptotic genes, such as BIM, PUMA which suppress the cell cycle gene CCND2 (a typical 
cell cycle gene) by direct transcriptional control [94]. Hence, down regulation of the PI3K-Akt pathway, or effectively, lack of growth factors (remembering mTORC2 is also the up-stream activator of Akt) leading to inhibition of both mTORC1,2 would cause accumulation of FOXOs in the nucleus (see Figure 2 and Figure 3). The activation of BIM, PUMA (in the nucleus by FOXOs) down regulates CCND2 and the consequence is apoptosis. Moreover, there is evidence that protein FOXOs upregulate CDKI p27KIP1, and hence promote cell cycle arrest at the G1/S boundary, and we can view that FOXOs cause apoptosis by arresting the cell at the G1/S boundary [94]. Note that all the FOXO1, FOXO3, and FOXO4 are expressed in mammals. FOXO1 is highly expressed in adipose, while FOXO3 is abundant in various tissues including brain, heart, kidney, and spleen. We use the symbol FOXO 1, 3 to represent such proteins in the majority of organs here [94].

On the other hand, there are two other cell death processes. Cysteine-aspartic proteases (caspase), are a family of protease enzymes (about 12 in human) in the cytoplasm, playing essential roles in programmed cell death including apoptosis, pyroptosis and necroptosis, but we will consider only apoptosis here. The apoptopic caspases are subclassified as: Initiator caspases (caspase-2, caspase-8, caspase-9, caspase-10) and executioner caspases (caspase-3, caspase- 6 and caspase-7). First note that the BCL2 family members form hetero- or homodimers and act as anti- or pro-apoptotic regulators, plus other functions. Proteins BAK and BAX are two such members and BAK is constitutively attached to the outer membrane of the mitochondria (OMM), whereas BAX is in the cytosole [95]. Cell stress activates pro-apoptotic protein BID, and recruits BAX to BAK, leading to activation of the BAK/BAX system. Once activated, BAK and BAX form proteolipid pores in the OMM, allowing release of cytochrome $\mathrm{c}$ to the cytosole, promoting caspase activation. The cytosolic cytochrome $\mathrm{c}$ binds to the heptameric apoptotic protease activating factor 1 (APAF-1) in the cytoplasm; APAF-1, then recruits initiator caspase-9 there, forming the (Apaf-1-cytochrome-c-caspase 9) complex, which is also called apoptosome. After activation, the caspase 9 leaves the structure and activates executioner caspases which then participate in degradation of cellular components. This process is called intrinsic apoptosis [96]. On the cell membrane there are receptors called death receptors such as the FAS receptor (FasR, also known as apoptosis antigen 1, APO-1). Fas forms the deathinducing signaling complex (DISC) upon Fas ligand (such as TNF-related protein) to the cytoplasmic tail of the receptor (called the death domain), which recruits the adapter protein such as Fas-associated protein with a death domain (FADD), in response to the stated stimulus of ligand binding. FADD would, in turn, activate an initiator caspase (e.g. caspase 8 ). This caspase activates typically executioner caspase 3, leading to apoptosis. This apoptotic process, being triggered by an external source, is called an extrinsic apoptosis. In Figure 3, we present a schematic diagram of these three processes. We do not list the different caspase members because the pro-caspases are found in different subcellular compartments (such as only pro-caspase- 2 was found in the nuclear fraction) related to their activation mechanisms, the details of which are still under research 


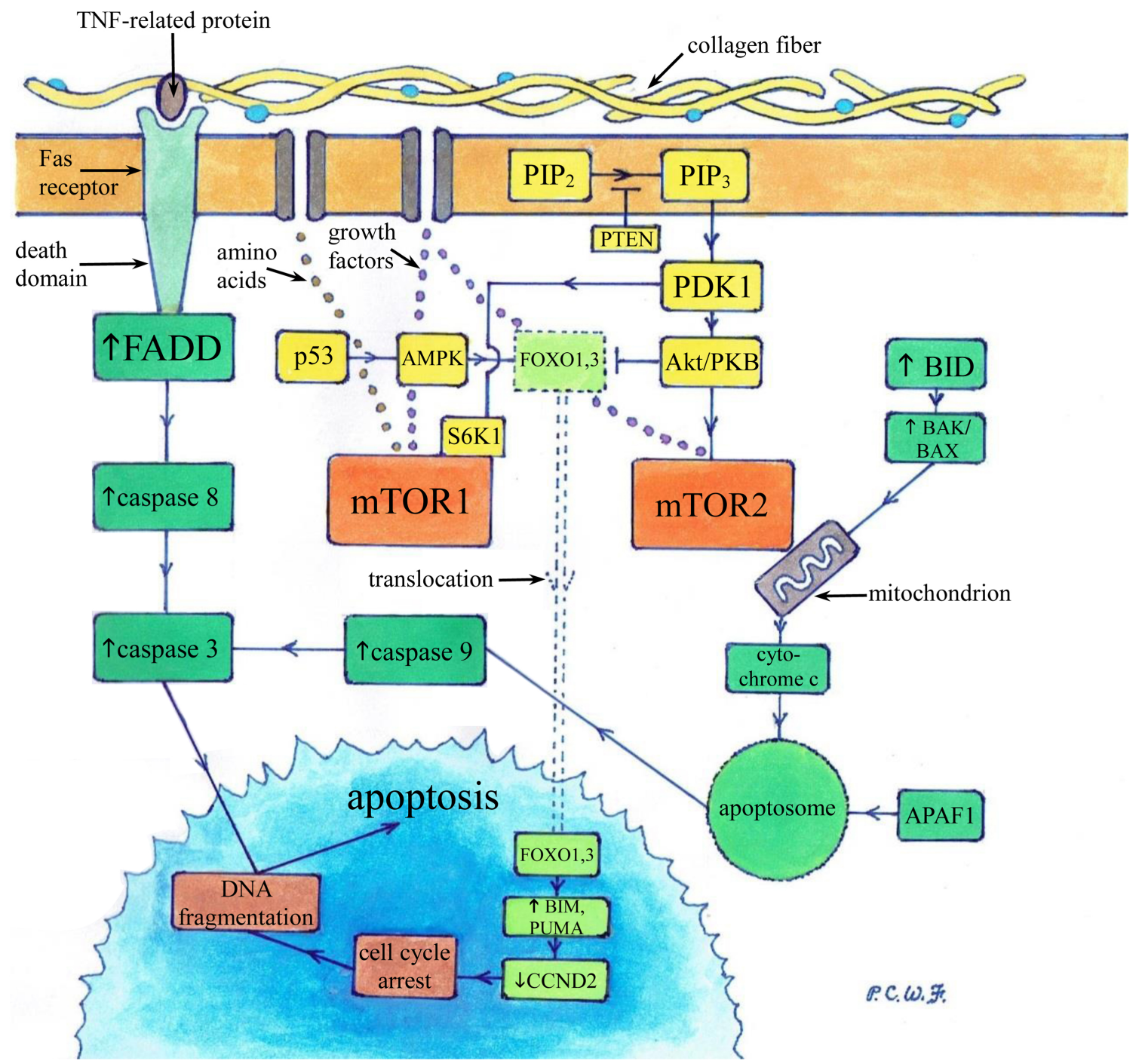

Figure 3. The BCL2 family members form hetero- or homodimers and act as anti- or pro-apoptotic regulators, plus other functions. Proteins BAK and BAX are two such members. BAK is constitutively attached to the outer membrane of the mitochondria (OMM) [95]. Cell stress recruits BAX to BAK and the BAK/BAX system is activated. Once activated, BAK and BAX form proteolipid pores in the OMM, allowing release of cytochrome $c$ to the cytosole, promoting caspase activation. Apoptotic protease activating factor 1 (APAF-1) is found in the cytoplasm; APAF-1, then recruits initiator caspase-9 there, forming the (Apaf-1-cytochrome-c-caspase 9) complex, which is also called apoptosome. After activation, the caspase 9 leaves the structure and activates executioner caspases which then participate in degradation of cellular components. This process is called intrinsic apoptosis [96]. Death receptor Fas forms the death-inducing signaling complex (DISC) upon Fas ligand binding (with Tumor necrosis factor TNF, say). Such binding activates the cytoplasmic tail of the receptor (called the death domain), which recruits the adapter protein, forming and activating a structure called "Fas-associated protein with a death domain (FADD)", in response to the stated stimulus of ligand binding. FADD would, in turn, activate an executioner caspase, such as caspase 3, leading to apoptosis, as schematically represented in the figure. This process is called extrinsic apoptosis. Following the pathways in Figure 2, downregulation of PI3K-AKT pathway (e.g. through inhibition by PTEN) leads to translocation of the dephosphorylated FOXO3A into the nucleus. Nuclear FOXO3A activates several pro-apoptotic genes, such as BIM, PUMA which suppress the cell cycle gene CCND2 (a typical cell cycle gene), resulting cell cycle arrest. DNA fragmentation occurs. With reference to the functions of pathways mentioned in Figure 2, effectively, dowregulation of mTORC1,2 or PI3K-AKT pathway leads to apoptosis. This is the known third apoptotic pathway. There is cross-talk between FOXOs and caspases in fibroblasts [100]. Figure 3 was hand-painted by author PCWF. 
[97] [98]. The intrinsic and extrinsic processes are adopted from Figure 2 of [99] and FOXO-dependent pathway follows from Figure 2 of this paper, with more specification. We would remark that there is also cross-talk between FOXOs and caspases in fibroblasts [100], so that effectively all the three pathways stated may form a network. We will leave that aspect alone until there is more evidence of such relation from more cell types.

\subsection{PERK-eIF2 $\alpha$-ATF4-CHOP Apoptotic Signaling Machinery}

In addition to the three apoptotic pathways described above, there is another pathway which is related to the mechanism of drug action within the scope of this paper. When a naïve protein enters the ER, members of the HSP70 family (Section 2) called Grp78, Grp94, Calreticulin are doing the quality control work in ER. Apart from treating a naïve protein in three ways as introduced in Section 1 , driving the cell to apoptosis is another action. The overall action to accumulation of misfolded proteins inside ER is called Unfolded Protein Response (UPR). The UPR has three functions: 1) adaptive response which attempts to restore homostasis (Figure 1); 2) feedback control, which turns off 1) if there are too many misfolded proteins accumulated inside ER, then 3) there is pathway to drive the cell to death [101]. For 3) to act, note that the Inositol-requiring enzyme 1 (IRE1), which is an ER-transmembrane protein, is sensing and responding to ER stress. IRE1 contains an ER luminal stress-sensing domain and a domain called RNase facing the cytoplasm. Upon receiving signal for action 3), IRE1 proteins oligomerize and activate their RNase activity [102]. There are two more proteins at the ER membrane; one is the protein kinase RNA-like endoplasmic reticulum kinase (PERK) which activates itself by oligomerization and autophosphorylation of the domain facing the luminal side. Activation of PERK in turn activates the third transmembrane protein, i.e. transcription factor (ATF4), which functions as a basic transcription factor. The activated ATF4 causes translational attenuation by directly phosphorylating the $\alpha$ subunit of the regulating initiator (called eIF2 $\alpha$ ) of the mRNA translation pathway [103]. ATF4 also enhances the expression of pro-apoptotic CCAAT/enhancer-binding protein-homologous protein (CHOP), leading eventually to translational attenuation of the protein machinery involved in running the cell cycle progression. The result is the cell is arrested in the G1 phase-apoptosis occurs [104]. In other words, inhibition of HSP70 in cancer cells would drive the cells to follow the PERK-eIF2 $\alpha$ ATF4-CHOP apoptotic pathway, leading to anti-cancer effects. Here CCAAT is a box motif in many enhancers. This is one reason for choosing HSP70 inhibitors as potential anti-cancer drugs.

\section{What Have We Learned from Experiments Using Inhibitors of HSP90, mTOR, HSF1 to Treat Cancer Cells, in Vitro and in Vivo?}

\subsection{Passive Potential Drugs}

Inhibition of protein synthesis via inhibition of the mTORC1,2 complexes, trig- 
gering natural death of cancer cells through activation of p53, inhibition of HSPs and HSF1, deprivation of amino acids, food, growth factors can stop cancer proliferation to different degrees. We call these drugs "passive potential drugs/ measures", as they have profound effects also on healthy cells. We will review below some relevant benefits of certain typical ones being studied extensively recently in their anti-cancer action below.

\subsection{Targeting HSP90 Alone}

Heat shock protein 90 (HSP90), together with its co-chaperones, can help over 200 nascent polypeptides to fold correctly, eventually leading to synthesis of the proper proteins for constitutive cell signaling, physiological processes, and adaptive responses to various stresses. Now we know that this complex machinery/structure participates even in transcriptional regulation and chromatin remodeling. In cancer, accumulation of mutated proteins, presence of high level of reactive oxygen species, low $\mathrm{pH}$, or even the presence of an abnormal number of chromosomes (not 45 or 47, aneuploidy disease) form an unfavorable microenvironment for the cancer cells to survive. It is obvious intuitively that an inhibitor of HSP90 is one class of potential drugs to be considered as a clinical measure to kill cancer cells. This typical inhibitor disrupts HSP90 activity by replacing ATP in the N-terminal nucleotide-binding pocket. Such inhibition destabilizes a large number of oncoproteins, leading to blockade of tumorigenic signaling pathways, resulting in arrest of cancer cell proliferation, with further induction of apoptosis [105]. There are over 13 such inhibitors being tested and many are used in pre- and some in clinical trials. Novobiocin, geldanamycin, 17-AAG (tanespimycin), NVP-AUY922, NVP-HSP990 are five among those potential medicines [7] [106]. The last two members (NVP-AUY922, NVP-HSP990) have shown anti-cancer effects in primary cancer cells and animal models of melanoma, myeloma, gastric cancer, non-small-cell lung cancer (NSCLC), hepatocellular cancer, sarcoma, and breast cancer (see review in [107]). Of interest, human cancer xenograft models (i.e. human cancer cells being transplanted, either under the skin or injected into the specific organ) GTL-16, NCI-H1975, BT474, and MV4 were implanted subcutaneously into mice models. Standard pharmacokinetics-pharmacodynamics analysis shows that NVP-HSP990 is a potent and selective HSP90 inhibitor, inhibits growth of a range of cancer cells just stated. We would not discuss the details of these xenograft models here.

However, we would emphasize that the importance of physiological functions of the HSPs as explained in details in previous sections. A very sharp balance has to be achieved for the host to survive and killing cancer cells at the same time. It is of importance to understand the mechanism via which any HSP inhibitor works, the details of which are hot lines of research at present. In fact inhibitors of several HSPs are under clinical trials (see e.g. [108]). We found that one FDA approved drug Gilotrif, which is a client of HSP90, together with a HSP90 inhibitor showed much better anti-cancer effects than using Gilotrif alone in in vivo animal study (see Table 1). 
Table 1. Examples of HSP-based cancer vaccine and HSP-related anti-cancer drugs.

\begin{tabular}{|c|c|c|}
\hline $\begin{array}{l}\text { FDA approved drugs } \\
\text { to treat cancer }\end{array}$ & Basic mechanism of action proposed & $\begin{array}{l}\text { Type of cancers \& reference } \\
\text { support of mechanism(s) before } \\
\text { or after FDA approval }\end{array}$ \\
\hline $\begin{array}{l}\text { Sipuleucel-T } \\
\text { (Oncophage Vitespen) } \\
\text { HSP based cancer } \\
\text { vaccines first } \\
\text { approved in } \\
\text { April, } 2010\end{array}$ & $\begin{array}{l}\text { Person-specific vaccine. In preparation, first HSPs and antigens are isolated } \\
\text { from a patient's cancer cells. The HSP/antigen complexes are made into a } \\
\text { vaccination. The patient receives injection once a week. Peptides of } \\
\text { HSP member Grp } 96 \text { to be cross-presented to immunity cells, } \\
\text { thereby killing the cancer cells with such recognition. }\end{array}$ & $\begin{array}{l}\text { Prostate cancer according to [172]. } \\
\text { Refer to review on mechanism of } \\
\text { some prototype vaccines in } \\
\text { Section 7.1 and 7.2. Consult } \\
\text { discussion on possible non-person- } \\
\text { specific, non-cancer-specific vaccine } \\
\text { in Section } 8 .\end{array}$ \\
\hline $\begin{array}{l}\text { The drug Gilotrif } \\
\text { (afatinib), which is a } \\
\text { client protein of } \\
\text { HSP90, was approved } \\
\text { by FDA on July } \\
2013 \text { to treat } \\
\text { non-small-cell-lung } \\
\text { cancer. Ganetespib, an } \\
\text { HSP90 inhibitor, } \\
\text { together with gilotrif } \\
\text { as combination of } \\
\text { anti-cancer measure } \\
\text { in in vivo mice model } \\
\text { study is discussed } \\
\text { here. }\end{array}$ & $\begin{array}{l}\text { The epidermal growth factor receptor (EGFR) is a tyrosine kinase } \\
\text { receptor. HERs are also transmembrane tyrosine kinase receptors. These } \\
\text { receptors belong to the ErbB receptor family. They are known to be } \\
\text { expressed by, and involved in the growth of a number of cancer cells. } \\
\text { Gilotrif was demonstrated to bind the kinase domains of EGFR, HER2 \& } \\
\text { HER4 and thus irreversibly inhibits tyrosine kinase autophosphorylation, } \\
\text { resulting in downregulation of ErbB signaling. However, these kinases are } \\
\text { clients of, and binding strongly to HSP90 [173]. It is therefore not surprising } \\
\text { that HSP90 inhibitor Ganetespib, combined with inhibitor Gilotrif of such } \\
\text { kinases would reduce the synthesis of other HSPs other than HSP90 } \\
\text { (because HSP90 is bound to heat shock factor 1; see Figure 2), and would } \\
\text { enhance the inhibition of the mTORC1 pathway, causing stronger } \\
\text { anti-cancer effects (as compared to the situation using Gilotrif alone) } \\
\text { in in vivo mice model study reported [174], in our opinion. }\end{array}$ & $\begin{array}{l}\text { The support of the drug Gilotrif to } \\
\text { treat metastatic non-small cell lung } \\
\text { cancer with EGFR mutations is based } \\
\text { mainly on the clinical trial reported } \\
\text { in [175]. See Sections } 2 \text { and 3, with } \\
\text { Figure } 2 \text { of the present paper on } \\
\text { functions of HSP90. See also [176] }\end{array}$ \\
\hline $\begin{array}{l}\text { OSU-03012 (Ar-12) } \\
\text { Pre-Clinical Trial }\end{array}$ & $\begin{array}{l}\text { High level of Akt was frequently detected in brain tumor such as Vestibular } \\
\text { schwannoma. At first, this drug was developed from cyclooxygenase- } 2 \\
\text { inhibitor celecoxib.OSU-03012 is an inhibitor of the upstream } \\
\text { protein PDK1, leading to inhibition of protein synthesis induced } \\
\text { by the mTORC1 pathway, therefore it could be interpreted } \\
\text { effectively as mTOR inhibitor initially. }\end{array}$ & $\begin{array}{c}\text { Brain tumor like Vestibular } \\
\text { schwannoma according to [177] } \\
\text { [178]. See Section } 5.2 \text { with Figure } 2 \\
\text { on details of mechanism according to } \\
\text { authors' review opinion. }\end{array}$ \\
\hline OSU-03012 (Ar-12) & & $\begin{array}{l}\text { The drug was inferred to treat } \\
\text { glioblastomas also according to }\end{array}$ \\
\hline $\begin{array}{l}\text { Clinical Trial, Phase I } \\
\text { was announced in } \\
2013[179]\end{array}$ & $\begin{array}{l}\text { More recently, it was found that OSU-03012 suppresses HSP70 member } \\
\text { GRP78/BiP expression that causes PERK-dependent apoptosis. }\end{array}$ & $\begin{array}{l}\text { [180]. See Section } 5.6 \text { on the } \\
\text { PERK-eIF2 } \alpha \text {-ATF4-CHOP apoptotic } \\
\text { signaling machinery for details, } \\
\text { according to authors' review opinion. }\end{array}$ \\
\hline $\begin{array}{l}\text { Torisel } \\
\text { (temsirolimus), } \\
\text { approved by FDA in } \\
\text { May, 2007; } \\
\text { intravenous injection }\end{array}$ & $\begin{array}{l}\text { Interferes with the growth and spread of cancer cells in the body via } \\
\text { inhibiting protein synthesis initiated by the mTOR pathway. These } \\
\text { proteins include those that regulate progression through the cell cycle. } \\
\text { It is also used jointly with interleukin } 2 \text { and interferon alpha. }\end{array}$ & $\begin{array}{l}\text { Kidney cancer (metastatic renal cell } \\
\text { carcinoma) according to [181]. See } \\
\text { Section } 5.2 \text { with Figure } 2 \text { for the } \\
\text { protein synthesis mechanism, and } \\
\text { Section } 5.3 \text { with Figure } 3 \text { on } \\
\text { FOXO-translocation induced } \\
\text { apoptosis, according to } \\
\text { authors' review opinion. }\end{array}$ \\
\hline $\begin{array}{l}\text { Afinitor (everolimus), } \\
\text { approved by FDA in } \\
\text { April 2012, oral }\end{array}$ & $\begin{array}{l}\text { FKBP-12 is an immunophilin and peptidyl-prolyl cis-trans isomerase, and } \\
\text { Everolimus binds to FKBP-12, forming a complex. This complex binds to } \\
\text { mTORC1 kinase directly, and inhibits the mTORC1 pathway, leading to } \\
\text { inhibition of protein synthesis of the cancer cell. }\end{array}$ & $\begin{array}{l}\text { It was approved by FDA to treat } \\
\text { renal angiomyolipoma associated } \\
\text { with tuberous sclerosis complex, but } \\
\text { the study of reference [182] reports } \\
\text { that the drug has efficacy on } \\
\text { proliferation of giant cell astrotomas, } \\
\text { pulmonary and skin lesions } \\
\text { associated with tuberous } \\
\text { sclerosis complex. }\end{array}$ \\
\hline
\end{tabular}


Afinitor

(everolimus), approved July 2012, oral

Afinitor (everolimus), FDA approved May 2011, oral
The human epidermal growth factor receptor 2 (HER2), which is encoded by the ErbB2 gene, is a protein that appears on the surface of some breast cancer cells. HER2-negative breast cancers have little or no HER2 protein and are considered to be low-grade cancers. A cancer is called hormone-receptor-positive (or HR+) and the cancer cells, like normal breast cells, may receive signals from the hormone that could promote growth. FKBP-12 is an immunophilin and peptidyl-prolyl cis-trans isomerase, and Everolimus binds to FKBP-12, forming a complex. This complex binds to mTORC1 kinase directly, and inhibits the mTORC1 pathway, leading to inhibition of protein synthesis of the cancer cell.

\section{To treat hormone} receptor-positive, HER2-negative breast cancer. Phase 3 trial in patients with hormone-receptor-positive advanced breast cancer showing that the addition of everolimus to endocrine therapy shows improved efficacy [183] [184].
Autocrine factor such as insulin-like growth factor 1, has been implicated in the proliferation of pancreatic neuroendocrine tumor cells [185]. The growth factor activates both the mTORC1,2 complexes and the network described in Section 3 (see Figure 2). Everolimus inhibits the protein mTOR and thus the mTOR pathway of protein synthesis. Based on the third trial of the key reference, everolimus has been shown to reduce cell proliferation, angiogenesis, and glucose uptake in in vitro and/or in vivo studies [185].
To treat advanced pancreatic neuroendocrine tumors. [186] [187]. See details of Section 3 of this paper.

\subsection{If One Attempts to Inhibit HSP90, HSF1 Has to Be Knocked down Too}

Oozytes from Xenopus laevis frogs were kept at $18^{\circ} \mathrm{C}$. After heat shock at $33^{\circ} \mathrm{C}$ for $1 \mathrm{hr}$, treatment with a HSP90 inhibitor novobiocin significantly diminished HSF1-HSE-binding activity in a dose-dependent manner. The analysis of the same paper points out that as HSF1 is closely associated with the HSP90 complex, three mechanisms have to be considered related to the function of the HSP90 inhibitor as a potential drug. The drug has to 1) inhibit the chaperone function of the HSP90 itself; 2) inhibit the trimerization of HSF1, so as to inhibit HSF1-HSE binding; 3) inhibit the transcription of HSP genes in the nucleus. The outcome of that study already suggests that one specific inhibition (on HSP90 as a chaperone) is not sufficient for at least as a temporary anti-cancer therapy. In fact, inhibition of HSP90 has been shown to increase HSF1 trimer stability and prolongs the heat shock response [109].

On the other hand, the newly developed RNA interference (RNAi) technique is an RNA-mediated gene silencing mechanism. In a cell system, "silencing" is achieved via the delivery of a double-stranded RNA (dsRNA) that matches the mRNA target sequence. The dsRNA can be delivered as a siRNA (short interfering RNA) via transfection, or shRNA (short hairpin RNA or shRNA) by transfection or viral delivery of a plasmid. Analysis of a large scale RNAi screen has already been proved to be useful to understand the gene function of a cell system. Applying this large scale RNAi technique to samples from 50 liver cancer patients, HSF1 was identified as a sensitizer of HSP90 inhibitor, and that a com- 
bination of HSF1 inhibitor and HSP90 inhibitor has a pronounced effect in inhibiting the action of HSP90 [107]. The RNAi technique with HSF1 knockdown and application of HSP90 inhibitor (NVP-HSP990 or NVP-AUY922) was also applied to mice models and the following cancer cell lines: melanoma (A375, A2058), hepatocellular carcinoma (Hep3B, Huh7) and colon cancer (HCT116). The results substantiate the suggestion that the transcriptional activities of HSF1 induced by a HSP90 inhibitor provide a feedback mechanism to limit the activity of the HSP90 inhibitor [107].

\subsection{Targeting mTOR Cascade Alone}

Intrahepatic cholangiocarcinoma (CCA) is an aggressive cancer with poor prognosis [110]. Applying mTOR inhibitor to CCA models/subjects lead to some success [111]. On the other hand, the PI3K/Akt/mTOR signaling network (Sections 5.1 and 5.2) also plays important roles in survival, apoptosis, metabolism, motility, and angiogenesis of cells, including normal and CCA cells. For at least a decade, the rapamycin and its analogues (called rapalogs in general) have been applied to treat a variety of cancers in many model/clinical studies, with some success and some irresponsive results [9] [112]. Two inhibitors of mTORC1 have already been approved by FDA as anti-cancer drugs, and we list them in Table 1 .

\subsection{Targeting Both mTOR Cascade with NVP-BEZ235 and HSP90 with NVP-AUY922-Studies Using Cancer Cells from Patients and in Vivo Animal Models}

In the ABC-02 trial, 410 patients, suffering from locally advanced or metastatic cholangiocarcinoma, gallbladder cancer, or ampullary (opening to duodenum) cancer, were randomly assigned to receive (A) cisplatin (as a cytotoxic agent) plus gemcitabine as compared to those treated with (B) gemcitabine alone. The median overall survival was 11.7 months among the 204 patients in group (A) and 8.1 months among the 206 patients in group (B) respectively. There were 327 deaths. In the 8.2 months follow-up trial, the authors concluded that patients in group (A) were associated with a significant survival advantage without the addition of substantial toxicity [110]. More recently, specimens were obtained from 78 patients with macroscopic appearance of CCA who had under gone hepatectomy between 1989 and 2006 [113]. These specimens were stained for HSP90 and PTEN in order to analyze the involvement of the Akt-mTOR pathway and function of HSP90 (Figure 2). Physical examination, blood tests (CEA \& CA 19-9), ultra-sound examination of the remnant liver were followed up. Statistical analysis revealed that poor nutritional status, positive margin status (cancer cells extending to the edge of the tissue), high HSP90 and low PTEN expressions were correlated independently to the (predicted) unfavorable overall survival in these macroscopic appearance-CCA patients after hepatectomy. Then the effects of treatment on the cancer cells were analyzed with treatment 1) 
NVP-AUY922 (an HSP90 inhibitor), or treatment 2) NVP-BEZ235 (an Akt-mTOR pathway inhibitor), or treatment 3 ), which is a combined treatment of 1) \& 2). It was demonstrated in the in vitro study that treatment 3) induced cancer cell death. Based on in vivo study, it was also demonstrated that a specific combination dosage of NVP-AUY922 \& NVP-BEZ235 caused tumor regression in a CCA rat animal model (see Figure 5 of [113]). We would, however, remark that blocking the systemic Akt-mTOR pathway and the activity of HSPs would interfere with normal cell proliferation and (normal) cell function. It would be important, in our opinion, to analyze in what ways the inhibitor NVP-AUY922 affect the function of HSP90 complex, which has over 200 clients and being attached to the HSF1, the release of which would induce transcription of a series of HSPs.

\section{Knowledge Learned from Experiments Striving to Develop Cancer Vaccines Based on Antigens Bound to Heat Shock Proteins, with a Series of Examples Emphasizing on the Roles of HSP70}

\subsection{Immunized with Antigens Prepared from the HSPs of the Host, One of the Earliest Cancer Vaccines Was Prepared}

As mentioned in Section 2.8, the heat shock response triggered by HSF1 is "faithful" to the host (cancer) cell for its survival-HSF1 controls numerous HSP gene expressions, reprogramming the cells to acquire the ability to inhabit, and invade, in a stressful, toxic tumor niche [114]. With the help of self-generated HSPs, the conventional therapy is impeded, and even favors metastatic conditions (Section 3.2). For this major reason, HSPs were considered by a number of scientists/(clinical experts) to be the cause of carcinogenesis, and many HSP inhibitors have been developed to treat cancer as explained in a previous section. On the other hand, cancer cells often carry mutated or aberrant proteins, and they appear as peptides/short proteins which become tumor-associated antigens (TAA). These antigens would stimulate the host immunity response at the cancer site. The crucial and "intrinsic" methodology of anti-cancer therapy is therefore to identify these antigens and find, or induce endogenously ways to present these antigens to the immunity cells for the usual process of immunity response. Over a decade ago, immunized with antigens prepared from the HSPs of the host, one of the earliest cancer vaccines was prepared [115]. Following, various experiments from different groups demonstrated that these antigens can elicit antigen-specific cytotoxic T lymphocytes (CTLs) to react, and a number of experiments on preparation of cancer vaccines began to be developed. At first, it was thought that the antigen is cancer-specific and person-specific, but the discovery to be discussed in Section 7.3 suggests that cancer vaccine to cover at least a range of cancers might be prepared, potentially over-coming the practical hurdles that a large number of human cancer specimens and a large number of can- 
cer cell lines are needed to make various vaccines for therapeutic usage.

\subsection{In the Prototype Cancer Vaccines Preparation, Either HSP70-Complex with Peptides, or Pure HSP70 Was Used as Antigen for Cancer Vaccine, Leading to Promising Efficacy under Different Settings}

The roles played by HSP90 have been reviewed in Section 2. We will concentrate on the mechanisms involving other HSPs, particularly HSP70, which is the second abundant HSP in the human body. Through such series of investigations in the past decade, several prototypes of cancer vaccines have been developed. There is HSP70 vaccine associated with peptide derived from fusion of DC and (ovarian \& breast) cancer cells [116], having the result of inducing $\mathrm{T}$ cells that expressed high levels of IFN- $\gamma$ (which could kill cancer cells). This study, plus some others (see e.g.an earlier study [117]), suggests at least for some cancers, it is important to keep the complex HSP70-TAA as antigen, rather than just the TAA peptide itself. In another very recent example, intratumorally injection of purified HSP70 to an in vivo model of metastatic (from muscle to the lungs) RA-2 rat rhabdomyosarcoma showed superior anti-cancer effect as compared with a HSP70 mixture with tumor antigens. Note that the HSP70 protein was purified from bovine muscle and then mixed with tumor extract from the rat model. The authors particularly remarked: "The most interesting observation was that exogenous HSP70, by extrusion of its cellular analog, increased the sensitivity of tumor cells to cytotoxic lymphocytes in the appropriate assay" [118].

Note that similar in vitro experimental evidence with C6 glioblastoma cells was also reported in 2014. In particular, injection of pure human recombinant HSP70 caused a remarkable delay in tumor growth and elongation of the survival time of animal models. It was noted also that the therapeutic effect was accompanied by the growth of specific CD4+ and CD8+ T lymphocytes and activation of cytotoxic NK cells [119].

Moreover, photodynamic therapy has been applied to treat human glioblastoma spheroids (derived from patient) in vitro. It was observed that the treatment might have generated an altered cancer microenvironment, promoting adaptive immunity. Cancer cells were observed to undergo necrosis (or apoptosis) releasing cancer antigens that can be taken up by DCs. It was inferred that HSPs induced on the surface or released by the cancer cell promote DC maturation. To test whether HSP70 was involved in promoting DC activity, the spheroids were pre-incubated with goat-anti-human HSP-70 polyclonal IgG antibody [120] [121], and the answer was positive.

Another interesting study involving HSP70 \& NK cells in anti-cancer effects was reported earlier. Four cell lines of human pancreas carcinoma cells (Colo357) and human colon (CX2) carcinoma cells were separated, using HSP70-specific monoclonal antibody respectively into the four sublines: Colo-/Colo+ and CX-/ 
CX+ [122]. Different amounts of HSP70-specific monoclonal antibody were mixed with these cell lines so that these four cell lines only distinguish in their percentages of HSP70 membrane-positive cells with the following characterizations: Colo- (34\%), Colo+ (73\%); CX- (20\%), CX+ (90\%). It was found that the NK cells migrated specifically toward TKD (which is a partial HSP70 sequence Thr-Lys-Asp-Asn-Leu-Leu-Gly-Arg-Phe-Glu-Leu-Ser-Gly, known to be able to stimulate the cytolytic activity of $\mathrm{NK}$ ) and exosomes derived from Colo+ and $\mathrm{CX}+$ carcinoma cells, and the HSP70-specific antibody completely abrogated the stated "induced" migratory activity of NK cells. The result is: the NK cells killed the HSP70-expressing pancreas and colon cancer cells readily. Thus, it appears that HSP70 plays a rather profound role, across species, in the stated existing therapy to treat cancer, leading to positive anti-cancer effects. We found there was one person-specific, cancer-specific vaccine approved by FDA, to treat prostate cancer; see Table 1.

\section{Discussions-Attempting to Provide Some Answers to a Number of Mysteries/Controversies in Treating Cancers with Passive Potential Drugs Discussed in Section 6, and the Development of General HSP-Based Cancer Vaccines}

\subsection{The Difference in Functions of Intracellular and Extra-Cellular HSPs}

Since HSPs have been detected in the circulation, they must have been excreted from the host cells. In fact, recent research points to two extremities of the duties performed by these HSPs. Intracellular functions have just been discussed in the previous sections: they are mainly protective in handling protein folding problems. Once they are secreted, they perform their immunity duties-being proinflammatory (see Table 1 of [123]). Moreover, it was found that HSPs from a certain family (with different sizes) were associated with a range of cancerous peptide antigens in cancer cells. It was exactly this property that cancer vaccines might be developed as they would recognize cancer cells when injected inside the human body, playing the role of antigen presentation [124] [125] [126]. Moreover, we have presented brief evidence that HSP70 could induce the immunity of the natural killer cells, which are not cancer-type-specific at the end of Section 7.2. More details will be followed up in later sections.

A protein needs to have an $\mathrm{N}$-terminal hydrophobic signal sequence in order to be secreted through the conventional process into the interstitium. Inflammatory cells, however, release polypeptides by secretory lysosomes, and can secret cytokine IL-1 $\beta$ outside the cell [127]. Since HSPs do not possess the $\mathrm{N}$-terminal hydrophobic signal sequences, they are expected to be secreted rather through a way similar to that associated with cytokine secretion. There are other ways of secretion too [128]. Having gone through the above analysis, it is not difficult to see that two schools of thought emerge. In one school of thought on immunity response is: there are damage-associated molecular pattern mole- 
cules (DAMPs), or signals/molecules called "alarmins", which induce pro-inflammatory activation of macrophages, further contributing to the progression of injury of certain organ [129]. Since there are reports of detecting HSPs in cancer cells and at sites associated with inflammatory situations, HSPs are considered as examples of DAMPs. Another trend of analysis is that HSPs can capture intracellular antigens and present them to antigen-presenting cells, mediating the crosspriming of recipient cells [130]. In fact, HSPs can be secreted in free form (thus bringing out antigen signal), as membrane-bound molecules, or being leaked out from cells during necrotic death [123]. These extra-cellular HSPs are highly immunostimulatory. Note that if a cell undergoes apoptosis, the cell membrane remains as an envelope with phospholipid phosphatidylserine, as a signal for engulfment by macrophages and the cytosolic materials are not released to the interstitium to trigger inflammatory signals. In summary, intracellular HSPs are protectors of proteins and health of the host cell directly, but extra-cellular HSPs are pro-inflammatory, but still can play a very important protective role of the living organism in a different way.

\subsection{Two Distinctive Ways of Phagocytosis to Engulf Dead Cells}

In addition, adapting the analysis in [123], the phagocyte (in treating apoptotic cells) would release interleukin-10 (IL-10) \& transforming growth factor- $\beta$, which are anti-inflammatory. In contrast, during necrotic death, the cytosolic materials such as urate, nucleic acids, chromatin proteins are leaked out; in this case, the phagocyte would release interleukin-6 (IL-6), tumor-necrosis factor instead, which would induce inflammatory action taken by other immunity cells (see Figure 2 of [123]). Such a difference in engulfment of cells with these two types of deaths can be realized intuitively: necrotic death leaks out antigens. Depending on the types of cell death (apoptosis or necrosis), the phagocytes emit different cytokines, which affect the action of other immunity cells.

\subsection{Systemic Mild Hyperthermia Can Shift the Pro-Inflammatory Activity of IL6 to Anti-Tumorigenic Function by Promoting Trafficking of DCs, as Antigen Presenting Cells, from Narrow Tumor Vasculature to the Tumor Site through Extravasation}

Before we discuss in details the cross-presentation mechanism, we need to study the plausible mechanism by which the immunity cells reach the cancer site.

The microenvironment of a cancer region is generally chronic inflammatory, inducing the recruitment of 1 ) heterogenous immune cells originated from bone marrow stem cells (or called "myeloid-derived suppressor cells", or MDSCs), 2) mature $\mathrm{T}$ helper cells expressing surface protein $\mathrm{CD} 4,3$ ) tolerogenic dendritic cells (which can induce/maintain immune tolerance) and 4) tumor-associated macrophages (which can be derived from circulating monocytes or resident tissue macrophages). During carcinogenesis, these cells usually are not strong enough to destroy the cancer-induced immunosuppression and to restore normal immune surveillance. 
Note that thermoregulation involves extensive neural and vascular networks in the skin and visceral organs to maintain an optimal range of temperatures within the body for the benefit of the host organism, and is one homeostatic system in all vertebrates. It has been known for long that fever is a body response to the acute phase of infection or injury. That such a response has been maintained throughout evolution for over about several hundred million years strongly suggests that it is beneficial to immunity and overall survival [131]. Since the rise in temperature to regulate the immune system is only a few degrees $\mathrm{C}$ around the ambient body temperatures for many species known, we hypothesize, in the branch of thermal medicine, that such a response is evolutionarily-conserved, and there exists sensitive "thermal set points" that regulate the immune system. Intuitively, one could expect that externally applied hyperthermia to a body region would cause the body to offer a counter reaction to restore the temperature in that particular region; this response might change the patho-physiological conditions, including the conditions of the immune response.

Hyperthermia increases blood flow rate in the vasculature with enhancement of cancer cells metabolism, leading to increased hypoxia-inducible factor (HIF-1), increased ROS production and induction of vascular endothelial growth factor (VEGF) expression (which stimulates vasculogenesis) [132].

Since there are seemingly contradictory results on whether HSPs are pro- or anti-cancer, we will discuss in more details here on how the immunity system works after the cancer cells are formed. Since there are ample examples reporting the benefits of mild hyperthermia as anti-cancer therapy, we will discuss in more details the crucial steps with experimental evidence as to how the immunity cells interact with the cancer cells there when they are treated with mild hyperthermia of $<43^{\circ} \mathrm{C}$, similar to the temperature reached (at the cancer site) after some enduring exercise. First, we will introduce a very interesting process of $\mathrm{T}$ cells trafficking.

Cancer has long been linked to inflammation and a number of pro-inflammatory cytokines, among which cytokine IL6 has been considered to support cancer cell proliferation, survival, and metastatic dissemination. It is known that tumor-associated macrophages (TAM), neutrophils, myeloid-derived suppressor cells (MDSC), and CD4+ regulatory $\mathrm{T}$ cells (Treg) are among the key immune cells that have demonstrated to drive neoplastic progression, and all these cells secret IL6, plus other cytokines and factors [133] [134]. In fact, clinically, cancer patients have poor prognosis when their serum concentrations of IL- 6 are high [135]. On the other hand, paradoxically, IL-6 has been shown by different groups to interfere with the development/differentiation of antigen-presenting cells such as dendritic cells (DC) that are necessary for priming cytotoxic $\mathrm{T}$ cells which are anti-cancer [136] [137]. Let us consider the environment of a cancerous region. It is known that the hypoxia-inducible factor $1-\alpha$ (HIF-1- $\alpha$ ), is considered to be the master transcriptional regulator of cellular and developmental response to hypoxia. It is known clinically that high interstitial pressure (high ISFP) would 
impede the arrival of chemotherapeutic medicine to reach the cancer site and hypoxia does not support the efficacies of both chemo- and radio-therapies because blood vessels are too narrow, though many in number, in the tumor region. During an inflammatory response, via IL6 signaling or mild hyperthermia at $\left(38^{\circ} \mathrm{C}-40^{\circ} \mathrm{C}\right)$, the endothelial cells (pinkish in Figure 4) of the blood vessel mobilize the protein called E-selectin (an adhesion molecule) from inside the cell to the endothelial cell surface (orange in Figure 4). When the T cell rolls along the internal blood vessel wall, the E-selectin binds to protein L-selectin of the $\mathrm{T}$ cell. The $\mathrm{T}$ cell is tethering and rolling with such binding. After chemokine activation, a C-C-motif chemokine receptor 7 (CCR7, marked yellow) appears on the surface of the $\mathrm{T}$ cell. The counter-part of this chemokine activation on the endothelial cell is C-C motif chemokine ligand 21 (CCL21) [138]. After this stage, the $\mathrm{T}$ cell rolls on while developing an integrin called lymphocyte-associated antigen 1 (LFA-1) which anchors firmly on another adhesion molecule-intercel-

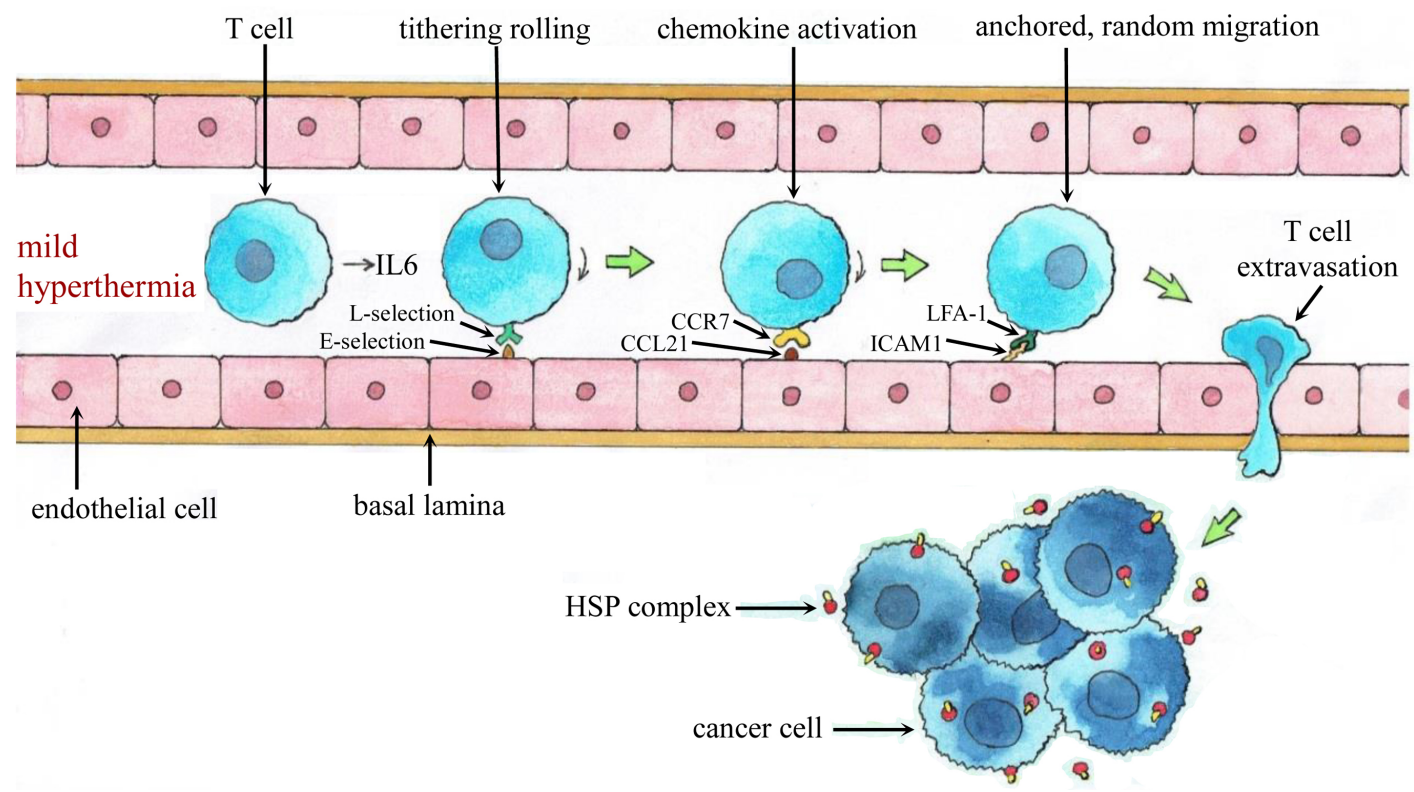

Figure 4. Better trafficking of immune cells to the tumor site via mild hyperthermia or IL 6 trans-signaling. During an inflammatory response, via IL6 signaling, the endothelial cells (pinkish in Figure 4) of the blood vessel mobilize the protein called E-selectin (an adhesion molecule) from inside the cell to the endothelial cell surface (orange in Figure 4). When the T cell rolls along the internal blood vessel wall, the E-selectin binds to protein L-selectin (triggered by IL6 signaling) of the T cell. The T cell is tethering and rolling with such binding. After chemokine activation, a C-C-motif chemokine receptor 7 (CCR7, marked yellow) appears on the surface of the $\mathrm{T}$ cell. The counter-part of this chemokine activation on the endothelial cell is called C-C motif chemokine ligand 21 (CCL21). After this stage, the $\mathrm{T}$ cell rolls on while developing an integrin called Lymphocyte-associated antigen 1 (LFA-1) which anchors firmly on another adhesion molecule called Intercellular Adhesion Molecule 1 (ICAM-1). After this anchorage, the T cell starts to migrate at random directions [139], and have better chance of extravasation from the blood vessel, and reaching the cancer site in the lymph node. The cancer cells are painted in blueish-grey color, with HSP complex (red circle with yellow intrusion) as antigen. The endothelial wall in practice is the wall of a post-capillary venous swellings called High endothelial venules (HEV). To kill cancer cells, the T cells have to leave from the HEV via extravasation and IL6 or mild hyperthermia $\left(38^{\circ} \mathrm{C}-40^{\circ} \mathrm{C}\right)$ marks the initiation of the cytotoxic process [140]. Figure 4 was hand-painted by author PCWF. 
lular adhesion molecule 1 (ICAM-1). After this anchorage, the $\mathrm{T}$ cell starts to migrate at random directions [139], and has a better chance of extravasation from the blood vessel to the cancer site in the lymph node (or, in general, the interstitium). The cancer cells are painted in blueish-grey color, with HSP complex (red circle with yellow intrusion) as antigens. The endothelial wall in practice is the wall of a post-capillary venous swellings called high endothelial venules (HEV). To kill cancer cells, the T cells have to go through extravasation from the HEV. We do not know whether mild hyperthermia is the cause of IL6 secretion, but either factor starts the initiation of the cytotoxic process [140].

\subsection{Updated Mechanism of Cross-Presentation and Cytotoxic Action of Anti-Cancer Immunity, with Emphasis on the Roles of Inducible, Rather than Constitutive HSPs and the Mannose Receptors}

Consider the situation where the APC are in the vicinity of cancer cells. It is well established that the antigen presenting cells include dendritic cells, macrophages, Langerhans cells and B cells. In order to study the mechanism of antigen presentation, the lymphoid macrophage line P388D1 and the (immortalized) DC line D2SC/1 were used in [141] as antigen presenting cells. The choice of including both macrophages and DCs was suggested by experiments based on positive stimulation of CTLs by macrophages pulsed with HSP gp96/peptide complexes in vitro. In other words, the HSPs are taken up by the macrophages and are represented (cross-presented) by the MHC class I molecules of the macrophages, leading to cytotoxic action of lymphocytes [142]. Electron microscopy examination suggests that receptor (of APC)-mediated endocytosis (RME) processes of HSPs by the macrophages and Langerhans cells do take place [142]. With standard labelling techniques, the MHC1 molecules and HSPs were revealed to be co-localized in the endosomal structures, where transfer of HSP associated peptides onto MHC class I molecules occur. It was only realized several years ago that HSP90 is responsible to "pull out" antigen from the endosome (a membrane-bound compartment inside eukaryotic cells, thought to be originated from the Golgi apparatus) to the cytosole where MHCI molecule is located; the detailed mechanism is described in [143]. In Figure 5(a), we show schematically the result reported in [144]: the HSP complex (the red circle represents the HSP and the yellow cylindrical part represents the peptide, considered as one key part of the antigen) from the exosomes around the cancer cell move to the mannose receptor of the APC [142]. Based on the study of reference [141], we suggest that the (mannose) receptors for the HSP-associated antigen during carcinogenesis have been developed on the APCs through evolution. Figure 5(b) indicates the endocytosis process, and the mannose receptor with the antigen is within the cytosole. There are MHC I (bright green) and II molecules in general. MHCIs are found near the endosome (purple) [144]. We neglect the function of CD4+ $\mathrm{T}$ cell (with MHCII in the conventional concept) for simplicity in discussion. 


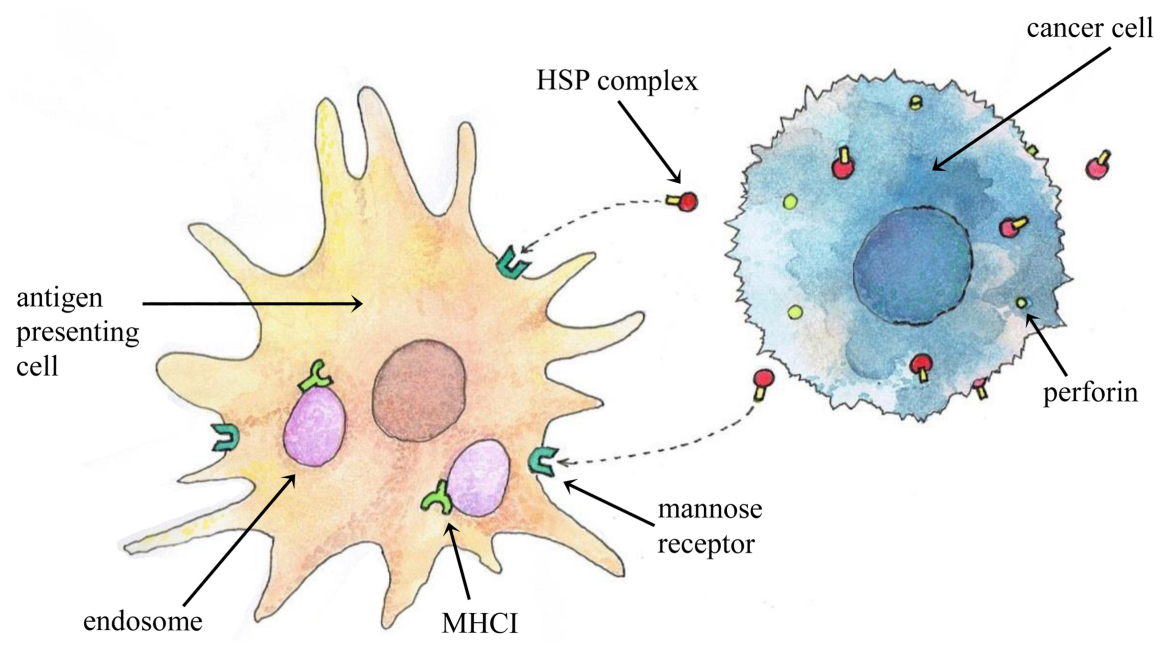

(a)

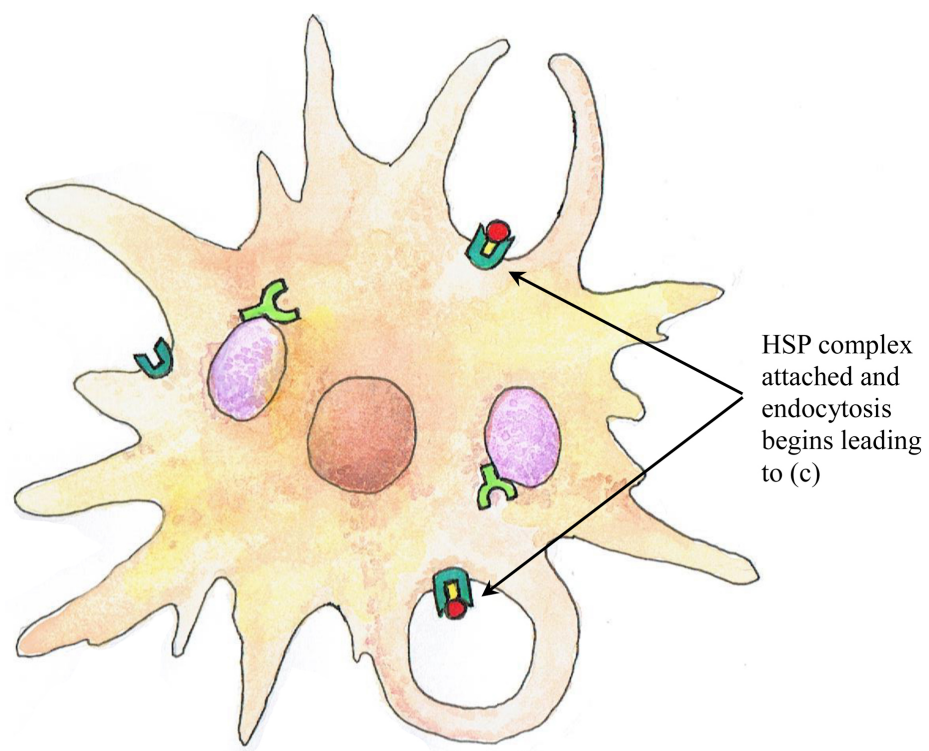

(b)

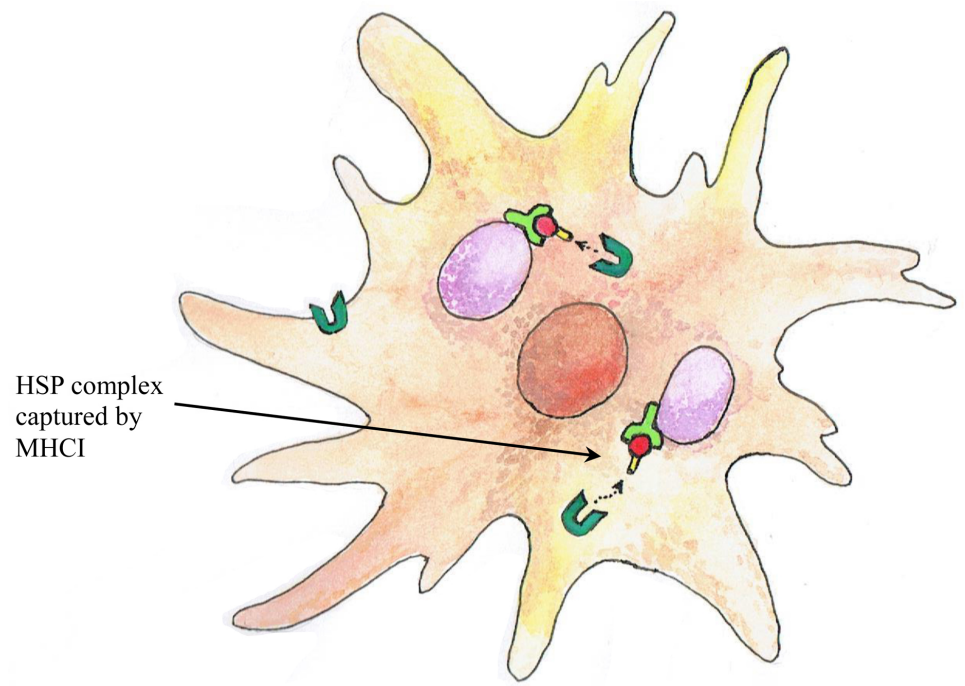

(c) 


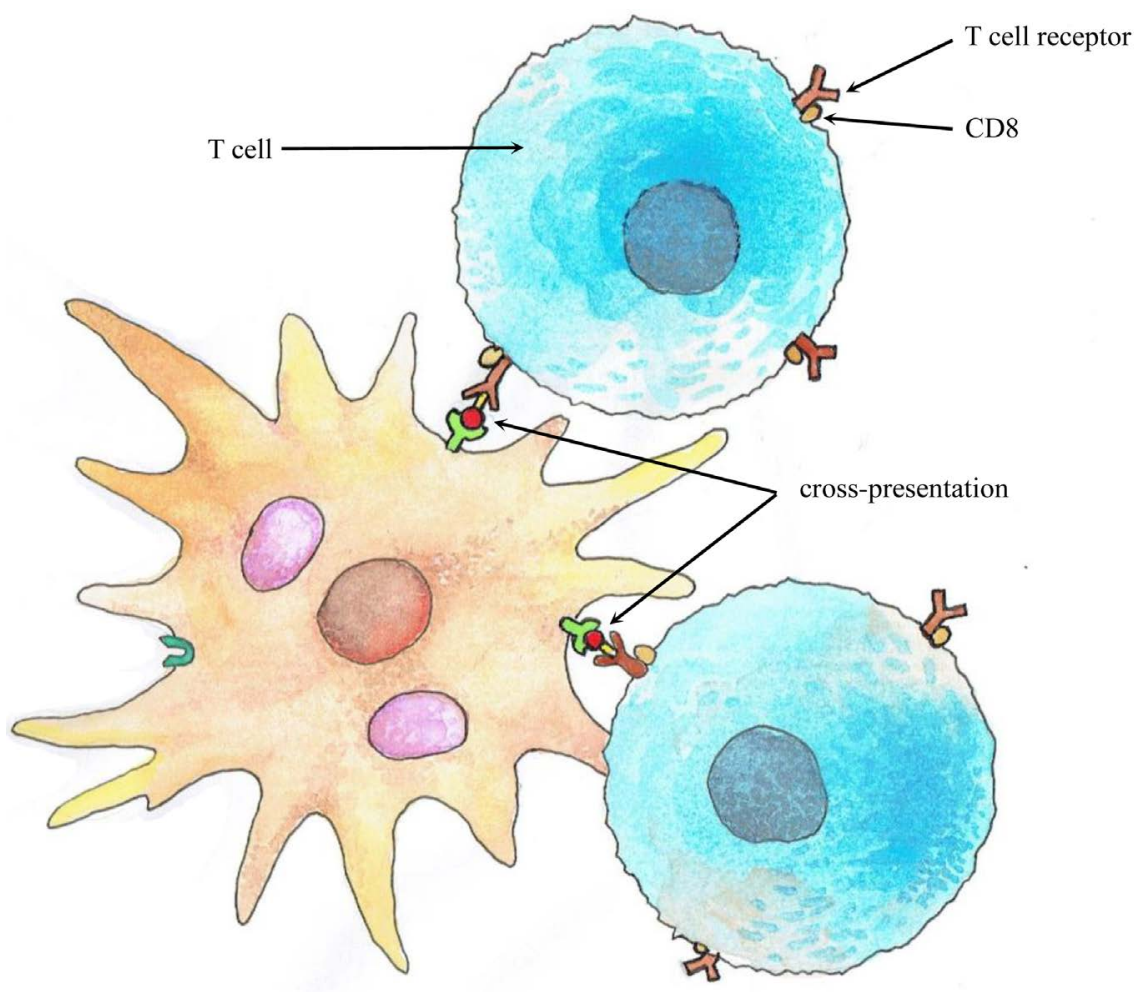

(d)

Figure 5. Cross or representation of antigen in anti-cancer immunity. (a) The antigen presenting cell (APC) can be dendritic cells, macrophages and Langerhans. The Mannose receptor (deep green) of APC receives the HSP complex (as part of the exosomes, which contain other proteins or fragments) from the vicinity of a cancer cell. Perforins are small pores on the cancer surface. (b) When a Mannose receptor captures an antigen, endocytosis begins, and the Mannose receptor with the antigen is within the cytosole. There are MHC I (bright green) and II molecules in general. MHCIs are found near the endosome (purple), a membrane-bound compartment inside eukaryotic cells, thought to be originated from the Golgi apparatus. We neglect the involvement of CD4+ T, which contains MHCII, for simplicity in discussion. (c) The antigen is passed from the Mannose receptors to the MHCI molecules. (d) The MHCI molecules with the attached antigens are re-expressed on the cell surface of the APC. Cytokines are sent from APC to the potential cytotoxic T cells to signal the degree of maturation. Figure 5 was hand-painted by author PCWF.

Figure 5(c) indicates that the antigen is passed from the mannose receptors to the MHCI molecules. Figure 5(d) indicates that the MHCI molecules with the attached antigens are re-expressed on the cell surface of the APC. Cytokines are sent from APC to the potential cytotoxic T cells to signal different stages of maturation, and such maturation process is already known; this aspect is not shown for simplicity. We represent schematically in Figure 6(a) that after activation, the cytotoxic T lymphocytes (CTL) recognize the HSP complex as antigen. The $\mathrm{T}$ cell receptor (TCR) is attached to the antigen on the surface of the cancer cell, and granzymes are sent from CTL to the cancer; the cytotoxic granzymes pass through perforins (having pores) and enter the cytosole, killing the cancer cell. Polypeptide-related sequence is a cell surface glycoprotein encoded by the MICA 


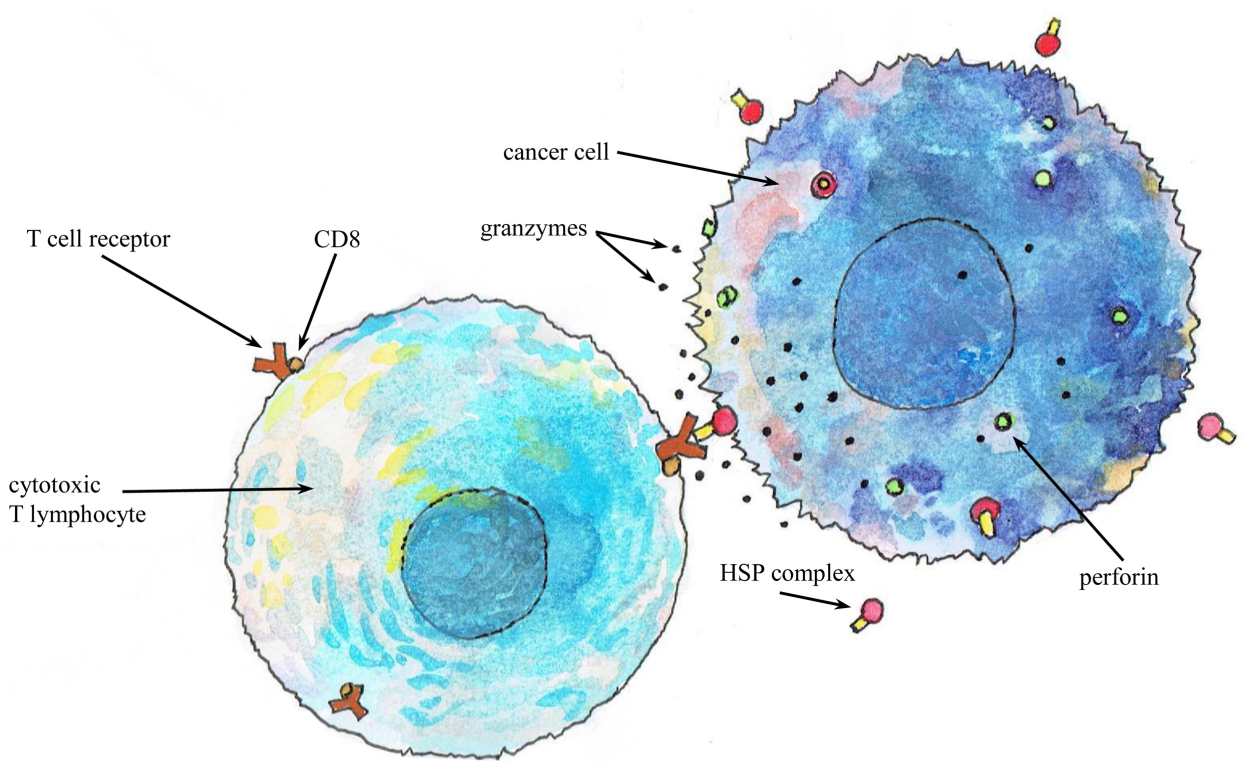

(a)

Hyperthermia activates natural killer cell

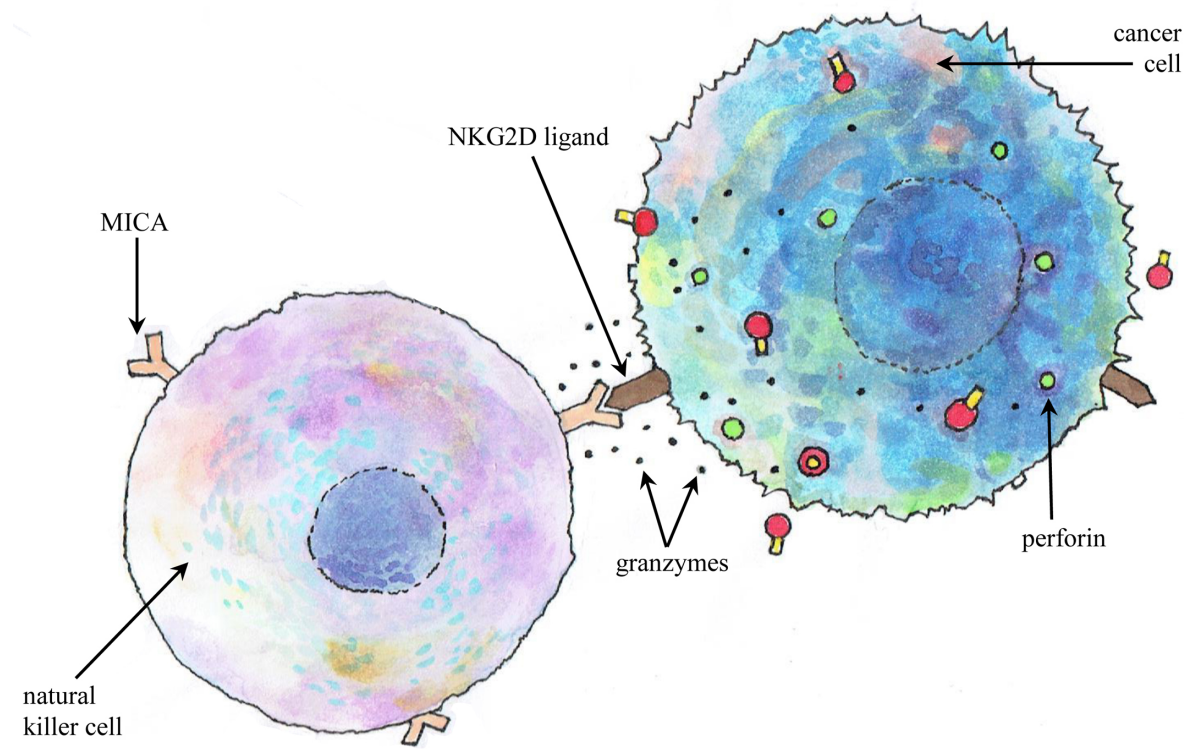

(b)

Figure 6. Cytotoxicity action of CTL and NK. (a) After activation, the cytotoxic T lymphocytes (CTL) recognize the HSP complex as antigen.The T cell receptor (TCR) is attached to the antigen on the surface of the cancer cell, granzymes are sent from CTL to the cancer; the cytotoxic granzymes pass through Perforins (having pores) and enter the cytosole, killing the cancer cell. (b) Polypeptide-related sequence is a cell surface glycoprotein encoded by the MICA gene within the MHC locus, and is called the MICA protein [145]. For a normal cell, MICA has a similar structure as a MHCI molecule. For a cancer cell, MICA works as a stress-induced ligand for the Natural killer group 2, member D (NKG2D) receptor of the natural killer cell (NK). When NKG2D binds to MICA, granzymes are sent from NK through the Perforins to the cancer cell to take the cytotoxic action. It is inferred in [46] that sensitization of MICA in cancer cell of subjects occurred after local mild hyperthermia at $39.5^{\circ} \mathrm{C}$ for 6 hours or $43^{\circ} \mathrm{C}$ for 30 minutes; the NK can readily bind to MICA and exert its cytotoxicity. Figure 6 was hand-painted by author PCWF. 
gene within the MHC locus, and is called the MICA protein [145]. For a normal cell, MICA has a similar structure as a MHCI molecule. For a cancer cell, MICA works as a stress-induced ligand for the natural killer group 2, member D (NK2D) receptor of the natural killer cell (NK). It is inferred in [46] that sensitization of MICA in cancer cell of subjects occurred after application of local mild hyperthermia at $39.5^{\circ} \mathrm{C}$ for $6 \mathrm{hr}$ or $43^{\circ} \mathrm{C}$ for $30 \mathrm{~min}$; the NK2DNK can readily bind to MICA and exert its cytotoxicity. In Figure 6(b), we show the idea that when NK2D binds to MICA, granzymes are sent from NK through the perforins to the cancer cell to take the cytotoxic action. Some induced HSPs must have been involved to cause this anti-cancer effect.

We would remark that around two decades ago, in order to study the influence of HSP70 expression in the tumorigenicity on cancer cells in the rat colon carcinoma model, various clones (such as HSPs) with different tumorigenic potentials have been obtained from the same parental tumor to test their efficacies. Only some clones showed some positive tumorigenic effects. It is of great interest that among "possible antigens" tested, tumors co-segregated with expression of inducible HSP70 (iHSP70) but not with constitutive HP70 (cHSP70), implying there is a distinctive difference in tumorigenicity of (iHSP70) and (cHSP70) [146]. Heat shock would induce the (inducible) expressions of HSPs, including iHSP70. Therefore, the anti-cancer effect of hyperthermia is in line with the experimental findings of [146]. It was also remarked that the receptor-mediated antigen presentation is up to 10,000 -fold more efficient than the presentation of peptides taken up by the conventional phagocytosis [144]. In other words, the existence of the mannose receptors on DCs gives them a very high capacity to present glycosylated antigens with very few cell concentrations. It is interesting to note that no colocalization of mannose receptor and MHCII molecules were found. MHCII molecules are associated with presentation from APC to immatured $\mathrm{T}$ cells which require other cytokine signals and conditions to be matured. The result on the stated cross-presentation involving the mannose receptor for direct cytotoxic action against cancer also avoids the formation of CD4+ T cells to become Treg cells, resulting cancer tolerance [144]. It is already known that exogenous HSP-70 binds macrophage lipid raft microdomain and stimulates phagocytosis-we anticipate that such a process is involved in both MHC-I and MHC-II presentation of antigens [147].

\subsection{In Vitro Evidence of Extra-Cellular HSP70 or Its Sequence Induces Migration of natural Killer Cells to Kill the Cancer Cells}

Following up with the discussion in the last section, extracellular localized HSPs, in particular HSP70s play key roles in the activation of the immune system. The NK cells, the first line of defense, do not have to find their specific match to identify an invader and have no memory. They use the CD16, a receptor molecule of the Ig superfamily, on the NK cell's membrane to recognize and bind to 
any cancer cell or virally infected cell. There is direct evidence that membranebound HSP70 was identified as a target structure for the cytolytic attack by the NK cells which secret granzymes [148].

It is established that the Rab GTPases regulate many steps of membrane traffic. Study of enrichment of the Rab protein indicates that both inducible and constitutive cytosolic proteins HSP70, TKD peptide (a partial HSP70 sequence) and Bag-4 (a short molecular chaperone), but not Grp94 (chaperone inside ER), were detected outside the cancer cell as exosomes, which are nano-sized vesicles. These exosomes are "treasures" to induce elimination of cancer cells. Whether Rab GTPases would regulate the secretion of HSPs is an interesting issue.

\subsection{The Evidence That CD4+ T Cells Can Be "Trained" to Have Cytotoxic Power against MHCII Positive Cells also}

$\mathrm{CD} 4+\mathrm{T}$ cells have been thought to play a "helper" role in promoting the maturation of $\mathrm{CD} 8+\mathrm{T}$ cells which kill the cancer. Most of the conclusions on the immunity mechanism related to $\mathrm{T}$ cells are based on in vitro experiments. Since $\mathrm{CD} 4+\mathrm{T}$ cells are associated with MHCII molecules, much more attention has been paid to MHCI-related cytotoxic action of CD8+ T cells. However, over two decades ago, it was reported that transfection of syngeneic MHC class II genes into the (transplantable) mouse fibrosarcoma model SaI abrogates the malignancy of the tumor in the autologous host, and protects the host against subsequent challenges with the same type of cancer [149]. Following the previous study, using the transgenic severe combined immunodeficiency (SCID) mice models which lack $\mathrm{B}$ cells and antibodies, but with many more $\mathrm{CD} 4+\mathrm{T}$ cells than $\mathrm{CD} 8+\mathrm{T}$ cells, it was demonstrated that $\mathrm{CD} 4+\mathrm{T}$ cells (alone) have strong anti-tumor effects against the mineral-oil induced plasmacytomas (MOPC, A which is a discrete, solitary mass of neoplastic monoclonal plasma cells in either soft tissue or bone). This tumor develops in the peritoneal cavity of oil-injected $\mathrm{BALB} / \mathrm{c}$ mice, which is an albino, laboratory-bred strain of the house mouse [150]. An interesting investigation has also been reported recently [151]. The cancer cells of $\mathrm{BALB} / \mathrm{c}$ origin, called MOPC 315 of the stated melanoma secrets a protein called myeloma M315, which is endocytosed and processed by APCs (of $\mathrm{BALB} / \mathrm{c}$ origin). A fragment encompassing residues $91-101$ is presented on the MHC class II molecule I-E d to cloned Id-specific 4B2A1 CD4 + T cells. After injection, the mouse model now becomes the Id-specific TCR transgenic mouse model (4B2A1) which has the Id-specific CD4+ T cells. These $\mathrm{T}$ cells were found to be able to kill MHCII (positive) cells directly like effector CD8+ T cells. It was inferred that the primary activation of the "naïve" cancer-specific CD4+ T cells required presentation of cancer-specific antigen by the MHCII molecules originated by the cancer cell itself [151] [152].

The reader is referred to Figure 1(a) and Figure 1(d) of [151] on such principle. This result is certainly another positive step in cancer eradication. However, the hurdle is to transfer common cancer cells to MHCII positive cancer cells. 
The success would be another cancer vaccine itself. We will not discuss the rather involved process about presentation of antigen by MHCII molecule by cancer cells here in this paper.

\subsection{Plausibility of Preparing Non-Person-Specific, Almost Non-Cancer-Specific Vaccine to Cover a Wide Range of Cancers, Based on Very Recent Evidence that Injection of Pure HSP70 into Cancer Can Penetrate Cancer Cells and Pulls Its Intracellular Analog Outside of the Cell, Providing Enhanced Anti-Cancer Effects}

In Section 7, the vaccines developed have to be at least cancer specific. In a new study, employing a model of RA-2 rat rhabdomyosarcoma, it was discovered that injection of pure HSP70 (derived from Bovine) into the tumor demonstrates an effective anti-tumor prophylactic effect as compared with an HSP70 mixture with cancer antigens. Following, in the same study, pure human recombinant HSP70 was injected into brains of rats with intracranial C6 glioma tumor. It was reported that such injections caused a significant delay in cancer growth and increase in the survival rate of the animals bearing the stated cancer. Moreover, the therapeutic effect was reported to be accompanied also by the growth of specific CD4+ and CD8+ T lymphocytes and activation of cytotoxic NK cells. Such treatment contributes to increase of both innate and adaptive immunity abilities [118]. There are in fact other reports using pure HSP70 as therapy. For examples, HSP70 in a hydrogel composition was applied on the skin surface on top of B16 mouse melanoma. In this case, significant inhibition of tumor growth and elevation of the survival rate was reported [153].

To study the mechanism behind the anti-cancer effects of HSP70, in vitro experiments were carried out in which C6 glioma or B16 melanoma cells incubated with fluorescently labeled HSP70 being stained with antibody recognizing the TKD-peptide; TKD-peptide is a partial HSP70 sequence capable of stimulating the cytolytic and proliferative activity of NK cells [119]. This study revealed that exogenous HSP70 caused the endogenous HSP70 to be released to the extracellular matrix. Now phloretin can increase the efficacy of HSP70 penetration into B16 mouse melanoma cells through promotion of pore formation in the cell membrane. In [154], phloretin was therefore applied together with pure HSP70, leading to elevation of cancer cell sensitivity to cytotoxic lymphocytes by $16 \%$ $18 \%$, a result inferred to arise from more (endogenous) HSP70 molecules released to the external side of the cell membrane.

We anticipate that whereas pure HSP70 was "driven" into the cancer cell, the "expelled" endogenous HSP70 complexes carry with them the polypeptides having the signature of cancer, as antigens to be recognized by the cytotoxic cells. Instead of using phloretin, the interaction of dipole modifiers with amphotericin-ergosterol complexes can also enhance the penetration effect of HSP70 [155]. There is evidence that HSP70, but not other HSPs, has strong affinity to lipid raft in the brain. We suspect that lipid rafts help the trafficking of HSP70 at 
least intracellularly [156]. That the usage of HSP70 as an anti-cancer drug has passed through the pre-clinical test, as reported in [154]. We refer the readers to other examples taking pure HSPs as anti-cancer drugs in reference [119].

Based on the experimental results in the sub-sections of 8 so far presented, it is definitely plausible to prepare a small number of HSP-based vaccines in the near future that cover a variety of cancers. We have concentrated on the mechanism action of HSP70, but do not exclude a few other HSPs may work in a similar way. Since HSP90 and HSP70 are the two most abundant HSPs in the human body, naturally they deserve to be considered with top priority. The rest of Section 8 provides further support.

\subsection{Antigens from HSP27 and HSP90 in Multiple Myeloma Cells Can Be Used to Develop Cancer Vaccine for Such Cancer, as another Example}

Normally, plasma cells produce antibodies and play a key role in immune function. However, uncontrolled proliferation of these cells in the bone marrow leads to multiple myeloma (MM), causing bone pain, bone fractures, anemia, and infections, and is the second most common haematological malignancy in U.S.A. [157]. The first step to establish an effective cellular immunotherapy is to find antigens with strong immunogenicity that is expressed in most myeloma patients. Note that myeloma cells synthesize many abnormal/monoclonal proteins which are mis-folded, unfolded or forming aggregates. From the view point of the cancer cells, the cells must synthesize many HSPs as chaperones, plus other proteins for their survival. Among the proteins synthesized by the cancer cells include many oncoproteins, such as IKK $\alpha$ and IKK $\beta$ which are involved in the $\mathrm{NF}-\kappa \mathrm{B}$ signaling pathway. Thus, any measure leading to down regulation or inhibition of HSP90 $\alpha$ family class A member 1 (HSP90 AA1) or HSP90, Heat Shock Protein Family B (Small) Member 1 (HSPB1) or commonly known HSP27 and heat shock protein family A member 13 (HSPA13), or HSP70, cause apoptosis of myeloma cells (see, e.g. [158] [159]). Employing four human myeloma cell lines (U266, RPMI-8226, ARH77 and LP-1) and multiple myeloma cells donated by patients, plus human leukocyte antigen- $A^{\star} 0201$ (HLA-A2.1) transgenic mice models, a number of findings were reported in [159], which are summarized below: 1) Expressions of HSP90, HSP70, HSPA27 are elevated in most multiple myeloma cells (from 350 patients), compared with normal (cells from 24 healthy volunteers) using Cancer Outlier Profile Analysis. 2) We have explained that the peptide associated to a HSP is considered to be the (selective) target for development of cancer vaccine. The peptides called aa362 and aa670 derived from HSP90, the peptide hp70 from HSP70 and the peptide hp27 from HSP27, were identified to be potentially capable of binding to the human leukocyte antigen- $A^{\star} 0201$. Among these 4 peptides, aa670 and hp27 were found to have the highest binding affinity (same order of magnitude of the flu matrix peptide). Such a result indicates that the HSP90-complex and the HSP27-complex are relevant members to be considered as therapeutic measure for treating mul- 
tiple myeloma. 3) After immunization of HLA-A ${ }^{\star} 0201$-transgenic mice with the peptides aa670 and hp27 (as antigens), splenocytes isolated from such mice were found to contain abundant peptide-specific T lymphocytes, and CD8+ T lymphocytes. These $\mathrm{T}$ cells were found to be able to kill the autologous antigen-presenting cells pulsed with HSPs, but not the unpulsed ones. 4) The detection of HSPs peptide-specific cytotoxic T lymphocytes were found in the blood of multiple myeloma patients as well as healthy volunteers. Such a result indicates that the peptides mentioned could be presented by antigen presenting cells naturally. The CD8+ T could recognize and kill these cells in healthy normal. Result 4) substantiates result 3) on the antigenicity property of the HSP-associated peptides.

\subsection{Overexpression of Constitutive HSPs Is Not the Cause, but the Consequence of Carcinogenesis}

It is known generally that during aging, the HSP synthesis in most cells declines. In particular, the heat shock response of some classes of neurons weakens in certain regions of Alzheimer's disease (AD) or neuro-degenerative patients, resulting in decrease in the ability to deal with proteotoxic stress [160]. In contrast to normal aging cells, it is found that there are de novo increases (or expansion of HSP expression) in HSP synthesis in many cancer cell lines (see e.g. [161]). More HSPs are synthesized and released are the reasons for such a result, as explained before. In fact, there are epidemiological studies showing negative correlation between the risk of cancer in persons with $\mathrm{AD}$ or other neurodegenerative diseases. Based on epidemiological studies, it was noted that cancer survivors have a $20 \%-50 \%$, relatively low risk of developing $\mathrm{AD}$ and Parkinson's disease, and patients with these neurodegenerative conditions have a significantly lower incidence of developing cancer [162]. In making the above statements, we refer to decrease in constitutive HSPs in the aged, and over expression of constitutive HSPs in cancer cells. There is a room for adjustment-through increasing the level of inducible HSPs by mild hyperthermia in the aged and neuro-degenerative patients. In doing that, it seems that these patients are subject to a higher risk of developing cancer. However, mild hyperthermia amounts to increase in temperature resulting from exercise; there is no evidence that exercise is correlated to a higher risk of cancer, and is harmful to the neuro-degenerative patients.

In order to participate in a series of physiological functions, a (large) HSP has to be detached from its client peptides (proteins). HSP70 and other chaperones utilize an ATPase domain to hydrolyze ATP and then take on a free conformation [163]. The small HSP27 does not have such an ATPase domain, and HSP70 can react to take away the clients from HSP27; therefore, HSP70 appears to play role in "activating" the smaller HSPs. The key effector of HSP gene transcription is heat shock factor 1 (HSF1).

It is undebatable that HSPs functions as chaperones for proteostasis for healthy and cancer cell alike. In many situations, there may not be sufficient constitutive HSPs in normal cells/organells to initiate activation of the antigen presenting cells in the manner already reviewed. In that case, more inducible heat 
shocks would be helpful, explaining the many papers reporting the anti-cancer effects of mild hyperthermia. In our view, the presence of HSPs, and HSF1 around cancer sites is not the cause, rather as the consequence of carcinogenesis.

\subsection{Upon Mild Hyperthermia, Sub-Telomeric DNA Is Found to Be a New Target of HSF1 with the Physiological Function of Maintaining Telomere Integrity. HSF1 Is Not a Factor Driving the Specie to Extinction, but Protects the Host Organism}

Under physiological conditions, HSF1 is in a complex with other proteins in a monomeric inactive state. Upon heat shock or other types of stress, HSF1 undergoes an activation process involving post-translational modifications, nuclear localization and trimerization. The HSF1 trimer then binds to heat shock elements (HSEs) throughout the genome whose consensus-sequence is a tandem array of three oppositely oriented "AGAA" motifs [164]. In humans, so far ten isoforms are found: HSF1, 2, 3, 4, 5; HSF2BP, HSFX1, X2, HSFY1, Y2.

On the other hand, a telomere is a region of repetitive nucleotide sequences at each end of a chromosome, protecting that end from 1) deterioration or 2) from fusion with neighboring chromosomes. Structural stability is maintained by a shelterin/telosome complex so that 3) this end region is not recognized as a double-strand break by the DNA damage repair machinery, which triggers fusion in 2). There are 6 proteins in this complex and TRF2 is the one that effectively protects process 2 ). Telomeres are transcribed by RNA polymerase II into a heterogeneous long non-coding RNA chain called telomeric repeat containing RNA (TERRA) [165].

In [166], 1) HeLa wild type cells (derived from cervical cancer cells), 2) human foreskin fibroblasts transfected with the catalytic subunit of the telomerase TERT (HFF2 cells) were the models of study. HSF1 knock-out cells were also included in the study. Standard wet lab and dry lab techniques were used to carry out the investigation. Comparing stressed (mild hyperthermia at $43^{\circ} \mathrm{C}$ ) and unstressed cells, it was found that HSF1 was required for TERRA accumulation. The HSF1 expression in the wild type HeLa cells was found to maximize between $30-45 \mathrm{~min}$ at $43^{\circ} \mathrm{C}$. In particular, it was shown in [166] that upon application of mild hyperthermia at $43^{\circ} \mathrm{C}$ as a stress, HSF1 binds to subtelomeres (of the telomeres that contain heat shock elements) to trigger TERRA accumulation and protects the telomeres from the plausible accumulation of "telomericdysfunction-induced foci" (TIF) caused by stress exposure. In other words, the sub-telomeric DNA is found to be a new target of HSF1 with the physiological function of maintaining telomere integrity. Moreover, telomeric DNA damages are significantly enhanced in HSF1 deficient cells. Therefore, just mild hyperthermia is linked up directly with longevity itself. This investigation substantiates the study of a different group where HSE was identified within TERRA proximal promoters on seven chromosome ends [167]. We infer that the result can be applied to healthy and cancer cells alike, because we consider the result mentioned is an intrinsic property of the telomeres in the DNA. This new result 
explains the benefits of healthy cells in organs under mild hyperthermia like exercise. Similarly, the cancer cells enjoy the same benefits along the line of longevity. In the long run, HSF1 is not a factor driving the specie to extinction, else HSFs and HSPs would not have been conserved throughout evolution.

It is almost a common knowledge that carcinogenesis involves 1) growth without the influence of growth factor, 2) escaping from natural cell death and senescence pathways, 3) promotion of angiogenesis, plus 4) metastasis [168]. We would remark that HSF1 protects the integrity of telomeres is a homeostasis process for cell health, rather than causing the cell to escape from the normal senescence pathways. We would remark also that tipping the balance too much to the other side would effectively extending the telomeres, with conditions favorable to the hallmarks of carcinogenesis, resulting in positive correlation of cancer development.

\subsection{Examples of HSP-Based Vaccine and HSP-Related Anti-Cancer Drugs}

We aim to provide the basic mechanisms behind the plausible benefits of treating cancer patients with mainly HSP70-based vaccine, HSP inhibitors and mTORC1,2 inhibitors, mild hyperthermia (which amounts to enhance inducible HSP activity), and to highlight certain crucial questions to be answered in future experiments. In the recent few years, there are several hundred trials using individual or combination of HSPs inhibitors to treat various types of cancers, from animal studies, in vitro cell line investigations, to preclinical trials, and even a few on clinical trials. A number of HSP-based, non-HSP-based cancer vaccines are also under study. It is far too long to list these studies, even in the simplest tabular format, in this paper. The readers are referred to two references [169] [170] which lists many tens of HSP inhibitors under various stages of trials, with different combinations of HSP inhibitors. If we provide particulars relating to the biomedical mechanisms of the potential measures/drugs and present the results of analyses here, our paper will be exceesive long, with lots of materials outside the main theme. It takes years usually for a potential drug to become FDA approved drugs.

In this section, we would rather review/analyze in a concise manner several drug examples more closely related to the mechanisms presented in this paper. The drugs or their combination with potential components are FDA drugs.

In searching through the literature, we have found one HSP-based cancer vaccine, which is person-specific, cancer-specific, approved by FDA in 2010. The action of a HSP-based vaccine has been discussed in the text. This is listed as column one in Table 1. The basic mechanisms of action is entered in the second column, and the key references, the sections and figures of this paper related to each item is presented in the second and third columns. The drug Gilotrif, which is a FDA approved drug to treat non-small-cell-lung-cancer, is purposely chosen because it is a client of HSP90, bringing the connection of tyrosine kinase receptors to $\mathrm{HSP}(\mathrm{s})$, an important fact hardly emphasized in literature. Gilotrif in 
combination of a HSP90 inhibitor (Ganetespib) demonstrated stronger anti-cancer effects in in vivo animal study, than in the situation where only Gilotrif was used. This result suggests that combination of such type would have a potential to become a very good anti-cancer drug.

The drug with symbol name OSU-0312 (Ar-12) appears twice in the table, because it was demonstrated to have anti-cancer effects in two seemingly different pathways. In the preclinical trial, it worked as a PDK1 inhibitor, and hence mTOR inhibitor. During the phase I clinical trial, it was found that it inhibited HSP70 also, driving the cancer to follow the PERK-CHOP apoptosis machinery, which is described in details in Section 5.6. If one goes through Sections 3 and 5 of this paper, the result in the clinical trial is expected. Such result is also important in developing anti-cancer drugs, because regulation of HSP70 member (in particular Grp78) is connected to the PERK-dependent apoptosis process. We list the drug temsirolimus, approved by FDA as an mTOR inhibitor to treat metastatic renal cancer and interpret the cancer cells go through the FOXO-translocation-induced apoptosis (see Figure 3). The drug everolimus, an mTOR inhibitor, was approved by FDA three times in two years to treat renal, astrotomas cancers associated with tuberous sclerosis complex, plus breast and pancreas cancers. There are three roles for this drug alone; the mechanisms in the second columns of the three roles are slightly different because some different proteins are involved in the mTOR inhibition processes. Having gone through the mechanism of actions briefly described for the other drugs in the table, as well as the detail discussion of the PDK1-AktmTOR-HSF1 network, the several apoptosis pathways in the text, it is easy to follow the proposed actions in the second column of the three rows pertaining to everolimus. The reader can also consult [171] relating to discussion of part of the stated mechanism associated to potential liver cancer treatment.

\section{Some Crucial Unanswered Questions, Debatable Issues and Certain Proposals for Future Research/Treatment}

\subsection{Debatable Issue: Two Faces of the Same Coin and Proposed Strategy to Treat Cancers, as a Matter of Principle}

It is tempting to ask the question: why do intracellular HSPs play such strong protective role, but play such a strong pro-inflammatory and immunity role, once outside the cell? We would provide a speculative answer here: all living organisms need HSP to survive; in fact, a plant HSP70 has 70\% homology with that of humans. HSPs are treasures, and are to be used in the "quiescent" condition intracellularly. The immunity system has evolved to a state to recognize the fact that if a cell is secreting too many HSPs, that host cell must be in big trouble, and the best way for the host organism to survive is to eliminate that cell by cytotoxic $\mathrm{T}$ cell or natural killer cell. Moreover, another recent discovery that after mild hyperthermia, the NK cells would develop the NKG2D receptor on its surface to which the MICA molecule on the surface of a cancer cell binds, (Figure 6) is a further addition to the immunity strength. In view of the analysis presented 
from different angles, and guided by intuition, we hold the view that in general, building the strength in our immunity system, i.e. using anti-cancer vaccine as a preventive measure, is certainly the best choice, if the vaccine does not bring in serious side effects. However, based on the analysis presented schematically in Figure 2, as a matter of principle, we speculate that the inhibitors of HSPs and mTORC1 could well be very useful, but we need to see the therapeutic results for some time and find out the response of the healthy cells to these passive drugs. It is tempting to speculate that using special drug delivery technique (such as using nano-particles) to target the tumor might be worth considering.

\subsection{Proposal of Further Research: What Is the Status of the Client Proteins Attached to a HSP when a HSP Inhibitor Is Applied to Treat Cancer?}

As stated in Section 8 and Table 1, though many HSP inhibitors (HSPI) and their combinations are being tried by different research groups, we have found only one HSPI drug has been approved by FDA. It provides positive efficacy to treat non-small-cell-lung-cancer in subjects, and gastric cancer cells in in vitro study. Referring to the left side of Figure 2, a HSP90 is attached to the HSF1, HSP40, plus over 200 protein clients. HSP90 also participates in the protein folding machinery in ER (right side of Figure 2). When a HSPI acts a HSP, some clients may be released, and some may be damaged altogether. Logically, some of these clients take part in physio-pathological functions of some kinds. We have to learn from future experiments what pathways are triggered after the action of the HSPI. So far, as we have emphasized in Section 8.11, tyrosine kinase receptors are clients of HSP90.

Likewise, the mTORC1,2 complexes are attached to a number of HSPs. We need to know what become of these HSPs after the application of mTORC1,2 inhibitor to treat cancer cells. We have pointed out that inhibition of mTOR1, 2 complexes could cause translocation of FOXO1, 3 to the nucleus, initiating an apoptosis process. We wish to find out the efficient ways to send cancer cells to any one of the apoptosis processes discussed in Sections 5.5 and 5.6.

\subsection{Proposal of Further Research: Understanding the Translocation Mechanism of Endogenous HSP70-Complex from Cancer Cells to Extracellular Domain by (Injected/Penetrated) Exogenous Pure HSP70-The Hope of Developing a General Cancer Vaccine}

Now refer to Section 8.7 on preparing a rather general vaccine to cover a range of cancers. To understand the translocation mechanism of endogenous HSP70 with peptides from cancer cell to join the "exosome pool" is of prime importance. It has been suggested that either one or all the following processes are at work: 1) a classical, endocytotic pathway, 2) non-classical process involving secretory lysosomal endosomes process [128], 3) via lipid rafts trafficking mechanism [119]. Further research on the details of this particular "HSP replace- 
ment" mechanism is necessary. Moreover, we might have to learn also techniques such as the application of pholoretin [154], dipole modifier [155] as means of (exogenous) HSP70 penetration to the cancer site. In addition, the exposition of endogenous HSP70 complex causes maturity of both types of T cells, plus activation of NK cells [119]. This issue echoes the benefits of mild hyperthermia which has similar effects of promoting innate immunity ability as illustrated in Figure 6(b). There is also evidence that mild hyperthermia enhance immunity of $\mathrm{T}$ cells as discussed in Section 3.1. The main issue of this section is driving to develop vaccine and covers a large number of cancers, avoiding person-specific, cancer-specific restrictions as much as possible. In passing, we would remark that over two decades ago, it was already known that extracellular HSP70 enhances the rate and capacity of macrophage-mediated phagocytosis at 6 times the basal rate [147]. It is constructive to find out whether other pure HSPs have similar ability. We put forth the notion that other HSPs (not only HSP70) may also form bases for preparation of anti-cancer vaccines.

\subsection{Proposal of Further Research: Analysis of the Activity of the Relevant Cells as a Function of Temperature}

There is ample evidence that mild hyperthermia plays protective role in anti-cancer action (Section 3.1). Temperature-dependent investigation of the relevant action of cells (including the immunity cells certainly) and proteins, lipids in the development of anti-cancer measures is desirable.

\subsection{Proposal of Further Research: It Is Important to Understand how and under What Conditions Constitutive HSPs Are Synthesized}

Although we understand the activation of HSF, inducing its binding with HSE in the nucleus, would lead to synthesis of inducible HSPs of various types. What is the up-stream factor of constitutive HSPs? From the study of [62], it seems that some un-identified factor(s) would activate the generation of constitutive HSPs, and the process declines with age.

Understanding the answer to the above question leads us to find out if there is any method to enhance the generation of constitutive HSPs, because the amount of the inducible HSPs can be increased simply by applying hyperthermia. Over one decade ago, Western-blot analysis with HSP90 antibody showed that the leukemia cells contained much higher concentration of HSP90 than the normal peripheral mononuclear cells. The gene expression of HSP90 $\alpha$ was also found to be enhanced in the leukemia cell lines and the acute leukemia cells from patients as compared with the normal blood cells [188]. Finding mechanism/drug to knock out gene expression of HSP90 is perhaps a therapy to treat leukemia, remembering also the question asked in Section 9.1: what is the response of healthy cells to HSPI. Further research to understand the abnormal gene expression of HSP90 $\alpha$ is desirable, in our opinion. Such study may be analyzed together with the gene mutation study in Section 9.10. In traditional Chinese medicine, 
warm Bian stone and moxibustion treatments have a long history as noninvasive health-care measures, and to treat a number of diseases, based on application of mild hyperthermia and mechanical stimulation [189].

\subsection{Proposal of Further Research: To Understand the Mechanism behind the Hyper-, Hypo-Thermia Treatment Reviewed in Section 3.3}

There is evidence that the myeloid derived suppressor cells would promote cancer invasion, as reviewed in Section 3.3. Using a special hyper- and hypo-thermia treatment, however, HSP70 seemed to be able to inactivate the harmful (to the host patient) MDSCs and restore the immune cells to participate in their normal immunity duty, thus inhibiting the metastasis process of mammary metastatic lung cancer model. It would be interesting and of practice importance on repeating such experiments on other cell lines and investigate the change in behavior of the cells involved during the cooling period.

\subsection{Proposal of Further Research: On Cancer Vaccine for the Advanced State of Cancer with Participation of CSC/CIS}

We have reviewed in Section 4.2 that there is as a small population of cancer cells, called cancer stem-like cells (CSC) or cancer-initiating cells (CIS) having the ability of high self-renewal, differentiation, and having tumor-initiating functions. We need to target these cells at the advanced/metastatic state of cancer. The studies cited in Section 4.2 suggests that HSP27 may be a good target to develop cancer vaccine at least for a number of cancers such as breast, lung, colon and prostate cancers [62]. Moreover, it was found in [190] that a HSP40 family protein, homolog, subfamily B, member 8 (DNAJB8), which is expressed preferentially in the CSC/CIC population cancer cells, is a novel CSC antigen, particularly in renal cell carcinoma (RCC) and testis cancer. Thus, we have to work on the mechanism why such cancer-specific HSPs (especially the smaller ones) can be taken as antigens in developing cancer vaccines, particularly for the advanced state of carcinogenesis. It is worth noting that HSF1 has a role in the maintenance of CSCs/CICs independent of stress, when these cancer cells are formed. Such surprising result suggests that the known physiological aspect that HSF1 is activated only by stimuli may have to be re-examined.

\subsection{Controversy: The Combined Activation of mTORC1,2 Was Found to Inhibit Lymph Node Metastasis in Patients}

There is evidence that mTORC1,2 combined lead to activation of Th1 and Th2 cells as discussed in Section 5.3. Figure 7 summarizes the very recent finding of anti-lymph node metastasis of the combined effects of Th1 and Th2 under clinical setting. There seems to be a contradiction in results reviewed in Section 5.3 and other examples of using mTOR inhibitors to treat cancers, showing positive efficacies. However, our opinion is that the seemingly controversy comes from a game of tug of war. To be amplified in the concluding remarks. 


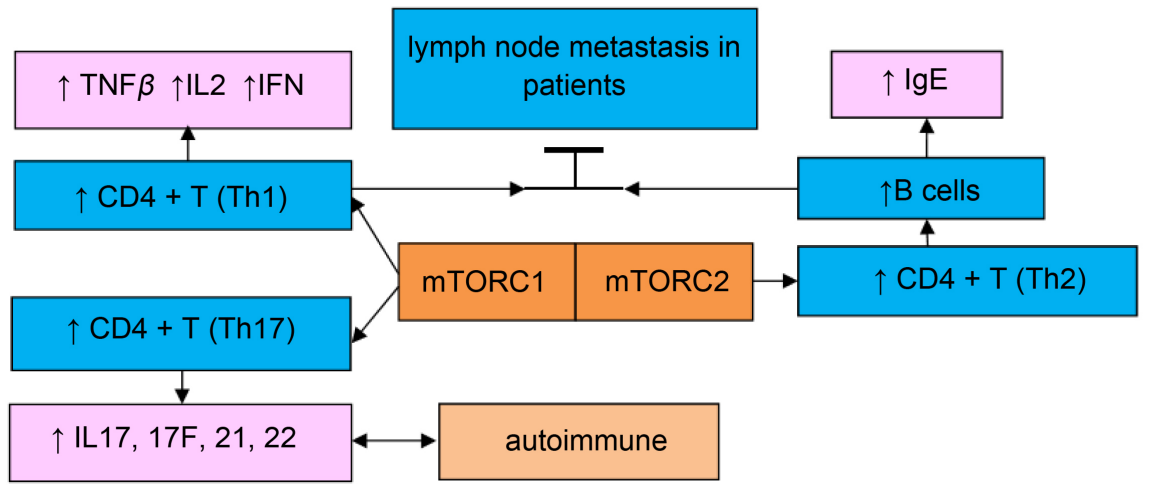

Figure 7. mTORC1 and mTORC2 activates Th1, Th17 and Th2 cells respectively. The combined activation of these immunity cells was found to inhibit lymph node metastasis in patients (Section 5.3). IgE is immunoglobulin, an antibody in the immune system. Other symbols have been defined before.

\subsection{Proposal of Further Research: On Suitable Exercise for Patients}

Also in Section 5.3, we have discussed the influence of mechanical stimuli on the protein complex mTORC1. Knowing the correlation of mTORC1 activation and the specific type of exercise (such as endurance exercise, which is characterized by the repetition of low to moderate force contractions over a prolonged period of time) might be a guide to the type of exercise to be recommended to cancer patients, within their physical ability [83]. Non-invasive treatment might then work partly as mTOR inhibitor in a self-regulated manner in the body.

\subsection{Supporting the Determination of Early Markers of Carcinogenesis Based on Lipidomics}

During the discussion of HSP intra-extra-cellular translocation in Section 9.3, we have come across lipid raft as a vehicle. Extracellular HSP70 binds the macrophage membrane, on its lipid raft microdomain. Disruption of lipid properties of the cell membrane, and hence characteristics of lipid rafts, HSP70-raft interaction would abrogate the HSP-mediated increase in phagocytosis [147].

Although a Eukaryotic cell membrane maintains an overall bilayer structure under physiological conditions, it contains other lipid like phosphatidylethanolamine (PE), which has a small polar headgroup; such a geometrical shape induces the occurrence of local high-membrane curvature, supporting the modification of the bilayer structure into a nonbilayer one, such as inverted hexagonal phase. In fact, the membrane structure is precisely regulated, to canter for fusion, endocytosis, signaling, and for the activity of certain membrane-bound enzymes [191]. An exogenous stress such as heat shock can cause transient membrane defects, with accompanying change in permeability, resulting in fluidization and the formation of nonbilayer structure. There are also changes in lipid-based signaling cascades and alterations in calcium transport. The sHSPs have sequence related to the vertebrate lens-crystallins in the eye. A number of sHSPs (HSP17, 25, 27) are found to participate, by interaction with the lipids in 
the membrane, to restore the integrity of the membrane under thermal fluctuations [191] [192]. A cancer cell also acquires thermotolerance which is undesirable in therapeutic treatment. Recent investigation using B16 melanoma cell (a murine skin cancer cell line) suggests that the lipid rafts microdomains, rather than de novo synthesis of HSPs, play the more crucial role in acquisition of thermotolerance in these skin cancer cells [193]. Alerted by the basic origin of thermotolerance (plus other stress-tolerance based on similar argument) leads us to realize the importance of lipidomics. In fact, there are more and more new types of lipids found in the recent several years [194]. A total of 84 patients with early-stage breast cancer (stage 0-II) and 110 with benign breast disease participated in a recent study. 367 lipid species (containing mainly various phospholipids) were identified by lipidomics. The authors identified 15 lipid species which could be considered to form a panel as a set of plasma biomarkers for the diagnosis of early breast cancer [195]. Hopefully, similar analysis can be conducted for other cancers. In our opinion, the study on the interaction of each set of (marker) lipids with the de novo synthesis of HSPs is also useful, because change in lipids in the cell membrane is likely to be associated with the change in the effects of heat shock.

\subsection{Supporting the Inclusion of Genetic Mutation Analysis during the Evolution of Carcinogenesis}

Cancer is a genetic disease and that somatic mutations of oncogenes and tumor suppressor genes are now considered to be the initiating factors in carcinogenesis. However, as the cancer evolves, there could well be change in the characteristics of mutations within a group of cancer cells. Cancer genome sequencing has recently been developed to study the underlying genetic aberrations that drive carcinogenesis. Intratumor heterogeneity (ITH) has been investigated in cancer using whole-exome sequencing (WES) of multiple regions of individual cancer biopsies under clinical setting. For example, up to $70 \%$ of mutations were found to occur in a heterogeneous pattern across spatially separated locations in particular renal cancers [196]. Somatic mutations in the MAPK pathway were found to be the driver events in the majority of melanomas, implying that the mTORC1 pathway might be involved. Moreover, evolution of three distinct activating PI3K phosphatidylinositol 3-kinase catalytic subunit PI3K CA mutations (p.V344G, p.R38H, and p.H1047R) and a stop mutation in PI3K R1 in a large lymph node metastasis (Mm1641) were reported [197]. These two sets of results suggest that members of the PDK1-Akt-mTOR network might be mutated. The mTORC1 inhibitor was considered as an anti-cancer drug was based originally on the growth property reviewed in Section 5. The results just mentioned in [197] using the recent genome sequencing technique suggests that some members of the PDK1-Akt-mTORC2 pathway might be mutated also for melanoma to develop. Injecting cells from a human prostate cancer cell line PC-3 (null for PTEN) into mice with the Rictor gene knocked out would inhibit the development of prostate cancer as compared to control. Such a result sug- 
gests that mTORC2 is required for the formation of prostate cancer (see Section 5 for more details of Rictor and PTEN) [198]. Perhaps due to such evidence, mTORC2 inhibitor has been suggested might be a useful anti-cancer drug also [199]. While patients are treated with anti-cancer drugs based on various experimental and medical principles, it seems that whole-exomesequencing (WES) of multiple regions of individual cancers is a useful monitoring technique to analyze the development and to offer adjusting treatment during carcinogenesis. Whether mutation has occurred in members of the mTORC2 pathway, in the cases where mTOC2 inhibitors work as anti-cancer drugs, is still an unanswered question at this stage.

\section{Concluding Remarks}

We believe that as we proceed in biomedical research, using any modality, we would come up with a large number of pathways which are inter-connected. Using the "holistic approach", analyzing problems from various angles, is necessary. The analysis process is however limited by the complexity of the living organism, which is a complex system in modern technical definition. In practice, we can only identify certain key steps at a time, and incorporate works of different groups to advance just a single step. Detailed review from time to time can serve a bit in this purpose, and it is with such motivation the authors have written this article. Going through the updated representative analyses of the in vitro, in vivo, and clinical investigations, we observe that two main strategies are taken, attempting to cure the cancer disease. The passive modality is to block out the growth of proteins by inhibiting mTOR1, 2 and/or inhibiting the abundant HSPs/HSF1 so that the cancer cells cannot survive. In doing so, one of the several apoptotic processes would be in play, if the drug/measure demonstrates anti-cancer activity. However, we wish to learn more on their effects on healthy cells if these inhibitors are taken orally or by injection also. It is a tug-of war between the effects of activating the immunity system using vaccination (which is speculated to be much strengthened if mild hyperthermia is applied) and the usage of inhibitors to cut off the living sources of the cancer cells. The rather detail analysis of this paper seems to suggest that there is hope in developing a general cancer vaccine covering a range of cancers. Of course, there are still unanswered questions as listed in Section 9, waiting for results of further research. Moreover, we want to understand the mechanism of participation of the cancer stem-like cells at the late stage of carcinogenesis, to know more characteristics of the occurrence of heterogeneity in mutations even within one tumor, to find out the alteration of the lipid structure of the cancer cells in the course of development of the disease. Therefore, inclusion of genetic profile analysis, as well as analysis using techniques in the new field of lipidomics during therapeutic treatment might be helpful, as a matter of principle. Despite the above comments, we hold the optimistic opinion to speculate that scientists and clinical experts are walking along a path towards a state when most cancers might not appear, and if they do, most cancers might be cured in ten to fifteen years' time, 
based on the detail analysis of various contributions from different groups presented in this paper. We have found that HSPs play crucial roles in many pathways-this is the first paper of our series on the HSP story.

\section{Acknowledgements}

The authors express their sincere gratitude to various types of help from Mr. Benjamin Fung, brother of PCWF, and Dr. R. K. H. Kok, Department of Microbiology, University of Hong Kong during the preparation of this manuscript. The authors also declare that there is no conflict of interests in this academic project. Figures 1-6 were hand-painted by author PCWF.

\section{References}

[1] Conn, C.S. and Qian, S.B. (2011) mTOR Signaling in Protein Homeostasis. Cell Cycle, 10, 1940-1947. https://doi.org/10.4161/cc.10.12.15858

[2] Stefani, M. and Dobson, C.M. (2003) Protein Aggregation and Aggregate Toxicity: New Insights into Protein Folding, Misfolding Diseases and Biological Evolution. Journal of Molecular Medicine, 81, 678-699. https://doi.org/10.1007/s00109-003-0464-5

[3] Hooper, P.L., Tytell, M. and Vigh, L. (2010) Xenohormesis: Health Benefits from an Eon of Plant Stress Response Evolution. Cell Stress Chaperones, 15, 761-770. https://doi.org/10.1007/s12192-010-0206-x

[4] Morimoto, R.I. (2008) Proteotoxic Stress and Inducible Chaperone Networks in Neurodegenerative Disease and Aging. Genes \& Development, 22, 1427-1438. https://doi.org/10.1101/gad.1657108

[5] Amin, J., Ananthan, J. and Voellmy, R. (1988) Key Features of Heat Shock Regulatory Elements. Molecular and Cellular Biology, 8, 3761-3769. https://doi.org/10.1128/MCB.8.9.3761

[6] Kerfelt, M., Morimoto, R.I. and Sistonen, L. (2010) Heat Shock Factors: Integrators of Cell Stress, Development and Lifespan. Nature Reviews Molecular Cell Biology, 11, 545-555. https://doi.org/10.1038/nrm2938

[7] Menezes, D.L., Taverna, P., Jensen, M.R., Abrams, T., Stuart, D., Yu, G.K., Duhl, D., Machajewski, T., Sellers, W.R., Pryer, N.K. and Gao, Z. (2012) The Novel Oral Hsp90 Inhibitor NVP-HSP990 Exhibits Potent and Broad-Spectrum Antitumor Activities in Vitro and in Vivo. Molecular Cancer Therapeutics, 11, 730-739. https://doi.org/10.1158/1535-7163.MCT-11-0667

[8] Wust, P., Hildebrandt, B., Sreenivasa, G., Rau, B., Gellermann, J., Riess, H., Felix, R. and Schlag, P.M. (2002) Hyperthermia in Combined Treatment of Cancer. The Lancet Oncology, 3, 487-497. https://doi.org/10.1016/S1470-2045(02)00818-5

[9] Lin, T., Leung, C., Nguyen, K.T. and Figlin, R.A. (2016) Mammalian Target of Rapamycin (mTOR) Inhibitors in Solid Tumours. Clinical Pharmaceutical Journal.

[10] Fung, P.C.W. (2013) Chapter 5: Plausible Biomedical Consequences of Acupuncture Applied at Sites Characteristic of Acupoints in the Connective-Tissue-Interstitial-Fluid System. In: Chen, L.L. and Cheng, T.O., Eds., Acupuncture in Modern Medicine, IntechOpen, Rijeka, 95-131.

[11] WHO Cancer Fact Sheet. www.who.int/mediacentre/factsheets/fs297/en/

[12] Easton, D.P., Kaneko, Y. and Subjeck, J.R. (2000) The Hsp110 and Grp170 Stressproteins: Newly Recognized Relatives of the Hsp70s. Cell Stress \& Chaperones, 5 , 
276-290. https://doi.org/10.1379/1466-1268(2000)005<0276:THAGSP >2.0.CO;2

[13] Parsell, D.A., Taulien, J. and Lindquist, S. (1993) The Role of Heat-Shock Proteins Inthermotolerance. Philosophical Transactions of the Royal Society of London. Series $B, 339,279-286$. https://doi.org/10.1007/978-94-011-2108-8_4

[14] Deane, C.A. and Brown, I.R. (2017) Components of a Mammalian Protein Disaggregation/Refolding Machine Are Targeted to Nuclear Speckles Following Thermal Stress in Differentiated Human Neuronal Cells. Cell Stress and Chaperones, 22, 191-200. https://doi.org/10.1007/s12192-016-0753-x

[15] Finka, A. and Goloubinoff, P. (2013) Proteomic Data from Human Cell Cultures Refine Mechanisms of Chaperone-Mediated Protein Homeostasis. Cell Stress and Chaperones.

[16] Sreedhara, A.S., Kalmara, E., Csermelya, P. and Yu, F.S. (2004) Hsp90 Isoforms: Functions, Expression and Clinical Importance. FEBS Letters, 562, 11-15. https://doi.org/10.1016/S0014-5793(04)00229-7

[17] Li, J. and Structure, J.B. (2013) Function and Regulation of the Hsp90 Machinery. Biomedical Journal, 36, 106-117. https://doi.org/10.4103/2319-4170.113230

[18] Chen, Y., Wang, B., Liu, D., Li, J.J., Xue, Y., Sakata, K., Zhu, L.Q., Heldt, S.A., Xu, H. and Liao, F.F. (2014) Hsp90 Chaperone Inhibitor 17-AA Gattenuates A $\beta$-Induced Synaptic Toxicity and Memory Impairment. Journal of Neuroscience, 34, 24642470. https://doi.org/10.1523/JNEUROSCI.0151-13.2014

[19] Jayaprakash, P., Dong, H., Zou, M., Bhatia, A., O’Brien, K., Chen, M., Woodley, D.T. and Li, W. (2015) Hsp90a and Hsp90b Together Operate a Hypoxia and Nutrient Paucity Stress-Response Mechanism during Wound Healing. Journal of Cell Science, 128, 1475-1480. https://doi.org/10.1242/jcs.166363

[20] Eletto, D., Dersh, D. and Argon, Y. (2010) GRP94 in ER Quality Control and Stress Responses. Seminars in Cell and Developmental Biology, 21, 479-485. https://doi.org/10.1016/j.semcdb.2010.03.004

[21] Ramoroso, M., Matassa, D.S., Laudiero, G.A., Egorova, V.R., Polishchuk, S., Maddalena, F., Piscazzi, A., Paladino, S., Sarnataro, D., Garbi, C., Landriscina, M. and Esposito, F. (2012) TRAP1 and the Proteasome Regulatory Particle TBP7/Rpt3 Interact in the Endoplasmic Reticulum and Control Cellular Ubiquitination of Specific Mitochondrial Proteins. Cell Death and Differentiation, 19, 592-604.

https://doi.org/10.1038/cdd.2011.128

[22] Gushchanskayaa, E.S., Artemovb, A.V., Ulyanova, S.V., Peninb, A.A., Logachevab, M.D., Razina, S.V. and Gavrilova, A.A. (2014) Spatial Organization of Housekeeping Genes in Interphase Nuclei. Molecular Biology, 48, 886-895. https://doi.org/10.1134/S0026893314060053

[23] Brocchieri, L., Conway de Macario, E. and Macario, A.J.L. (2008) Hsp70 Genes in the Human Genome: Conservation and Differentiation Patterns Predict a Wide Array of Overlapping and Specialized Functions. BMC Evolutionary Biology, 8, 19. https://doi.org/10.1186/1471-2148-8-19

[24] Radons, J. (2016) The Human Hsp70 Family of Chaperones: Where Do We stand? Cell Stress and Chaperones, 21, 379-404. https://doi.org/10.1007/s12192-016-0676-6

[25] Pockley, A.G., Henson, B. and Multhoff, G. (2014) Extracellular Cell Stress Proteins as Biomarkers of Human Diseases. Biochemical Society Transactions, 42, 1744-1751. https://doi.org/10.1042/BST20140205

[26] Bukau, B. and Horwich, A.L. (1998) The Hsp70 and Hsp60 Review Chaperone Machines. Cell, 92, 351-366. https://doi.org/10.1016/S0092-8674(00)80928-9 
[27] Soltys, B.J. and Gupta, R.S. (1997) Cell Surface Localization of the $60 \mathrm{kDa}$ Heat Shock Chaperonin Protein (hsp60) in Mammalian Cells. Cell Biology International, 21, 315-320. https://doi.org/10.1006/cbir.1997.0144

[28] Jehad, A., Ali, T., Mohamed, A.F., Fahad, A.G., Irina, A.K., Engin, B., Preethi, C., Naser, E., Maha, H., Jeena, J., Sina, K., Abdelkrim, K., Samia, W., Said, D., Kazem, B. and Mohammed, D. (2013) DNAJB3/HSP-40 Cochaperone Is Downregulated in Obese Humans and Is Restored by Physical Exercise. PLoS ONE, 8, e69217. https://doi.org/10.1371/journal.pone.0069217

[29] Cyr, D.M. and Ramos, C.H. (2015) Specification of Hsp70 Function by Type I and Type II Hsp40. Subcellular Biochemistry, 78, 91-102. https://doi.org/10.1007/978-3-319-11731-7_4

[30] Chen, K.C., Qu, S., Chowdhury, S., Noxon, I.C., Schonhoft, J.D., Plate, L., Powers, E.T., Kelly, J.W., Lander, G.C. and Wiseman, R.L. (2017) The Endoplasmic Reticulum HSP40 Co-Chaperone ERdj3/DNAJB11 Assembles and Functions as a Tetramer. EMBO Journal, 36, 2296-2309. https://doi.org/10.15252/embj.201695616

[31] Yu, S. and MacRae, T.H. (2005) The Small Heat Shock Proteins and Their Role in Human Disease. FEB Journal, 272, 2613-2627.

https://doi.org/10.1111/j.1742-4658.2005.04708.x

[32] Taylor, R.P. and Benjamin, I.J. (2005) Small Heat Shock Proteins: A New Classification Scheme in Mammals. Journal of Molecular and Cellular Cardiology, 38, 433 444. https://doi.org/10.1016/j.yjmcc.2004.12.014

[33] Acunzo, J., Katsogiannou, M. and Rocchi, P. (2012) Small Heat Shock Proteins HSP27 (HspB1), $\alpha$ B-Crystallin (HspB5) and HSP22 (HspB8) as Regulators of Cell Death. The International Journal of Biochemistry \& Cell Biology, 44, 1622-1631. https://doi.org/10.1016/j.biocel.2012.04.002

[34] Van Why, S.K., Mann, A.S., Ardito, T., Thulin, G., Ferris, S., Macleod, M.A., Kashgarian, M. and Siegel, N.J. (2003) Hsp27 Associates with Actin and Limits Injury in Energy Depleted Renal Epithelia. Journal of the American Society of Nephrology, 13, 98-106. https://doi.org/10.1097/01.ASN.0000038687.24289.83

[35] Zou, J., Guo, Y., Guettouche, T., Smith, D.F. and Voellmy, R. (1998) Repression of Heat Shock Transcription Factor HSF1 Activation by HSP90 (HSP90 Complex) That Forms a Stress-Sensitive Complex with HSF1. Cell, 94, 471-480. https://doi.org/10.1016/S0092-8674(00)81588-3

[36] Westerheide, S.D. and Morimoto, R.I. (2005) Heat Shock Response Modulators as Therapeutic Tools for Diseases of Protein Conformation. The Journal of Biological Chemistry, 280, 33097-33100. https://doi.org/10.1074/jbc.R500010200

[37] Xiao, X., Zuo, X., Davis, A.A., McMillan, D.R., Curry, B.B., Richardson, J.A. and Benjamin, I.J. (1999) HSF1 Is Required for Extra-Embryonic Development, Postnatal Growth and Protection during Inflammatory Responses in Mice. EMBO Journal, 18, 5943-5952. https://doi.org/10.1093/emboj/18.21.5943

[38] McMillan, D.R., Xiao, X.Z., Shao, L., Graves, K. and Benjamin, I.J. (1998) Targeted Disruption of Heat Shock Transcription Factor 1 Abolishes Thermotolerance and Protection against Heat-Inducible Apoptosis. The Journal of Biochemistry, 273, 7523-7528.

[39] Van der Zee, J. (2002) Heating the Patient: A Promising Approach? Annals of Oncology, 13, 1173-1184. https://doi.org/10.1093/annonc/mdf280

[40] den Brok, M.H., Sutmuller, R.P., van der Voort, R., Bennink, E.J., Figdor, C.G., Ruers, T.J. and Adema, G.J. (2004) In Situ Tumor Ablation Creates an Antigen Source for the Generation of Antitumor Immunity. Cancer Research, 64, 4024-4029. 
https://doi.org/10.1158/0008-5472.CAN-03-3949

[41] Voets, T., Droogmans, G., Wissenbach, U., Janssens, A., Flockerzi, V. and Nilius, B. (2004) The Principle of Temperature-Dependent Gating in Cold- and Heat-Sensitive TRP Channels. Nature, 430, 748-754. https://doi.org/10.1038/nature02732

[42] Hildebrandt, B., Wust, P., Ahlers, O., Dieing, A., Sreenivasa, G., Kerner, T., Felix, R. and Riess, H. (2002) The Cellular and Molecular Basis of Hyperthermia. Critical Reviews in Oncology/Hematology, 43, 33-56. https://doi.org/10.1016/S1040-8428(01)00179-2

[43] Peer, A.J., Grimm, M.J., Zynda, E.R. and Repask, E.A. (2010) Diverse Immune Mechanisms May Contribute to the Survival Benefit Seen in Cancer Patients Receiving Hyperthermia. Immunologic Research, 46, 137-154. https://doi.org/10.1007/s12026-009-8115-8

[44] Ostberg, J.R., Dayanc, B.E., Yuan, M., Oflazoglu, E. and Repasky, E.A. (2007) Enhancement of Natural Killer (NK) Cell Cytotoxicity by Fever-Rangethermal Stress Is Dependent on NKG2D Function and Is Associated with Plasma Membrane NKG2D Clustering and Increased Expression of MICA on Target Cells. Journal of Leukocyte Biology, 82, 1322-1331. https://doi.org/10.1189/jlb.1106699

[45] Ito, A., Tanaka, K., Kondo, K., Shinkai, M., Honda, H., Matsumoto, K. and Saida, T. (2003) Tumor Regression by Combined Immunotherapy and Hyperthermia Using Magnetic Nanoparticles in an Experimental Subcutaneous Murine Melanoma. Cancer Science, 94, 308-313. https://doi.org/10.1111/j.1349-7006.2003.tb01438.x

[46] Toraya-Brown, S. and Fiering, S. (2014) Local Tumour Hyperthermia as Immunotherapy Formetastatic Cancer. International Journal of Hyperthermia, 30, 531-539. https://doi.org/10.3109/02656736.2014.968640

[47] Mace, T.A., Zhong, L., Kokolus, K.M. and Repasky, E.A. (2012) Effector CD8+ T Cell IFN-Gamma Production and Cytotoxicity Are Enhanced by Mild Hyperthermia. International Journal of Hyperthermia, 28, 9-18. https://doi.org/10.3109/02656736.2011.616182

[48] Tanaka, K., Ito, A., Kobayashi, T., Kawamura, T., Shimada, S., Matsumoto, K., Saida, T. and Honda, H. (2005) Intratumoral Injection of Immature Dendritic Cells Enhances Antitumor Effect of Hyperthermia Using Magnetic Nanoparticles. International Journal of Cancer, 116, 624-633. https://doi.org/10.1002/ijc.21061

[49] Atanackovic, D., Nierhaus, A., Neumeier, M., Hossfeld, D.K. and Hegewisch-Becker, S. (2002) $41.8^{\circ} \mathrm{C}$ Whole Body Hyperthermia as an Adjunct to Chemotherapy Induces Prolonged T Cell Activation in Patients with Various Malignant Diseases. Cancer Immunology, Immunotherapy, 51, 603-613. https://doi.org/10.1007/s00262-002-0327-x

[50] Zhang, H.G., Mehta, K., Cohen, P. and Guha, C. (2008) Hyperthermia on Immune Regulation: A Temperature's Story. Cancer Letters, 271, 191-204. https://doi.org/10.1016/j.canlet.2008.05.026

[51] Repasky, E.A., Evans, S.S. and Dewhirst, M.W. (2013) Temperature Matters! And Why It Should Matter to Tumor Immunologists. Cancer Immunology Research, 1, 210-216. https://doi.org/10.1158/2326-6066.CIR-13-0118

[52] Gabrilovich, D.I. and Nagaraj, S. (2009) Myeloid-Derived-Suppressor Cells as Regulators of the Immune System. Nature Reviews Immunology, 9, 162-174. https://doi.org/10.1038/nri2506

[53] Zhu, J., Zhang, Y., Zhang, A., He, K., Liu, P. and Xu, L.X. (2016) Anti-Tumor Immunity by Inducing Extracellular Hsp70-Dependent MDSC Differentiation. Scientific Reports, 6, 27136. https://doi.org/10.1038/srep27136 
[54] Nagaraj, S. and Gabrilovich, D.I. (2008) Tumor Escape Mechanism Governed by Myeloid-Derived Suppressor Cells. Cancer Research, 68, 2561-2563.

[55] Arts, H.J., Hollema, H., Lemstra, W., Willemse, P.H., De Veries, E.G., Kampinga, H.H. and Van der Zee, A.G. (1999) Heatshock-Protein-27 (hsp27) Expression in Ovarian Carcinoma: Relation in Response to Chemotherapy and Prognosis. International Journal of Cancer, 84, 234-238. https://doi.org/10.1002/(SICI)1097-0215(19990621)84:3<234::AID-IJC6>3.0.CO;2-9

[56] Lim, S.O., Park, S.G., Yoo, J.H., Park, Y.M., Kim, H.J., Jang, K.T., Cho, J.W., Yoo, B.C., Jung, G.H. and Park, C.K. (2005) Expression of Heat Shock Proteins (HSP27, HSP60, HSP70, HSP90,GRP78, GRP94) in Hepatitis B Virus-Related Hepatocellular Carcinomas and Dysplastic Nodules. World Journal of Gastroenterology, 11, 20722079. https://doi.org/10.3748/wjg.v11.i14.2072

[57] Zheng, H.C., Takahashi, H., Li, X.H., Hara, T., Masuda, S., Guan, Y.F. and Takano, Y. (2008) Overexpression of GRP78 and GRP94 Are Markers for Aggressive Behavior and Poor Prognosis in Gastric Carcinomas. Human Pathology, 39, 1042-1049. https://doi.org/10.1016/j.humpath.2007.11.009

[58] Wang, C., Zhang, Y., Guo, K., Wang, N., Jin, H., Liu, Y. and Qin, W. (2016) Heat Shock Proteins in Hepatocellular Carcinoma: Molecular Mechanism and Therapeutic Potential. International Journal of Cancer, 15, 1824-1834. https://doi.org/10.1002/ijc.29723

[59] Issels, R.D. (2008) Hyperthermia Adds to Chemotherapy. European Journal of Cancer, 44, 2546-2554. https://doi.org/10.1016/j.ejca.2008.07.038

[60] Tower, J. (2012) Stress and Stem Cells. Wiley Interdisciplinary Reviews. Developmental Biology, 1, 789-802. https://doi.org/10.1002/wdev.56

[61] Nakahata, K., Uehara, S., Nishikawa, S., Kawatsu, M., Zenitani, M., Oue, T. and Okuyama, H. (2015) Aldehyde Dehydrogenase 1 (ALDH1) Is a Potential Marker for Cancer Stem Cells in Embryonal Rhabdomyosarcoma. PLOS ONE. https://doi.org/10.1371/journal.pone.0125454

[62] Yasuda, K., Hirohashi, Y., Mariya, T., Murai, A., Tabuchi, Y., Kuroda, T., Kusumoto, H., Takaya, A., Yamamoto, E., Kubo, T., Nakatsugawa, M., Kanaseki, T., Tsukahara, T., Tamura, Y., Hirano, H., Hasegawa, T., Saito, T., Sato, N. and Torigoe, T. (2017) Phosphorylation of HSF1 at Serine 326 Residue Is Related to the Maintenance of Gynecologic Cancer Stem Cells through Expression of HSP27. Oncotarget, 8, 31540-31553.

[63] Shackelford, D.B. and Shaw, R.J. (2009) The LKB1-AMPK Pathway: Metabolism and Growth Control in Tumor Suppression. Nature Reviews Cancer, 9, 563-575. https://doi.org/10.1038/nrc2676

[64] Efeyan, A., Zoncu, R., Chang, S., Gumper, I., Snitkin, H., Wolfson, R.L., Kirak, O., Sabatini, D.D. and Sabatini, D.M. (2013) Rag GTPase-Mediated Regulation of mTORC1 by Nutrients Is Necessary for Neonatal Autophagy and Survival. Nature, 493, 679-683. https://doi.org/10.1038/nature11745

[65] Roccio, M., Bos, J.L. and Zwartkruis, F.J.T. (2006) Regulation of the Small GTPase Rheb by Amino Acids. Oncogene, 25, 657-664.

https://doi.org/10.1038/sj.onc.1209106

[66] Poüs, C. and Codogno, P. (2011) Lysosome Positioning Coordinates mTORC1 Activity and Autophagy. Nature Cell Biology, 13, 342-344.

https://doi.org/10.1038/ncb0411-342

[67] Sancak, Y., Bar-Peled, L., Zoncu, R., Markhard, A.L., Nada, S. and Sabatin, D.M. (2010) Ragulator-Rag Complex Targets mTORC1 to the Lysosomal Surface and Is 
Necessary for Its Activation by Amino Acids. Cell, 141, 290-303. https://doi.org/10.1016/j.cell.2010.02.024

[68] Vigil, D., Cherfils, J., Rossman, K.L. and Der, C.J. (2010) Ras Superfamily GEFs and GAPs: Validated and Tractable Targets for Cancer Therapy? Nature Reviews Cancer, 10, 842-857. https://doi.org/10.1038/nrc2960

[69] Chen, C.C., Jeon, S.M., Bhaskar, P., Nogueira, V., Sundararajance, D., Tonic, I., Park, Y. and Hay, N. (2010) FoxOs Inhibit mTORC1 and Activate Akt by Inducing the Expression of Sestrin3 and Rictor. Cell Press Volume, 18, 592-604. https://doi.org/10.1016/j.devcel.2010.03.008

[70] Sato, T., Nakashima, A., Guo, L. and Tamanoi, G. (2009) Specific Activation of mTORC1 by Rheb G-Protein in Vitro Involves Enhanced Recruitment of Its Substrate Protein. The Journal of Biological Chemistry, 284, 12783-12791. https://doi.org/10.1074/jbc.M809207200

[71] Feng, Z., Zhang, H., Levine, A.J. and Jin, S. (2005) The Coordinate Regulation of the p53 and mTOR Pathways in Cells. PNAS, 102, 8204-8209. https://doi.org/10.1073/pnas.0502857102

[72] Tanikawa, J., Ichikawa-Iwata, E., Kanei-Ishii, C., Nakaii, A., Matsuzawa, S., Reed, J.C. and Ishii, S. (2000) p53 Suppresses the c-Myb-Induced Activation of Heat Shock Transcription Factor. The Journal Biological Chemistry, 275, 15578-15585. https://doi.org/10.1074/jbc.M000372200

[73] Zarogoulidis, P., Lampaki, S., Turner, J.F., Huang, H., Kakolyris, S., Syrigos, K. and Zarogoulidis, K. (2014) mTOR Pathway: A Current, Up-to-Date Mini-Review (Review). Oncology Letters, 8, 2367-2370.

[74] Stöckli, J., Fazakerley, D.J. and James, D.E. (2011) Glut4 Exocytosis. Journal of Cell Science, 124, 4147-4159. https://doi.org/10.1242/jcs.097063

[75] Betz, C., Stracka, D., Prescianotto-Baschong, C., Frieden, M., Demaurex, N. and Hall, M.N. (2013) mTOR Complex 2-Akt Signaling at Mitochondria-Associated Endoplasmic Reticulum Membranes (MAM) Regulates Mitochondrial Physiology. PNAS, 110, 12526-12534. https://doi.org/10.1073/pnas.1302455110

[76] Martin, J., Masri, J., Bernath, A., Nishimura, R.N. and Gera, J. (2008) Hsp70 Associates with Rictor and Is Required for mTORC2 Formation and Activity. Biochemical and Biophysical Research Communications, 372, 578-583. https://doi.org/10.1016/j.bbrc.2008.05.086

[77] Oh, W.J., Wu, C.C., Kim, S.J., Facchinetti, V., Julien, L.A., Finlan, M., Roux, P.P., Su. B. and Jacinto, E. (2010) mTORC2 Can Associate with Ribosomes to Promote Cotranslational Phosphorylation and Stability of Nascent Akt Polypeptide. EMBO, 29, 3939-3951. https://doi.org/10.1038/emboj.2010.271

[78] Vittoria Zinzalla, V., Daniele Stracka, D., Wolfgang Oppliger, W. and Hal, M.N. (2011) Association with the Ribosome. Cell, 144, 757-768. https://doi.org/10.1016/j.cell.2011.02.014

[79] Gan, X., Wang, J., Su, B. and Wu, D. (2011) Evidence for Direct Activation of mTORC2 Kinase Activity by Phosphatidylinositol 3,4,5-Trisphosphate. The Journal of Biological Chemistry, 286, 10998-11002. https://doi.org/10.1074/jbc.M110.195016

[80] Chung, J., Kuo, C.J., Crabtree, G.R. and Blenis, J. (1992) Rapamycin-FKBP Specifically Blocks Growth-Dependent Activation of and Signaling by the $70 \mathrm{kd}$ S6 Protein Kinases. Cell, 69, 1227-1236. https://doi.org/10.1016/0092-8674(92)90643-Q

[81] Izumiya, Y., Hopkins, T., Morris, C., Sato, K., Zeng, L., Viereck, J., Hamilton, J.A., Ouchi, N., Le Brasseur, N.K. and Walsh, K. (2008) Fast/Glycolytic Muscle Fiber 
Growth Reduces Fat Mass and Improves Metabolic Parameters in Obese Mice. Cell Metabolism, 7, 159-172. https://doi.org/10.1016/j.cmet.2007.11.003

[82] Kubica, N., Crispino, J.L., Gallagher, J.W., Kimball, S.R. and Jefferson, L.S. (2008) Activation of the Mammalian Target of Rapamycin Complex 1 Is Both Necessary and sufficient to Stimulate Eukaryotic Initiation factor 2B[Var Epsilon] mRNA Translation and Protein Synthesis. The International Journal of Biochemistry \& Cell Biology, 40, 2522-2533. https://doi.org/10.1016/j.biocel.2008.04.010

[83] Goodman, C.A. (2013) The Role of mTORC1 in Regulating Protein Synthesis and Skeletal Muscle Mass in Response to Various Mechanical Stimuli. Physiology, Biochemistry and Pharmacology, 166. https://doi.org/10.1007/112_2013_17

[84] Delamarre, L., Pack, M., Chang, H., Mellman, I. and Trombetta, E.S. (2005) Differential Lysosomal Proteolysis in Antigen-Presenting Cells Determines Antigen Fate. Science, 307, 1630-1634. https://doi.org/10.1126/science.1108003

[85] Rudensky, A.Y. (2011) Regulatory T Cells and Foxp3. Immunological Reviews, 241, 260-268. https://doi.org/10.1111/j.1600-065X.2011.01018.x

[86] Greg, M., Delgoffe, G.M., Pollizzi, K.N., Waickman, A.T., Heikamp, E., Meyers, D.J., Horton, M.R., Xiao, B., Worley, P.F. and Powell, J.D. (2011)The Mammalian Target of Rapamycin (mTOR) Regulates T Helper Cell Differentiation through the Selective Activation of mTORC1 and mTORC2 Signaling. Nature Immunology, 12, 295-303. https://doi.org/10.1038/ni.2005

[87] Haabeth, O.A.W., Lorvik, K.B., Hammarström, C., Donaldson, I.M., Haraldsen, G., Bogen, B. and Corthay, A. (2010) Inflammation Driven by Tumour-Specific Th1 Cells Protects against B-Cell Cancer. Nature Communications, 2, 240. https://doi.org/10.1038/ncomms1239

[88] Ouyang, W., Kolls, J.K. and Zheng, Y. (2008) The Biological Functions of T Helper 17 Cell Effector Cytokines in Inflammation. Immunity, 28, 454-467. https://doi.org/10.1016/j.immuni.2008.03.004

[89] Guéry, L. and Hugues, S. (2015) Th17 Cell Plasticity and Functions in Cancer Immunity. BioMed Research International, 2015, Article ID: 314620.

[90] Romagnani, S. (1991) Type 1 T Helper and Type 2 T Helper Cells: Functions, Regulation and Role in Protection and Disease. International Journal of Clinical and Laboratory Research, 21, 152-158.

[91] Nishimura, T., Iwakabe, K., Sekimoto, M., Ohmi, Y., Yahata, T., Nakui, M., Sato, T., Habu, S., Tashiro, H., Sato, M. and Ohta, A. (1999) Distinct Role of Antigen-Specific T Helper Type 1 (Th1) and Th2 Cells in Tumor Eradication in Vivo. Journal of Experimental Medicine, 190, 617-627. https://doi.org/10.1084/jem.190.5.617

[92] Yang, S.W., Kang, S.H., Kim, K.R., In Hong Choi, I.H., Chang, H.S., Oh, Y.L. and Hong, S.W. (2016) Do Helper T Cell Subtypes in Lymphocytic Thyroiditis Play a Role in the Antitumor Effect? Journal of Pathology and Translational Medicine, 50, 377-384. https://doi.org/10.4132/jptm.2016.07.25

[93] Jacobson, M.D., Weil, M. and Raff, M.C. (1997) Programmed Cell Death Review in Animal Development. Cell, 88, 347-354. https://doi.org/10.1016/S0092-8674(00)81873-5

[94] Zhang, X., Tang, N., Hadden, T.J. and Rishi, A.K. (2011) Akt, FoxO and Regulation of Apoptosis. Biochimica et Biophysica Acta, 1813, 1978-1986.

[95] Renault, T.T., Floros, K.V. and Chipuk, J.E. (2013) BAK/BAX Activation and Cytochrome c Release Assays Using Isolated Mitochondria. Methods, 61, 146-155. https://doi.org/10.1016/j.ymeth.2013.03.030 
[96] Nunaez, G., Benedict, M.A., Hu, Y. and Inohara, N. (1998) Caspases: The Proteases of the Apoptotic Pathway. Oncogene, 17, 3237-3245. https://doi.org/10.1038/sj.onc.1202581

[97] Zhivotovsky, B., Samali, A., Gahm, A. and Orrenius, S. (1999) Caspases: Their Intracellular Localization and Translocation during Apoptosis. Cell Death \& Differentiation, 6, 644-651. https://doi.org/10.1038/sj.cdd.4400536

[98] Suzanne, C. and Jerry, M.A. (2002) The BCL2 Family: Regulators of the Cellular Life-or-Death Switch. Nature Reviews Cancer, 2, 647-656

[99] Mcllwain, D.R., Berger, T. and Mak, T.W. (2013) Caspase Functions in Cell Death and Disease. Cold Spring Harbor Perspectives in Biology, 5, a008656.

https://doi.org/10.1101/cshperspect.a008656

[100] Alikhani, M., Alikhani, Z. and Graves, D.T. (2005) FOXO1 Functions as a Master Switch That Regulates Gene Expression Necessary for Tumor Necrosis Factor-Induced Fibroblast Apoptosis. The Journal of Biological Chemistry, 280, 12096-12102. https://doi.org/10.1074/jbc.M412171200

[101] Oslowski, C.M. and Urano, F.F. (2011) Measuring ER Stress and the Unfolded Protein Response Using Mammalian Tissue Culture System. Methods in Enzymology, 490, 71-92. https://doi.org/10.1016/B978-0-12-385114-7.00004-0

[102] Booth, L., Roberts, J.L., Tavallai, M., Nourbakhsh, A., Chuckalovcak, J., Carter, J., Poklepovic, A. and Dent, P. (2015) OSU-03012 and Viagra Treatment Inhibits the Activity of Multiple Chaperone Proteins and Disrupts the Blood-Brain Barrier: Implications for Anti-Cancer Therapies. Cellular Physiology, 230, 1982-1998.

https://doi.org/10.1002/jcp.24977

[103] Bernales, S., Papa, F.R. and Walter, P. (2006) Intracellular Signaling by the Unfolded Protein Response. Annual Review of Cell and Developmental Biology, 22, 487-508. https://doi.org/10.1146/annurev.cellbio.21.122303.120200

[104] Clemens, M.J. (2001) Initiation Factor eIF2 Alpha Phosphorylation in Stress Responses and Apoptosis. Progress in Molecular and Subcellular Biology, 27, 57-89. https://doi.org/10.1007/978-3-662-09889-9_3

[105] Workman, P., Burrows, F., Neckers, L. and Rosen, N. (2007) Drugging the Cancer Chaperone HSP90: Combinatorial Therapeutic Exploitation of Oncogene Addiction and Tumor Stress. Annals of the New York Academy of Sciences, 1113, 202-216. https://doi.org/10.1196/annals.1391.012

[106] Trepel, J., Mollapour, M., Giaccone, G. and Neckers, L. (2010) Targeting the Dynamic HSP90 Complex in Cancer. Nature Review, Cancer, 10, 537-549.

[107] Chen, Y., Chen, J., Loo, A., Jaeger, S., Bagdasarian, L., Yu, J., Franklin Chung, F., Korn, J., Ruddy, D., Guo, R., Mclaughlin, M.E., Feng, F., Zhu, P., Stegmeier, F., Pagliarini, R., Porter, D. and Zhou, W. (2013) Targeting HSF1 Sensitizes Cancer Cells to HSP90 Inhibition. Oncotarget, 4, 816-829. https://doi.org/10.18632/oncotarget.991

[108] Hendriks, L.E.L. and Dingemans, A.M.C. (2017) Heat Shock Protein Antagonists in Early Stage Clinical Trials for NSCLC. Expert Opinion on Investigational Drugs, 26, 541-550. https://doi.org/10.1080/13543784.2017.1302428

[109] Conde, R., Belak, Z.R., Nair, M., O’Carroll, R.F. and Ovsenek, N. (2009) Modulation of Hsf1 Activity by Novobiocin and Geldanamycin. Biochemistry and Cell Biology, 87, 845-851. https://doi.org/10.1139/O09-049

[110] Valle, J., Wasan, H., Palmer, D.H., Cunningham, D., Anthoney, A., Maraveyas, A., Madhusudan, S., Iveson, T., Hughes, S., Pereira, S.P., Roughton, M. and Bridgewater, J. (2010) Cisplatin plus Gemcitabine versus Gemcitabine for Biliary Tract Can- 
cer. New England Journal of Medicine, 362, 1273-1281.

https://doi.org/10.1056/NEJMoa0908721

[111] Yothaisong, S., Dokduang, H., Techasen, A., Namwat, N., Yongvanit, P., Bhudhisawasdi, V., Puapairoj, A., Riggins, G.J. and Loilome, W. (2013) Increased Activation of PI3K/AKT Signaling Pathway Is Associated with Cholangiocarcinoma Metastasis and PI3K/mTOR Inhibition Presents a Possible Therapeutic Strategy. Tumor Biology, 34, 3637-3648. https://doi.org/10.1007/s13277-013-0945-2

[112] Markman, B., Dienstmann, R. and Tabernero, J. (2010) Targeting the PI3K/Akt/ mTOR Pathway-Beyond Rapalogs. Oncotarget, 1, 530-543. https://doi.org/10.18632/oncotarget.188

[113] Chen, M.H., Chiang, K.C., Cheng, C.T., Huang, S.C., Chen, Y.Y., Chen, T.W., Yeh, T.S., Jan, Y.Y., Wang, H.M., Weng, J.J., Chang, P.M.H., Liu, C.Y., Li, C.P., Chao, Y., Chen, M.H., Huang, C.Y.F. and Yeh, C.N. (2014) Antitumor Activity of the Combination of an HSP90 Inhibitor and a PI3K/mTOR Dual Inhibitor against Cholangiocarcinoma. Oncotarget, 5, 2372-2389. https://doi.org/10.18632/oncotarget.1706

[114] Scherz-Shouval, R., Santagata, S., Mendillo, M.L., Sholl, L.M., Ben-Aharon, I., Beck, A.H., Dias-Santagata, D., Koeva, M., Stemmer, S.M., Whitesell, L. and Lindquis, S. (2014) The Reprogramming of Tumor Stroma by HSF1 Is a Potent Enabler of Malignancy. Cell, 158, 564-578. https://doi.org/10.1016/j.cell.2014.05.045

[115] Blachere, N.E., Udono, H., Janetzki, S., Li, Z., Heike, M. and Srivastava, P.K. (1993) Heat Shock Protein Vaccines against Cancer. Journal of Immunotherapy with Emphasis on Tumor Immunology, 14, 352-356. https://doi.org/10.1097/00002371-199311000-00016

[116] Gong, J., Zhang, Y., Durfee, J., Weng, D., Liu, C., Koido, S., Song, B., Apostolopoulos, V. and Calderwood, S.K. (2010) A Heat Shock Protein 70-Based Vaccine with Enhanced Immunogenicity for Clinical Use. The Journal of Immunology, 184, 488-496. https://doi.org/10.4049/jimmunol.0902255

[117] Binder, R.J., Blachere, N.E. and Srivastava, P.K. (2001) Heat Shock Protein-Chaperoned Peptides but Not Free Peptides Introduced into the Cytosolare Presented Efficiently by Major Histocompatibility Complex I Molecules. The Journal of Biological Chemistry, 276, 17163-17171. https://doi.org/10.1074/jbc.M011547200

[118] Guzhova, I.V. and Margulis, B.A. (2016) HSP70-Based Anti-Cancer Immunotherapy. Human Vaccines \& Immunotherapeutics, 12, 2529-2535. https://doi.org/10.1080/21645515.2016.1190057

[119] Shevtsov, M.A., Komarova, E.Y., Meshalkina, D.A., Bychkova, N.V., Aksenov, N.D., Abkin, S.V., Margulis, B.A. and Guzhova, I.V. (2014) Exogenously Delivered Heatshock Protein 70 Displaces Its Endogenous Analogue and Sensitizes Cancer Cells to Lymphocytes-Mediated Cytotoxicity. Oncotarget, 5, 3101-3114. https://doi.org/10.18632/oncotarget.1820

[120] Etminan, N., Peters, C., Lakbir, D., Bunemann, E., Borger, V., Sabel, M.C., Hanggi, D., Steiger, H.J., Stummer, W. and Sorg, R.V. (2011) Heat-Shock Protein 70-Dependent Dendritic Cell Activation by 5-Aminolevulinic Acid-Mediated Photodynamic Treatment of Human Glioblastoma Spheroids in Vitro. British Journal of Cancer, 105, 961-969. https://doi.org/10.1038/bjc.2011.327

[121] Green, D.R., Ferguson, T., Zitvogel, L. and Kroemer, G. (2009) Immunogenic and Tolerogenic Cell Death. Nature Reviews Immunology, 9, 353-363.

https://doi.org/10.1038/nri2545

[122] Gastpar, R., Gehrmann, M., Bausero, M.A., Asea, A., Gross, C., Schroeder, J.A. and Multhoff, G. (2005) Heat Shock Protein 70 Surface-Positive Tumor Exosomes Sti- 
mulate Migratory and Cytolytic Activity of Natural Killer Cells. Cancer Research, 65, 5238-5247. https://doi.org/10.1158/0008-5472.CAN-04-3804

[123] Calderwood, S.K., Gong, J. and Murshid, A. (2016) Extracellular HSPs: The Complicated Roles of Extracellular HSPs in Immunity. Frontiers in Immunology, 7, 9 p.

[124] Gao, P., Sun, X., Chen, X., Wang, Y., Foster, B.A., Subjeck, J., Fisher, P.B. and Wang, X.Y. (2008) Secretable Chaperone Grp170 Enhances Therapeutic Activity of a Novel Tumor Suppressor, Mda-7/IL-24. Cancer Research, 68, 3890-3898. https://doi.org/10.1158/0008-5472.CAN-08-0156

[125] Zuo, D., Yu, X., Guo, C., Yi, H., Chen, X., Conrad, D.H., Guo, T.L., Chen, Z., Fisher, P.B., Subjeck, J.R. and Wang, X.Y. (2012) Molecular Chaperoning by Glucose-Regulated Protein 170 in the Extracellular Milieu Promotes Macrophage-Mediated Pathogen Sensing and Innate Immunity. The FASEB Journal, 26, 1493-1505.

https://doi.org/10.1096/fj.11-197707

[126] Salari, S., Seibert, T., Chen, Y.X., Hu, T., Shi, C., Zhao, X., Cueerier, C.M., Raizman, J.E. and O'Brien, E.R. (2013) Extracellular Hsp27 Acts as a Signaling Molecule to Activate NF-kappaB in Macrophages. Cell Stress Chaperones, 18, 53-63. https://doi.org/10.1007/s12192-012-0356-0

[127] Andrei, C., Dazzi, C., Lotti, L., Torrisi, M.R., Chimini, G. and Rubartelli, A. (1999) The Secretory Route of the Leaderless Protein Interleukin 1beta Involves Exocytosis of Endolysosome-Related Vesicles. Molecular Biology of the Cell, 10, 1463-1475. https://doi.org/10.1091/mbc.10.5.1463

[128] Mambula, S.S. and Calderwood, S.K. (2006) Heat Shock Protein 70 Is Secreted from Tumor Cells by a Nonclassical Pathway Involving Lysosomal Endosomes. The Journal of Immunology, 177, 7849-7857. https://doi.org/10.4049/jimmunol.177.11.7849

[129] Martin-Murphy, B.V., Holt, M.P. and Ju, C. (2010) The Role of Damage Associated Molecular Pattern Molecules in Acetaminophen Induced Liver Injury in Mice. Toxicology Letters, 192, 387-394. https://doi.org/10.1016/j.toxlet.2009.11.016

[130] Murshid, A., Gong, J. and Calderwood, S.K. (2012) The Role of Heat Shock Proteins in Antigen Cross Presentation. Frontiers in Immunology, 3, 63. https://doi.org/10.3389/fimmu.2012.00063

[131] Kluger, M.J., Kozak, W., Conn, C.A., Leon, L.R. and Soszynski, D. (1996) The Adaptive Value of Fever. Infectious Disease Clinics of North America, 10, 1-20. https://doi.org/10.1016/S0891-5520(05)70282-8

[132] Vardam, T.D., Zhou, L., Appenheimer, M.M., Chen, Q., Wang, W.C., Baumann, H. and Evans, S.S. (2007) Regulation of Alymphocyte-Endothelial-IL-6 Trans-Signaling Axis by Fever-Range Thermal Stress: Hot Spot of Immune Surveillance. Cytokine, 39, 84-96. https://doi.org/10.1016/j.cyto.2007.07.184

[133] Grivennikov, S.I., Greten, F.R. and Karin, M. (2010) Immunity, Inflammation, and Cancer. Cell, 140, 883-899. https://doi.org/10.1016/j.cell.2010.01.025

[134] Schreiber, R.D., Old, L.J. and Smyth, M.J. (2011) Cancer Immunoediting: Integrating Immunity's Roles in Cancer Suppression and Promotion. Science, 331, 1565 1570. https://doi.org/10.1126/science.1203486

[135] Lippitz, B.E. (2013) Cytokine Patterns in Patients with Cancer: A Systematic Review. The Lancet Oncology, 14, e218-e228. https://doi.org/10.1016/S1470-2045(12)70582-X

[136] Park, S.J., Nakagawa, T., Kitamura, H., Atsumi, T., Kamon, H., Sawa, S., Kamimura, D., Ueda, N., Iwakura, Y., Ishihara, K., Murakami, M. and Hirano, T. (2004) IL-6 Regulates in Vivo Dendritic Cell Differentiation through STAT3 Activation. The 
Journal of Immunology, 173, 3844-3854.

https://doi.org/10.4049/jimmunol.173.6.3844

[137] Chomarat, P., Banchereau, J., Davoust, J. and Palucka, A.K. (2000) IL-6 Switches the Differentiation of Monocytes from Dendritic Cells to Macrophages. Nature Immunology, 1, 510-514. https://doi.org/10.1038/82763

[138] Fisher, D.T., Chen, Q., Skitzki, J.J., Muhitch, J.B., Zhou, L., Appenheimer, M.M., Vardam, T.D., Weis, E.L., Passanese, J., Wang, W.C., Gollnick, S.O., Dewhirst, M.W., Rose-John, S., Repasky, E.A., Baumann, H. and Evans, S.S. (2011) IL-6 Trans-Signaling Licenses Mouse and Human Tumor Microvascular Gateways for Trafficking of Cytotoxic T Cells. The Journal of Clinical Investigation, 121, 38463859. https://doi.org/10.1172/JCI44952

[139] Smith, A., Bracke, M., Leitinger, B., Porter, J.C. and Hogg, N. (2003) LFA-1-Induced T Cell Migration on ICAM-1 Involves Regulation of MLCK-Mediated Attachment and ROCK-Dependent Detachment. Journal of Cell Science, 116, 3123 3133. https://doi.org/10.1242/jcs.00606

[140] Fisher, D.T., Appenheimer, M.M. and Evans, S.S. (2014) The Two Faces of IL-6 in the Tumor Microenvironment. Seminars in Immunology, 26, 38-47.

https://doi.org/10.1016/j.smim.2014.01.008

[141] Arnold-Schild, D., Hanau, D., Spehner, D., Schmid, C., Rammensee, H.G., de la Salle, H. and Schild, H. (1998) Cutting Edge: Receptor-Mediated Endocytosis of Heat Shock Proteins by Professional Antigen-Presenting Cells. Immunology, 162, 3757-3760.

[142] Suto, R. and Srivastava, P.K. (1995) A Mechanism for the Specific Immunogenicity of Heat Shock Protein-Chaperoned Peptides. Science, 269, 1585. https://doi.org/10.1126/science.7545313

[143] Udono, H. (2012) Heat Shock Protein Magic in Antigen Trafficking within Dendritic Cells: Implications in Antigen Cross-Presentation in Immunity. Acta Medica Okayama, 66, 1-6.

[144] Engering, A.J., Cella, M., Fluitsma, D.M., Hoefsmit, E.C., Lanzavecchia, A. and Pieters, J. (1997) Mannose Receptor Mediated Antigen Uptake and Presentation in Human Dendritic Cells. Advances in Experimental Medicine and Biology, 417, 183. https://doi.org/10.1007/978-1-4757-9966-8_31

[145] Bahram, S., Bresnahan, M., Geraghty, D.E. and Spies, T. (1994) A Second Lineage of Mammalian Major Histocompatibility Complex Class I Genes. Proceedings of the National Academy of Sciences of the USA, 91, 6259-6263.

[146] Ménoret, A., Patry, Y., Burg, C. and Pendu, J.L. (1995) Co-Segregation of Tumor Immunogenicity with Expression of Inducible but Not Constitutive hsp70 in Rat Colon Carcinomas. The Journal of Immunology, 155, 740-747.

[147] Wang, R., Kovalchin, J.T., Muhlenkamp, P. and Chandawarkar, R.Y. (2005) Exogenous Heat Shock Protein-70 Binds Macrophage Lipid Raft Microdomain and Stimulates Phagocytosis, Processing and MHC-II Presentation of Antigens. Blood, 2005-2559.

[148] Gastpar, R., Gross, C., Rossbacher, L., Ellwart, J., Riegger, J. and Multhoff, G. (2004) The Cell Surface-Localized Heatshock Protein 70 Epitope TKD Induces Migration and Cytolytic Activity Selectively in Human NK Cells. The Journal of Immunology, 172, 972-980. https://doi.org/10.4049/jimmunol.172.2.972

[149] Ostrand-Rosenberg, S., Roby, C.A. and Clement, V.K. (1991) Abrogation of Tumorigenicity by MHC Class II Antigen Expression Requires the Cytoplasmic Domain of the Class II Molecule. The Journal of Immunology, 147, 2419-2422. 
[150] Bogen, B., Munthe, L., Sollien, A., Hofgaard, P., Omholt, H., Dagnaes, F. and Dembic, Z. (1995) NaïveCD4+ T Cells Confer Idiotype-Specific Tumor Resistance in the Absence of Antibodies. European Journal of Immunology, 25, 3079-3086. https://doi.org/10.1002/eji.1830251114

[151] Haabeth, O.A.W., Tveita, A.A., Fauskanger, M., Schjesvold, F., Lorvik, K.B., Hofgaard, P.O., Omholt, H., Munthe, L.A., Dembic, Z., Corthay, A. and Bogen, B. (2014) How Do CD4+T Cells Detect and Eliminate Tumor Cells That either Lack or Express MHC Class II Molecules? Frontiers in Immunology Tumor Immunity, 5, 13 p.

[152] Wang, R.F. (2001) The Role of MHC Class II-Restricted Tumor Antigens and $\mathrm{CD}^{+} \mathrm{T}$ Cells in Antitumor Immunity. Trends in Immunology, 22, 269-276. https://doi.org/10.1016/S1471-4906(01)01896-8

[153] Abkin, S.V., Pankratova, K.M., Komarova, E.Y., Guzhova, I.V. and Margulis, B.A. (2013) Hsp70 Chaperone-Based Gel Composition as a Novel Immunotherapeutic Anti-Tumor Tool. Cell Stress Chaperones, 18, 391-396. https://doi.org/10.1007/s12192-012-0391-x

[154] Abkin, S.V., Ostroumova, O.S., Komarova, E.Y., Meshalkina, D.A., Shevtsov, M.A., Margulis, B.A. and Guzhova, I.V. (2016) Phloretin Increases the Anti-Tumor Efficacy of Intratumorally Delivered Heat-Shock Protein $70 \mathrm{kDa}$ (HSP70) in a Murine Model of Melanoma. Cancer Immunology, Immunotherapy, 65, 83-92.

https://doi.org/10.1007/s00262-015-1778-1

[155] Ostroumova, O.S., Efimova, S.S., Mikhailova, E.V. and Schagina, L.V. (2014) The Interaction of Dipole Modifiers with Amphotericin-Ergosterol Complexes. Effects of Phospholipid and Sphingolipid Membrane Composition. European Biophysics Journal, 43, 207-215. https://doi.org/10.1007/s00249-014-0946-0

[156] Zhu, Y.Z., Cao, M.M., Wang, W.B., Wang, W., Ren, H., Zhao, P. and Qi, Z.T. (2012) Association of Heat-Shock Protein 70 with Lipid Rafts Is Required for Japanese encephalitis Virus Infection in Huh7 Cells. Journal of General Virology, 93, 61-71. https://doi.org/10.1099/vir.0.034637-0

[157] Nalesnik, M.A. (2013) Plasma Cell Tumors in Transplant Patients. Blood, 121, 1247-1249. https://doi.org/10.1182/blood-2013-01-475947

[158] Lin, H., Kolosenko, I., Bjorklund, A.C., Protsyuk, D., Osterborg, A., Grander, D. and Tamm, K.P. (2013) An Activated JAK/STAT3 Pathway and CD45 Expression Are Associated with Sensitivityto Hsp90 Inhibitors in Multiple Myeloma. Experimental Cell Research, 319, 600-611. https://doi.org/10.1016/j.yexcr.2012.12.006

[159] Li, R., Qian, J., Zhang, W., Fu, W., Du, J., Jiang, H., Zhang, H., Zhang, C., Xi, H., Yi, Q. and Hou, J. (2014) Human Heat Shock Protein Specific Cytotoxic T Lymphocytes Display Potent Antitumour Immunity in Multiple Myeloma. British Journal of Haematology, 166, 690-701. https://doi.org/10.1111/bjh.12943

[160] Calderwood, S.K., Murshid, A. and Prince, T. (2009) The Shock of Aging: Molecular Chaperones and the Heat Shock Response in Longevity and Aging-A Mini-Review. Gerontology, 55, 550-558. https://doi.org/10.1159/000225957

[161] Calderwood, S.K., Khaleque, M.A., Sawyer, D.B. and Ciocca, D.R. (2006) Heat Shock Proteins in Cancer: Chaperones of Tumorigenesis. Trends in Biochemical Sciences, 31, 164-172. https://doi.org/10.1016/j.tibs.2006.01.006

[162] Driver, J.A. (2014) Inverse Association between Cancer and Neurodegenerative Disease: Review of the Epidemiologic and Biological Evidence. Biogerontology, 15, 547-557. https://doi.org/10.1007/s10522-014-9523-2

[163] Kityk, R., Vogel, M., Schlecht, R., Bukau, B. and Mayer, M.P. (2015) Pathways of 
Allosteric Regulation in Hsp70 Chaperones. Nature Communications, 6, 8308. https://doi.org/10.1038/ncomms9308

[164] Guertin, M.J. and Lis, J.T. (2010) Chromatin Landscape Dictates HSF Binding to Target DNA Elements. PLOS Genetics, 6.

[165] Blasco, M. and Schoeftner, S. (2008) Developmentally Regulated Transcription of Mammalian Telomeres by DNA-Dependent RNA Polymerase II. Nature Cell Biology, 10, 228-236. https://doi.org/10.1038/ncb1685

[166] Koskas, S., Decottignies, A., Dufour, S., Pezet, M., Verdel, A., Vourc'h, C. and Faure, V. (2017) Heat Shock Factor 1 Promotes TERRA Transcription and Telomere Protection upon Heat Stress. Nucleic Acids Research, 45, 6321-6333.

https://doi.org/10.1093/nar/gkx208

[167] Porro, A., Feuerhahn, S., Delafontaine, J., Riethman, H., Rougemont, J. and Lingner, J. (2014) Functional Characterization of the TERRA Transcriptome at Damaged Telomeres. Nature Communications, 5, 5379.

https://doi.org/10.1038/ncomms6379

[168] Hanahan, D. and Weinberg, R.A. (2011) Hallmarks of Cancer: The Next Generation. Cell, 144, 646-674. https://doi.org/10.1016/j.cell.2011.02.013

[169] Ciocca, D.R., Cayado-Gutiérrez, N., Maccioni, M. and Cuello-Carrión, F.D. (2012) Heat Shock Proteins (HSPs) Based Anti-Cancer Vaccines. Current Molecular Medicine, 12, 1-15. https://doi.org/10.2174/156652412803306684

[170] Gulley, J.L., Madan, R.A. and Schlom, J. (2011) Impact of Tumour Volume on the Potential Efficacy of Therapeutic Vaccines. Current Oncology, 18, e150-e157. https://doi.org/10.3747/co.v18i3.783

[171] Rizell, M., Andersson, M., Cahlin, C., Hafström, L., Olausson, M. and Lindnér, P. (2008) Effects of the mTOR Inhibitor Sirolimus in Patients with Hepatocellular and Cholangiocellular Cancer. International Journal of Clinical Oncology, 13, 66-70. https://doi.org/10.1007/s10147-007-0733-3

[172] Anassi, E. and Ndefo, U.A. (2011) Sipuleucel-T (Provenge) Injection. The First Immunotherapy Agent (Vaccine) for Hormone-Refractory Prostate Cancer. Drug Forcast, $P \& T, 36,197-202$.

[173] Citri, A., Harari, D., Shohat, G., Ramakrishnan, P., Gan, J., Lavi, S., Eisenstein, M., Kimchi, A., Wallach, D., Pietrokovski, S. and Yarden, Y. (2006) Hsp90 Recognizes a Common Surface on Client Kinases. The Journal of Biological Chemistry, 281, 14361-14369. https://doi.org/10.1074/jbc.M512613200

[174] Smith, D.L., Acquaviva, J., Sequeira, M., Jimenez, J.P., Zhang, C.H., Sang, J., Bates, R.C. and Proia, D.A. (2015) The HSP90 Inhibitor Ganetespib Potentiates the Antitumor Activity of EGFR Tyrosine Kinase Inhibition in Mutant and Wild-Type Non-Small Cell Lung Cancer. Targeted Oncology, 10, 235-245.

https://doi.org/10.1007/s11523-014-0329-6

[175] Sequist, L.V., Yang, J.C., Yamamoto, N., O’Byrne, K., Hirsh, V., Mok, T., Geater, S.L., Orlov, S., Tsai ,C.M., Boyer, M., Su, W.C., Bennouna, J., Kato, T., Gorbunova, V., Lee, K.H., Shah, R., Massey, D., Zazulina, V., Shahidi, M. and Schuler, M. (2013) Phase III Study of Afatinib or Cisplatin Plus Pemetrexed in Patients with Metastatic Lung Adenocarcinoma with EGFR Mutations. Journal of Clinical Oncolog.

[176] Lee, H., Saini, N., Parris, A.B., Zhao, M. and Yang, X. (2017) Ganetespib Induces G2/M Cell Cycle Arrest and Apoptosis in Gastric Cancer Cells through Targeting of Receptor Tyrosine Kinase Signaling. International Journal of Oncology, 51, 967-974.

[177] Zhu, J., Huang, J.W., Tseng, P.H., Yang, Y.T., Fowble, J., Shiau, C.W., Shaw, Y.J., Kulp, S.K. and Chen, C.S. (2004) From the Cyclooxygenase-2 Inhibitor Celecoxib to 
a Novel Class of 3-Phosphoinositide-Dependent Protein Kinase-1 Inhibitors. Cancer Research, 64, 4309-4318. https://doi.org/10.1158/0008-5472.CAN-03-4063

[178] Lee, T.X., Packer, M.D., Huang, J., Akhmametyeva, E.M., Kulp, S.K., Chen, C.H., Giovannini, M., Jacob, A., Welling, D.B. and Chang, L.S. (2009) Growth Inhibitory and Anti-Tumour Activities of OSU-03012, a Novel PDK-1 Inhibitor, on Vestibular Schwannoma and Malignant Schwannoma Cells. European Journal of Cancer, 45, 1709-1720. https://doi.org/10.1016/j.ejca.2009.03.013

[179] Asco University-A First-in-Human Phase I Trial of AR-12, a PDK-1 Inhibitor, in Patients with Advanced Tumors, Presented Monday, June 3, 2013.

[180] Booth, L., Cazanave, S.C., Hamed, H.A., Yacoub, A., Ogretmen, B. and Chen, C.H. (2012) OSU-03012 Suppresses GRP78/BiP Expression That Causes PERK-Dependent Increases in Tumor Cell Killing. Cancer Biology \& Therapy, 13, 224-236.

https://doi.org/10.4161/cbt.13.4.18877

[181] Hudes, G., Carducci, M., Tomczak, P., Dutcher, J., Figlin, R., Kapoor, A., Staroslawska, E., Sosman, J., McDermott, D., Bodrogi, I., Kovacevic, Z., Lesovoy, V., Schmidt-Wolf, G.H., Barbarash, O., Gokmen, E., O’Toole, T., Lustgarten, S., Moore, L. and Mozer, R.J. (2007) Temsirolimus, Interferon Alfa, or Both for Advanced Renal-Cell Carcinoma. New England Journal of Medicine, 356, 2271-2281. https://doi.org/10.1056/NEJMoa066838

[182] Franz, D.N. (2013) Everolimus in the Treatment of Subependymal Giant Cell Astrocytomas, Angiomyolipomas, and Pulmonary and Skin Lesions Associated with Tuberous Sclerosis Complex. Biologics, 7, 211-221.

[183] Beaver, J.A. and Park, B.H. (2012) The BOLERO-2 Trial: The Addition of Everolimus to Exemestane in the Treatment of Postmenopausal Hormone Receptor-Positive Advanced breast Cancer. Future Oncology, 8, 651-657.

https://doi.org/10.2217/fon.12.49

[184] Baselga, J., Campone, M., Piccart, M., Burris, H.A., Rugo, H.S., Sahmoud, T., Noguchi, S., Gnant, M., Pritchard, K.I., Lebrun, F., Beck, J.T., Ito, Y., Yardley, D., Deleu, I., Perez, A., Bachelot, T., Vittori, L., Xu, Z., Mukhopadhyay, P., Lebwohl, D. and Hortobagyi, G.N. (2012) Everolimus in Postmenopausal Hormone-ReceptorPositive Advanced Breast Cancer. New England Journal of Medicine, 366, 520-529. https://doi.org/10.1056/NEJMoa1109653

[185] Wichert, G.V., Jehle, P.M., Hoeflich, A., Koschnick, S., Dralle, H., Wolf, E., Wiedenmann, B., Boehm, B., Adler, G. and Seufferlein, T. (2000) Insulin-Like Growth Factor-I Is an Autocrine Regulator of Chromogranin A Secretion and Growth in Human Neuroendocrine Tumor Cells. Cancer Research, 60, 4573-4581.

[186] Yao, J.C., Shah, M.H., Ito, T., Bohas, C.L., Wolin, E.M., Van Cutsem, E., Hobday, T.J., Okusaka, T., Capdevila, J., de Vries, E.G., Tomassetti, P., Pavel, M.E., Hoosen, S., Haas, T., Lincy, J., Lebwohl, D. and Öberg, K. (2011) RAD001 in Advanced Neuroendocrine Tumors, Third Trial (RADIANT-3) Study Group Everolimus for Advanced Pancreatic Neuroendocrine Tumors. New England Journal of Medicine, 364, 514-523. https://doi.org/10.1056/NEJMoa1009290

[187] Missiaglia, E., Dalai, I., Barbi, S., Beghelli, S., Falconi, M., Peruta, M.D., Piemonti, L., Capurso, G., Florio, A.D., Fave, G.D., Pederzoli, P., Croce, C.M. and Scarpa, A. (2010) Pancreatic Endocrine Tumors: Expression Profiling Evidences: A Role for AKT-mTOR Pathway. Journal of Clinical Oncology, 28, 245-255. https://doi.org/10.1200/JCO.2008.21.5988

[188] Yufu, Y., Nishimura, J. and Nawata, H. (1992) High Constitutive Expression of Heat Shock Protein $90 \alpha$ in Human Acute Leukemia Cells. Leukemia Research, 16, 597605. https://doi.org/10.1016/0145-2126(92)90008-U 
[189] Fung, P.C.W. and Kong, R.K.C. (2016) The Integrative Five-Fluid Circulation System in the Human Body. Open Journal of Molecular and Integrative Physiology, 6, 45-97. https://doi.org/10.4236/ojmip.2016.64005

[190] Nishizawa, S., Hirohashi, Y., Torigoe, T., Takahashi, A., Tamura, Y., Mori, T., Kanaseki, T., Kamiguchi, K., Asanuma, H., Morita, R., Sokolovskaya, A., Matsuzaki, J., Yamada, R., Fujii, R., Kampinga, H., Kondo, T., Hasegawa, T., Hara, I. and Sato, N. (2012) HSP DNAJB8 Controls Tumor-Initiating Ability in Renal Cancer Stem-Like Cells. Cancer Research, 72, 2844-2854.

https://doi.org/10.1158/0008-5472.CAN-11-3062

[191] Tsvetkova, N.M., Ibolya Horvath, I., Török, Z., Wolkers, W.F., Balogi, Z., Shigapova, N., Crowe, L.M., Tablin, F., Vierling, E., Crowe, J.H. and Vigh, L. (2002) Small Heat-Shock Proteins Regulate Membrane Lipid Polymorphism. PNAS, 99, 1350413509. https://doi.org/10.1073/pnas.192468399

[192] Takahashi, A., Yamakawa, N., Mori, E., Ohnishi, K., Yokota, S., Sugo, N., Aratani, Y., Koyama, H. and Ohnishi, T. (2008) Development of Thermotolerance Requires Interaction between Polymerase-Beta and Heat Shock Proteins. Cancer Science, 99, 973-978. https://doi.org/10.1111/j.1349-7006.2008.00759.x

[193] Csoboz, B., Balogh, G.E., Kusz, E., Gombos, I., Peter, M., Crul, T., Gungor, B., Haracska, L., Bogdanovics, G., Torok, Z., Horvath, I. and Vigh, L. (2013) Membrane Fluidity Matters: Hyperthermia from the Aspects of Lipids and Membranes. International Journal of Hyperthermia, 1464-5157.

[194] Yore, M.M., Syed, I., Moraes-Vieira, P.M., Zhang, T., Herman, M.A., Homan, E.A., Patel, R.T., Lee, J., Chen, S., Peroni, O.D., Dhaneshwar, A.S., Hammarstedt, A., Smith, U., MeGraw, T.E., Saghatelian, A. and Kahn, B.B. (2014) Discovery of a Class of Endogenous Mammalian Lipids with Anti-Diabetic and Anti-Inflammatory Effects. Cell, 159, 318-332. https://doi.org/10.1016/j.cell.2014.09.035

[195] Chen, X., Chen, H., Dai, M., Ai, J., Li, Y., Mahon, B., Dai, S. and Deng, Y. (2016) Plasma Lipidomics Profiling Identified Lipid Biomarkers in Distinguishing Early-Stage Breast Cancer from Benign Lesions. Oncotarget, 7, 36622-36631. https://doi.org/10.18632/oncotarget.9124

[196] Gerlinger, M., Horswell, S., Larkin, J., Rowan, A.J., Salm, M.P., Varela, I., Fisher, R., McGranahan, N., Mattews, N., Santos, C.R., Martinez, P., Phillimore, B., Begum, S., Rabinowitz, A., Spencer-Dene, B., Gulati, S., Bates, P., Stamp, F., Pickering, L., Gore, M., Nicol, D., Hazell, S., Futreal, P.A., Stewart, A. and Swanton, C. (2014) Genomic Architecture and Evolution of Clear Cell renal Cell Carcinomas Defined by Multiregion Sequencing. Nature Genetics, 46, 225-233.

https://doi.org/10.1038/ng.2891

[197] Karakas, B., Bachman, K.E. and Park, B.H. (2006) Mutation of the PIK3CA Oncogene in Human Cancers. British Journal of Cancer, 94, 455-459. https://doi.org/10.1038/sj.bjc.6602970

[198] Guertin, D.A., Stevens, D.M., Saitoh, M., Kinkel, S., Crosby, K., Sheen J.H., Mullholland, D.J., Magnuson, M.A., Wu, H. and Sabatini, D.M. (2009) mTOR Complex 2 Is Required for the Development of Prostate Cancer Induced by Pten Loss in Mice. Cancer Cell, 15, 148-159. https://doi.org/10.1016/j.ccr.2008.12.017

[199] Kim, L.C., Rebecca, S. Cook, R.C. and Chen, J. (2017) mTORC1 and mTORC2 in Cancer and the Tumor Microenvironment. Oncogene, 36, 2191-2201. https://doi.org/10.1038/onc.2016.363 